\title{
Gas Generation Test Support for Transportation and Storage of Plutonium Residue Materials - Part 1: Rocky Flats Sand, Slag, and Crucible Residues
}

by

R. R. Livingston

Westinghouse Savannah River Company

Savannah River Site

Aiken, South Carolina 29808

This paper was prepared in connection with work done under the above contract number with the U. S. Department of Energy. By acceptance of this paper, the publisher and/or recipient acknowledges the U.S. Government's right to retain a nonexclusive, royalty-free license in and to any copyright covering this paper, along with the right to reproduce and to authorize others to reproduce all or part of the copyrighted paper. 


\section{DISCLAIMER}

This report was prepared as an account of work sponsored by an agency of the United States Government. Neither the United States Government nor any agency thereof, nor any of their employees, makes any warranty, express or implied, or assumes any legal liability or responsibility for the accuracy, completeness, or usefulness of any information, apparatus, product, or process disclosed, or represents that its use would not infringe privately owned rights. Reference herein to any specific commercial product, process, or service by trade name, trademark, manufacturer, or otherwise does not necessarily constitute or imply its endorsement, recommendation, or favoring by the United States Government or any agency thereof. The views and opinions of authors expressed herein do not necessarily state or reflect those of the United States Government or any agency thereof.

This report has been reproduced directly from the best available copy.

Available to DOE and DOE contractors from the Office of Scientific and Technical Information, P. O. Box 62, Oak Ridge, TN 37831; prices available from (423) 576-8401.

Available to the public from the National Technical Information Service, U. S. Department of Commerce, 5285 Port Royal Road, Springfield, VA 22161. 


\section{DISCLAIMER}

Portions of this document may be illegible in electronic image products. Images are produced from the best available original document. 
WSRC-TR-99-00223

Revision 0

\title{
Gas Generation Test Support for Transportation and Storage of Plutonium Residue Materials
}

\author{
Part 1: Rocky Flats Sand, Slag and Crucible Residues
}

Ronald R. Livingston

Strategic Materials Technology Department

Savannah River Technology Center

August 1999

Westinghouse Savannah River Company

Savannah River Site

Aiken, SC 29808

Prepared for the U.S. Department of Energy under contract DE-AC09-96SR18500 
THIS PAge Left INTENTIONALLY BLANK. 
WSRC-TR-99-00223

Revision 0

\section{Gas Generation Test Support for Transportation and} Storage of Plutonium Residue Materials

Part 1: Rocky Flats Sand, Slag and Crucible Residues

Strategic Materials Technology Department

Savannah River Technology Center

August 1999

Document Approvals

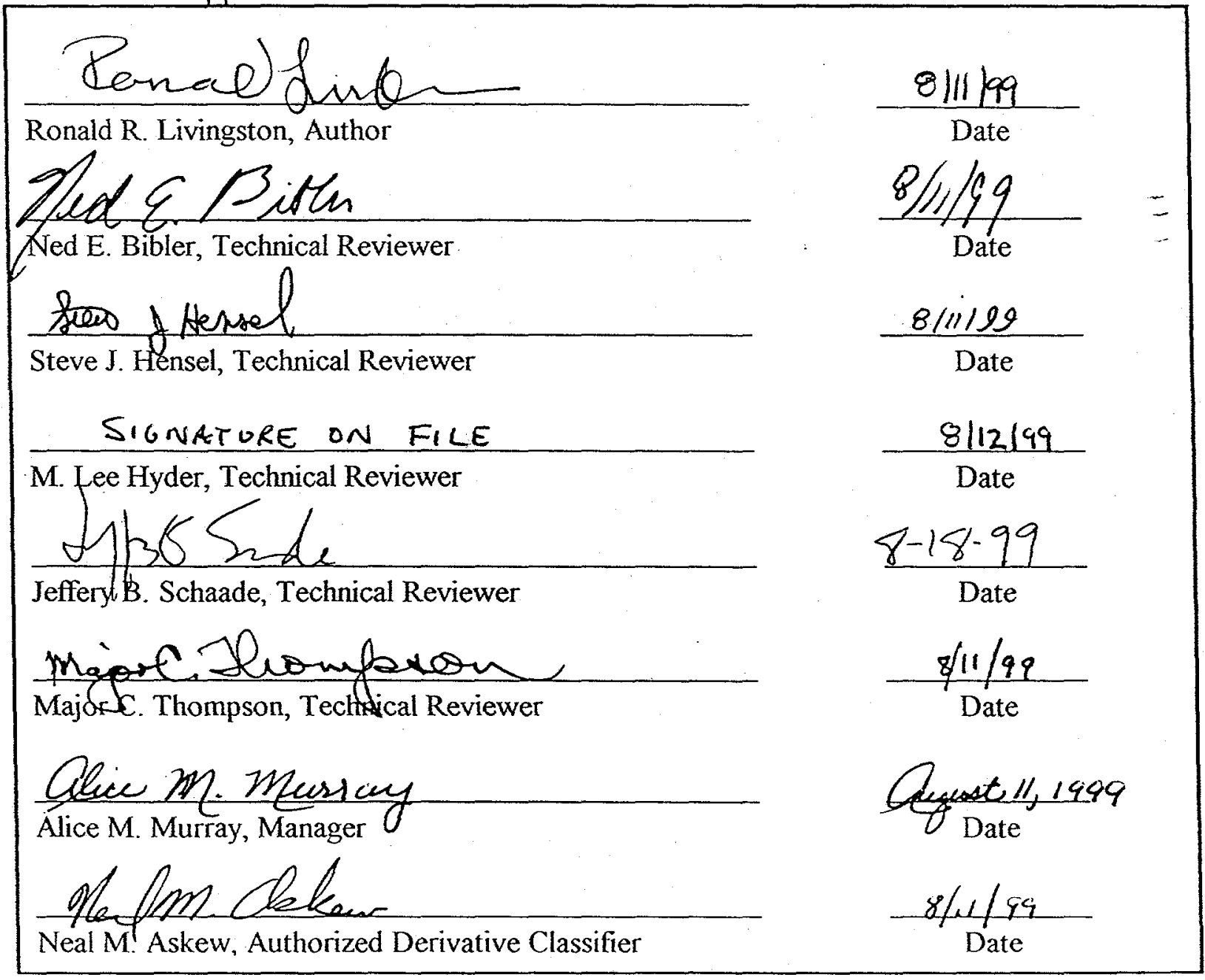




\section{Table of Contents}

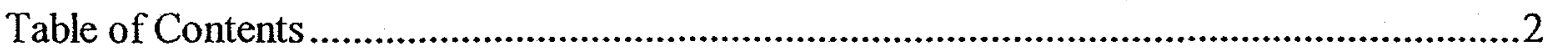

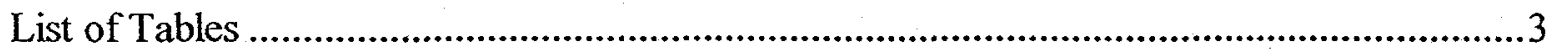

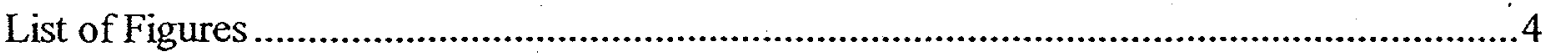

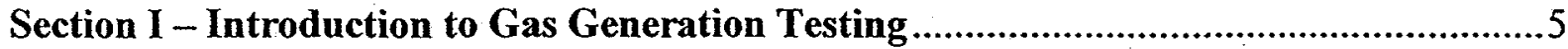

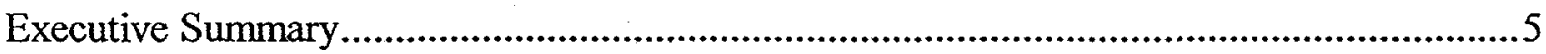

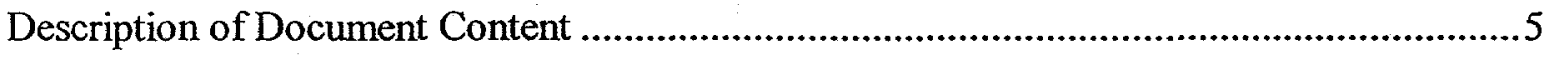

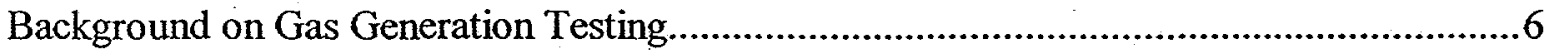

Section II - Gas Generation Testing .................................................................... 8

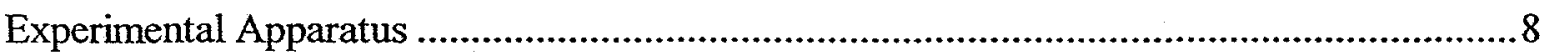

Gas Generation Test Protocol..................................................................................9

Samples and Surrogate Materials Used for GGTP ................................................. 10

Isotopic Analysis of Test Materials ........................................................................ 13

Gas Generation Test Standards......................................................................... 14

Gas Generation Rate Calculations.................................................................. 16

Chemical Reactions in SS\&C Surrogate Materials and Residue Samples ......................... 16

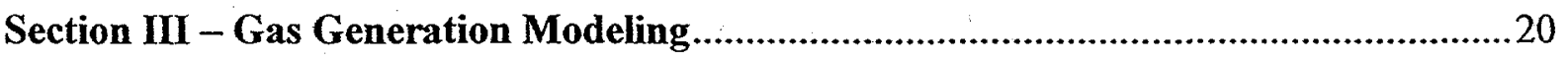

Description of the Analytical Radiolysis Model ............................................................... 20

Predictions of $\mathrm{H}_{2}$ Generation Rate using the Analytical Radiolysis Model........................20

Limitations of Modeling $\mathrm{H}_{2}$ Generation .........................................................21

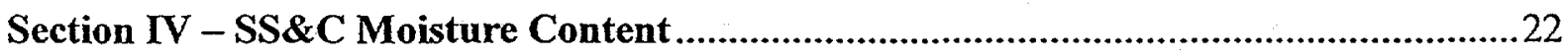

Moisture Measurements based on Weight Loss...........................................................22

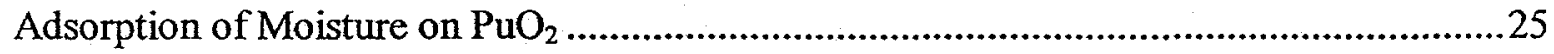

Adsorption of Moisture on SS\&C Residue Components ..............................................26

Moisture Measurement Data for Actual Samples of SS\&C .............................................27

Addition of Liquid Water to $\mathrm{PuO}_{2}$........................................................................28

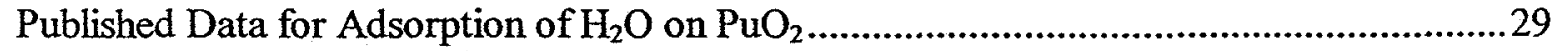

Effect of Moisture and Matrix Content on $\mathrm{H}_{2}$ Generation ..............................................30

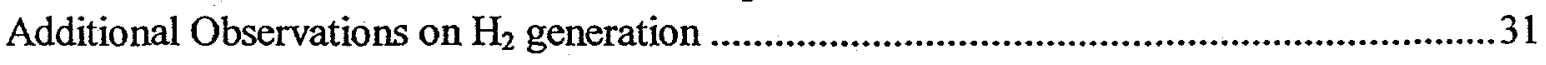

Section V - Radiolysis Effects In Residue Materials........................................... 33

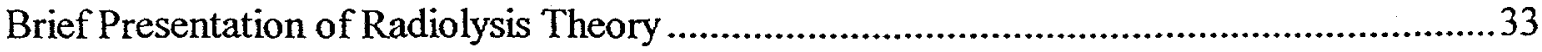




Section VI - Oxygen Content in SS\&C Gas Generation Tests....................................36

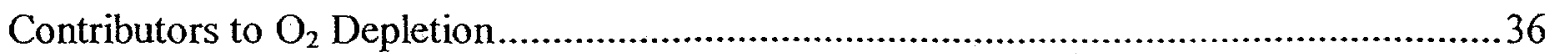

Observations on $\mathrm{O}_{2}$ Content of SS\&C Residues.....................................................36

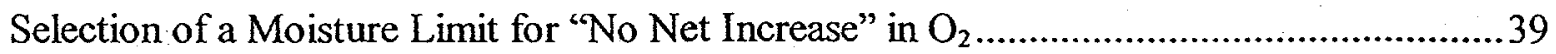

Effects of Radiation Exposure, Matrix Content and Temperature on $\mathrm{O}_{2}$ Content...............40

Statistical Evaluation of Oxygen in Gas Generation Tests ..............................................43

Measurement of Other Gases in the Test Apparatus..................................................44

Section VII - Review of Gas Generation Test Program Findings .............................45

Conceptual Model for Gas Generation.......................................................................45

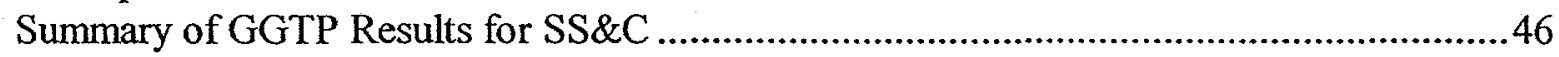

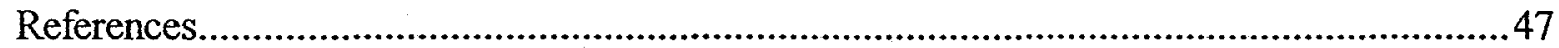

Attachment I - A Statistical Review of the Oxygen Data from the Gas Generation Tests

Supporting the Revision of the 9975 SARP (U) ........................................................50

\section{List of Tables}

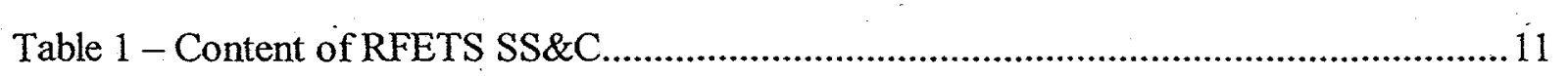

Table 2 - SS\&C Test Content and Set-up Data...................................................... 12

Table 3 - Isotopic Data and Decay Energy for RFETS SS\&C and SRS $\mathrm{PuO}_{2} \ldots \ldots \ldots \ldots \ldots \ldots . . \ldots \ldots$

Table 4 - Measurement of Gas Standards from Test Vessels ............................................... 14

Table 5 - Gas Measurement Data for SS\&C Residue Testing ........................................ 15

Table 6 - Spreadsheet Calculation of Initial and Final Gas Compositions............................ 17

Table 7 - Comparison of Model Predictions with Measured $\mathrm{H}_{2}$ Generation Rates ................ 21

Table 8 - Comparison of SRS TGA and RFETS Weight Loss Data ..............................27

Table 9 - Comparison of TGA Data with Known Water Addition to $\mathrm{PuO}_{2} \ldots \ldots \ldots \ldots \ldots \ldots \ldots . . . . . . . . .28$

Table 10 - Effect of Elevated Temperature on $\mathrm{O}_{2}$ content of SS\&C Residue......................42 


\section{List of Figures}

Figure 1 - The GGTP. Diagram of Laboratory Apparatus........................................................

Figure 2 - Sample Pressure and Temperature Profile for Gas Generation Testing.................. 10

Figure 3 - RFETS Sample Test Run 30 at Ambient Temperature ...........................................19

Figure 4 - RFETS Sample Test Run 36 at Elevated Temperature.............................................19

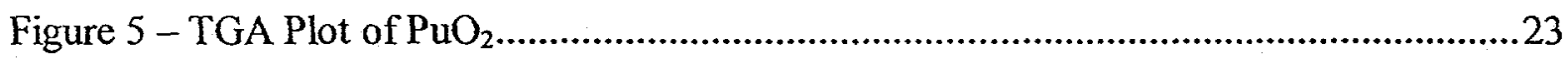

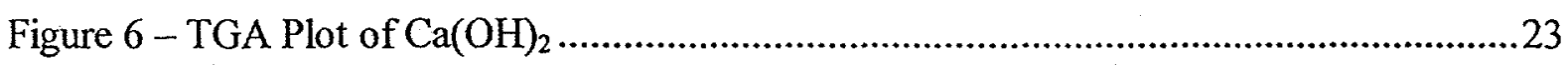

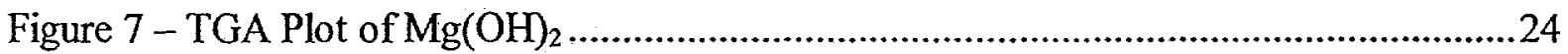

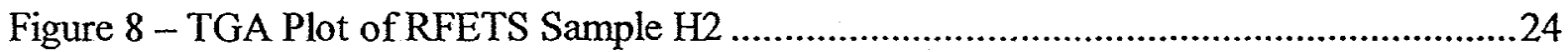

Figure 9 - Weight Gain of $\mathrm{PuO}_{2}$ in Humid Environments .....................................................26

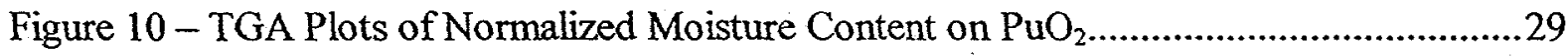

Figure $11-\mathrm{H}_{2}$ Generation Rate as a Function of Adsorbed $\mathrm{H}_{2} \mathrm{O}$ on $\mathrm{PuO}_{2} \ldots \ldots \ldots \ldots \ldots \ldots \ldots \ldots . . . . . . . .30$

Figure 12 - Hydrogen Gas Generation Rate for SS\&C Surrogate Materials ............................31

Figure 13 - Change in Oxygen v. Hydrogen Concentration ..................................................

Figure 14 - Change in Oxygen v. Hydrogen Generation Rate..................................................38

Figure 15 - Change in Oxygen v. Moisture Content for SS\&C Surrogates .............................39

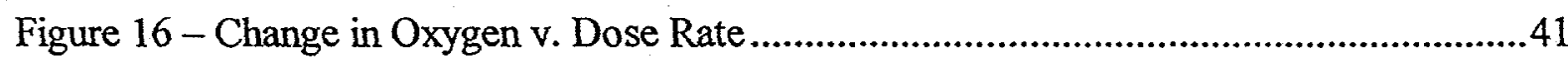

Figure 17 - Change in Oxygen v. SS\&C Matrix Contents .....................................................4

Figure 18 - Conceptual Model for Radiolysis of Adsorbed Species .......................................45 


\section{Section I - Introduction to Gas Generation Testing}

\section{Executive Summary}

The purpose of this report is to present experimental results that can be used to establish one segment of the safety basis for transportation and storage of plutonium residue materials. Gas generation testing of actual Sand, Slag and Crucible (SS\&C) residues from the Rocky Flats Environmental Technology Site (RFETS) and surrogate compositions representing SS\&C contents demonstrates that hydrogen gas $\left(\mathrm{H}_{2}\right)$ is generated from both chemical and radiation induced reactions. The chemical reaction of adsorbed moisture with calcium metal is very rapid at elevated temperature and produces $\mathrm{H}_{2}$ much faster than expected from radiolysis of adsorbed moisture. The rate of $\mathrm{H}_{2}$ production from radiolysis of adsorbed moisture varies based upon matrix composition. In tests of surrogate materials and actual SS\&C samples, the current analytical radiolysis model was found inadequate when weight loss at $210^{\circ} \mathrm{C}$ was used to estimate moisture content. In addition, test results show that partial oxygen gas $\left(\mathrm{O}_{2}\right)$ depletion occurs for many of the SS\&C residue materials, and no net increase in $\mathrm{O}_{2}$ is observed for all the $\mathrm{SS} \& \mathrm{C}$ residue materials when weight loss at $210^{\circ} \mathrm{C}$ is maintained below 2.3 percent. The observed depletion of $\mathrm{O}_{2}$ in sealed containers of SS\&C residue is supported by external studies of moist air radiolysis and gas sample data from plutonium oxide $\left(\mathrm{PuO}_{2}\right)$ containers after many years of storage.

\section{Description of Document Content}

This report was written to summarize what has been learned about gas generation for SS\&C residues. The presentation is divided into several sections to impose a level of organization tö an otherwise sprawling topic. The Table of Contents provides a detail listing of the document" sections and should be referenced to help the reader understand the flow of information provided in this report.

Section I includes the executive summary and background on the need for gas generation tests to support transportation and storage of plutonium $(\mathrm{Pu})$ residues. Section II provides an overview of gas generation test methods and a description of test data collected at the Savannah River Technology Center (SRTC). Section II also provides a platform for interpreting the results of this study and supports the ideas presented in the remaining sections.

One of the early priorities for gas generation testing was to validate the capability of an analytical radiolysis model. This effort is described in Section III, which includes a description of the model developed at SRTC and a comparison with actual test results for SS\&C surrogates.

A key parameter influencing gas generation rates and gas composition is moisture content of the residue. Section IV discusses the current means for measuring $\mathrm{H}_{2} \mathrm{O}$ in $\mathrm{SS} \& \mathrm{C}$, and presents data from the tests used to measure $\mathrm{H}_{2} \mathrm{O}$ adsorbed by residue matrix components. 
Radiation is one of the two principal driving forces behind gas generation and the resulting gas composition in sealed containers. A brief literature review of radiolysis effects that are anticipated to impact residue storage are covered in Section V.

The next section of this report is dedicated to a discussion of the observed $\mathrm{O}_{2}$ content in the gas generation testing for SS\&C residues. Section VI includes the basis for "no net increase in $\mathrm{O}_{2}$ " for sealed containers of SS\&C.

The final section of this report attempts to summarize what has been learned in the initial stages of the SRTC Gas Generation Test Program (GGTP) and draw conclusions based on the observed behavior of SS\&C residue and surrogate materials. Our current understanding of gas generation in $\mathrm{Pu}$ residue from radiolysis of adsorbed moisture is presented as a conceptual model.

\section{Background on Gas Generation Testing}

The transportation of $\mathrm{Pu}$ bearing residue materials requires a well-designed shipping package that has been rigorously tested to withstand normal and accident conditions. Pu-bearing contents can contribute to shipping package internal pressure by producing heat and gases from chemical and radiochemical reactions. ${ }^{1,2,41}$ Of particular concern is the production of $\mathrm{H}_{2}$, which could result in flammable gas mixtures within the shipping package. The Safety Analysis Report for the 9975 Package $^{3}$ (9975 SARP) uses an analytical model ${ }^{4}$ to predict the radiolysis of moisture in residue materials. The model estimates gas production as a linear function of the energy released by radioactive decay, the relative stopping power of matrix components including water, and the fraction of energy absorbed by water. The model assumes that water adsorbed by residue materials is decomposed by radiolysis to form stoichiometric proportions' of $\mathrm{H}_{2}$ and $\mathrm{O}_{2}$ at a rate similar to what is reported for aqueous solutions. The contents and shipping time are then constrained to prevent the formation of gas mixtures and pressures that would exceed limits for the 9975 package.

The 9975 SARP currently provides content descriptions for two categories of Pu residues. These descriptions are based on process knowledge of RFETS SS\&C and fluoride residues. In February 1999, SRTC initiated the GGTP for Pu residues. The purpose of this test program is to support safe packaging, transportation and storage of $\mathrm{Pu}$ residues. The first tests conducted under this program were designed to show that the gas generation model used in the 9975 SARP provides conservative $\mathrm{H}_{2}$ generation rates when applied to RFETS SS\&C and fluoride residues. Many of the initial tests were conducted using surrogates composed of $\mathrm{PuO}_{2}$ and a single non-radioactive component from the SS\&C list of contents. Additional gas generation measurements were made using samples of actual RFETS SS\&C. Efforts to study fluoride residues have been delayed pending definition of the treatment steps to be used prior to packaging

A mid-study review of the test results indicated that the analytical radiolysis model is not adequate for all materials allowed by the SS\&C content description. Comparison of measured versus calculated $\mathrm{H}_{2}$ generation rates showed the model under-predicts for some materials by nearly a factor of ten for the seven-day test period. A rapid reaction of calcium metal with moisture in the surrogate materials also was observed. The same pressure rise associated with 
rapid gas production was observed for the actual SS\&C samples at elevated temperatures. Chemical reactions, which contribute to the $\mathrm{H}_{2}$ concentration, are not considered in the analytical radiolysis model. The strong tendency toward $\mathrm{O}_{2}$ depletion for the SS\&C samples and the expected increase in $\mathrm{H}_{2}$ generation rate with elevated moisture on $\mathrm{PuO}_{2}$ also were noted during the mid-study review of the test results. Based on these observations, the GGTP changed the focus of the tests to determine a moisture limit (based on weight loss) that would provide no net increase of $\mathrm{O}_{2}$ for the $\mathrm{SS} \& \mathrm{C}$ residues. The terminology "no net increase" has been selected since there are several reaction mechanisms that contribute to the observed $\mathrm{O}_{2}$ concentration.

The purpose of this report is to summarize what has been learned about gas generation for SS\&C residues during the initial months of the GGTP for Pu residues. This report will primarily evaluate the gas generation experimental results that can be used to establish one segment of the safety basis required for packaging and transportation of RFETS SS\&C residues. Many of the test results may also be applied to storage of the SS\&C residue. 


\section{Section II - Gas Generation Testing}

\section{Experimental Apparatus}

The first task associated with measuring the gases generated by Pu residues during transportation and storage was to assemble an apparatus for experimental measurements. The apparatus was designed to allow monitoring gas generation rates and determining final gas compositions. The general approach used in the gas generation testing at SRTC was to seal test materials in sample vessels that were connected to pressure transducers and a gas manifold that was equipped for gas sampling. The details of the experimental set-up and test protocol are provided in the Task Technical and Quality Assurance (QA) Plan ${ }^{5}$ written at the initiation of the GGTP in SRTC. Figure 1 is a diagram of the laboratory set-up.

Figure 1 - The GGTP Diagram of Laboratory Apparatus

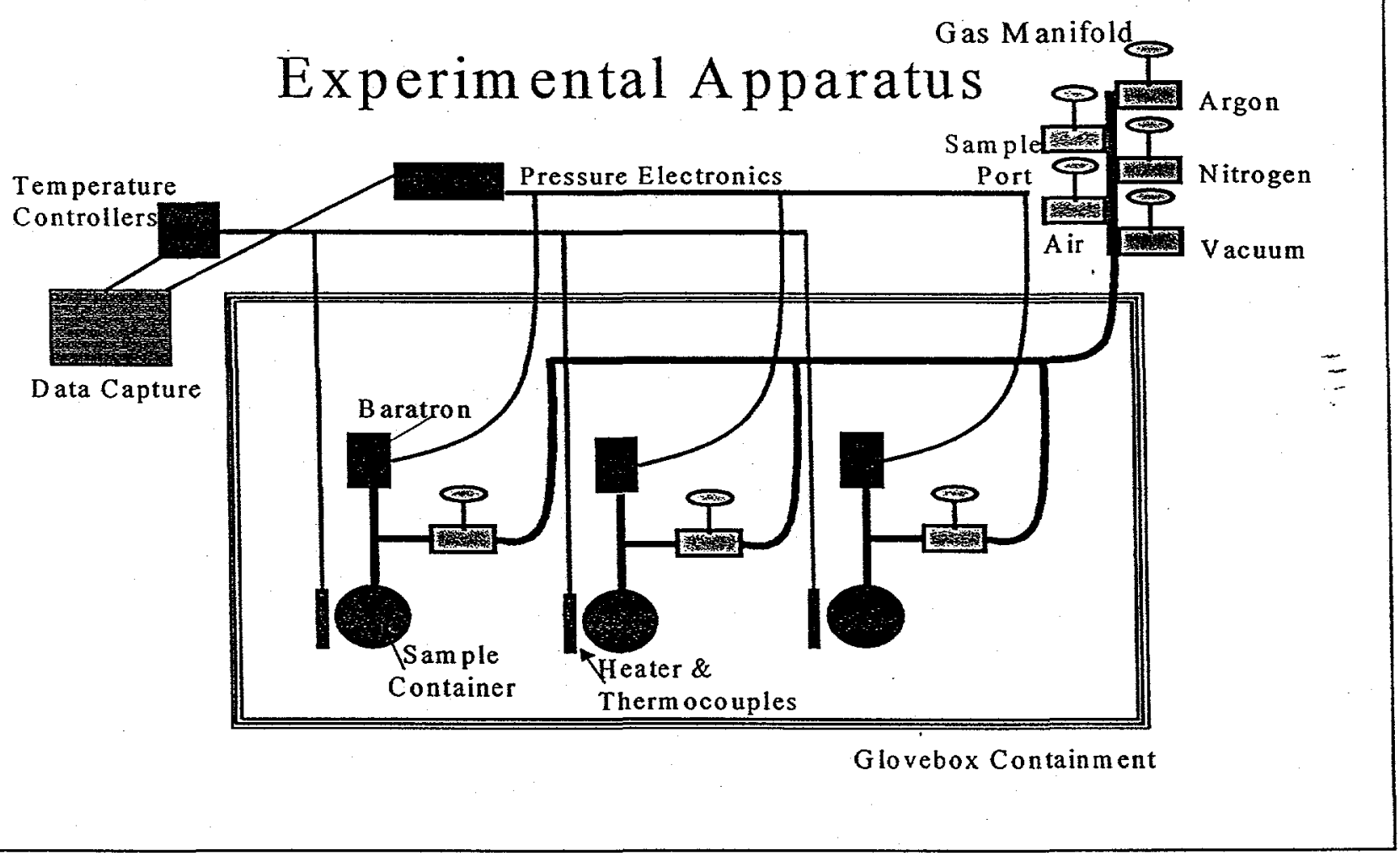

The sample vessels used in the SRTC testing were designed to be heated and have redundant temperature controls. The actual system used had six test positions that could be operated simultaneously. The sample vessels were maintained at ambient temperature or $90^{\circ} \mathrm{C}$ to assess the impact of thermal conditions. The $90^{\circ} \mathrm{C}$ temperature was selected because this was the highest sustained temperature expected for transportation of SS\&C residue. Thermocouples mounted in the side-wall of each sample vessel provided the temperature measurements. The heated zone of the apparatus included only the primary container, so that the valve and pressure transducer was not heated. The pressure measurements were made using high accuracy Baratron ${ }^{\mathrm{TM}}$ pressure transducers. 
Sample vessel sizes varied depending on the quantity of actual residue or surrogate material to be tested. Each of the test vessels is constructed of stainless steel with nominal container volumes ranging from 5 cubic centimeters (cc) up to about $100 \mathrm{cc}$. The volume of each container with residue was determined using Pressure-Volume-Temperature (PVT) data collected after each test run by expansion from a known volume. The vessels were attached to the larger apparatus using a Cajon ${ }^{\circledR} \mathrm{VCR}^{\circledR}$ fitting with stainless-steel gasket. Frequently the gaskets used in these tests contained sintered metal frits to minimize the spread of sample powders into the test apparatus. The face seals used by Cajon ${ }^{\otimes}$ are considered very reliable and are advertised to consistently provide helium leak rates less than $4 \times 10^{-9} \mathrm{cc}$ per second $(\mathrm{cc} / \mathrm{sec})$.

Each sample vessel was connected to a test stand, which was designed to retain the gases generated during testing and allowed continuous pressure measurements. The Baratron ${ }^{\mathrm{TM}}$ pressure transducers provided all stainless-steel parts in contact with the sample gas, which is ideal for $\mathrm{H}_{2}$ applications. The valves used to isolate each test stand from the gas manifold were NUPRO® stainless steel bellows valves with Kel-F valve seats. These valves were selected for their demonstrated ability to retain $\mathrm{H}_{2}$ and are frequently used in $\mathrm{H}_{2}$ applications at the Savannah River Site. The gas manifold was constructed from $1 / 8^{\text {th }}$ inch stainless tubing to minimize total volume.

The sample container, Baratron ${ }^{\mathrm{TM}}$, and valve portion of the test stand were assembled and leak tested prior to installation in the glovebox and connection to the manifold. Three of the six test assemblies used for gas generation testing were shown to have helium leak rates less than $8 \times 10^{-10} \mathrm{cc} / \mathrm{sec}$ at 150 PSIG prior to installation. For the other three test assemblies, leak rateswere shown to be less than $1 \times 10^{-6} \mathrm{cc} / \mathrm{sec}$ by measuring pressure change with time for the evacuated apparatus. ${ }^{6}$ Additional leak tests of installed system components were conducted by evacuating the system and monitoring for pressure rise with time.

\section{Gas Generation Test Protocol}

Each sample vessel was filled with a designated sample or surrogate material in an air atmosphere. The vessels' bulk contents were measured by change in vessel mass before and after filling. All operations were carried out in a glovebox containment unit to prevent the spread of alpha contamination associated with handling $\mathrm{Pu}$ materials. After a sample vessel was filled and mounted on the test stand, thermocouples were installed. When test conditions required elevated temperatures, a band heater and insulation were added. The temperature controllers used were on-off devices and maintained the temperature in about a $10^{\circ} \mathrm{C}$ window above the $90^{\circ} \mathrm{C}$ set point. Pressure and temperature measurements were displayed and logged during the nominal seven-day test period using a LabVIEW'T based computer program. Figure 2 provides an example of the data logged for each test. Sampling the vessel gas mixture and measuring the test stand volume concluded each test. 
Figure 2 - Sample Pressure and Temperature Profile for Gas Generation Testing

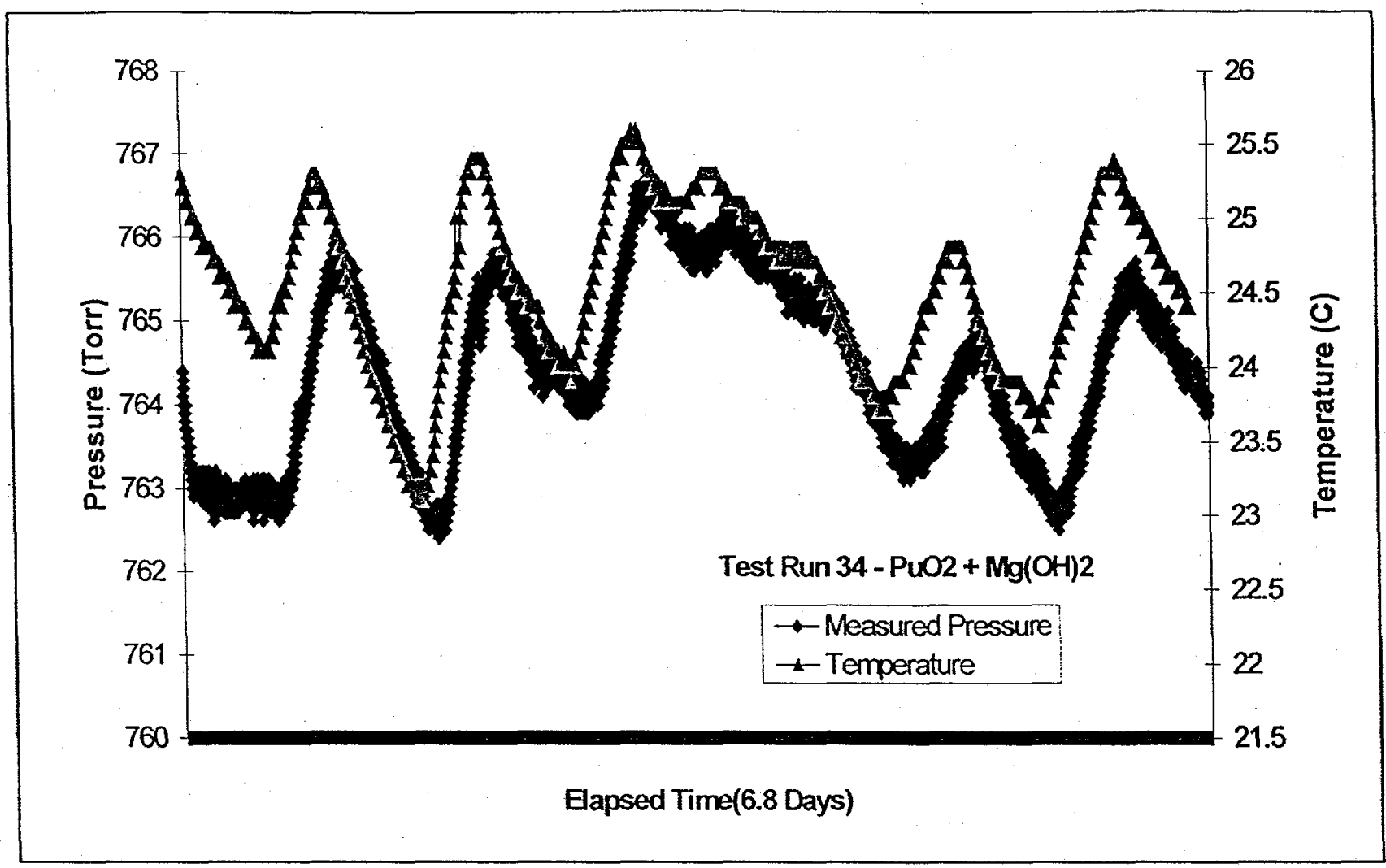

Gas samples were collected by first evacuating the common manifold using a vacuum pump, then opening the valve of a selected test position to expand the gas generated during testing into the evacuated manifold. A portion of the test gas was then removed from the manifold using gas-tight syringes. This sample gas was pulled through two $0.05 \mu \mathrm{M}$ filters that were located in the sample line to remove any potential radioactive particulate materials. Gas Chromatography (GC) was used to measure the $\mathrm{H}_{2}$ and $\mathrm{O}_{2}$ concentration in each sample ${ }^{7}$. Gas generation rates were subsequently calculated based on the measured gas concentrations, container volumes, temperatures, pressures, elapsed times.

Additional information on the sample and surrogate materials was required to support gas generation testing. This required measuring isotopic composition and moisture content of the test materials. Many of the samples were measured for moisture content using thermogravimetric analysis (TGA) following a protocol similar to the procedure used by RFETS. Isotopic composition was measured on a small subset of samples. Additional information on the analytical measurements used to characterize the test materials will be provided later in this report.

\section{Samples and Surrogate Materials Used for GGTP}

There were.two challenges that had to be addressed when selecting representative materials for gas generation testing of RFETS SS\&C. The first required selection of matrix components that would represent the content of SS\&C during transportation and storage. The range of 
SS\&C compositions is fairly broad as a consequence of variation in the production process and selective sorting of SS\&C components prior to storage at RFETS. To understand the potential impact of matrix content on the gas composition and gas generation rate from SS\&C residue, surrogate materials were needed that would provide a cross section SS\&C contents. The second challenge was to select a $\mathrm{PuO}_{2}$ representative of the actual RFETS SS\&C that could be used to generate surrogate compositions. Each of these issues will be addressed separately beginning with the selection of matrix materials need to develop SS\&C surrogates. Gas generation testing for RFETS SS\&C was initially constrained to surrogate materials that were selected based on the SS\&C content description provided in the 9975 SARP. Additional data on the variability and composition of RFETS SS\&C was also available from flow sheet development efforts. ${ }^{8,9,10,11}$ The contents of RFETS SS\&C, based on SRTC measurements as part of flow sheet development, are presented in Table 1.

Table 1 - Content of RFETS SS\&C

\begin{tabular}{|c|c|c|}
\hline SS\&C Matrix & -...-.-Weig & Percent----.. \\
\hline Component & Low Value & High Value \\
\hline $\mathrm{PuO}_{2}$ & 2 & 50 \\
\hline $\mathrm{CaF}_{2}$ & 20 & 60 \\
\hline $\mathrm{MgO}$ & 2 & 40 \\
\hline $\mathrm{CaCO}_{3}$ & 1 & 7 \\
\hline $\mathrm{Ca}(\mathrm{OH})_{2}$ & 1 & 10 \\
\hline $\mathrm{CaO}$ & 5 & 40 \\
\hline Calcium Metal & 0 & 11 \\
\hline
\end{tabular}

The contents and variability of RFETS SS\&C is similar to SS\&C generated at other Department of Energy Pu processing facilities. ${ }^{12}$

The initial approach selected by the GGTP, described in the Technical Task and QA Plan, required a series of 19 tests to evaluate the accuracy of the analytical radiolysis model. This approach used $\mathrm{PuO}_{2}$ and mixtures of $\mathrm{PuO}_{2}$ and SS\&C components listed above. This effort was expected to demonstrate that the analytical radiolysis model provided conservative $\mathrm{H}_{2}$ generation results for a cross section of residue materials, not to bound SS\&C contents by testing a large number of material mixtures. A nominal seven-day test period was selected to support rapid evaluation of model predictions and required an estimated minimum of 5 to $10 \mathrm{~g}$ of $\mathrm{PuO}_{2}$. This quantity of $\mathrm{PuO}_{2}$ was expected to produce sufficient $\mathrm{H}_{2}$ for $\mathrm{GC}$ measurements. A standard ratio of 1:3 ( $\mathrm{Pu}:$ Matrix) was selected for mixtures of $\mathrm{PuO}_{2}$ with each SS\&C component to prevent having to use container volumes greater than $100 \mathrm{cc}$. Additional tests then were planned to follow-up on data points identified as inconsistent with anticipated material behavior.

Table 2 provides brief descriptions and set-up data for the tests conducted by the SRTC GGTP that are relevant to SS\&C contents. Six of the tests were conducted on actual RFETS SS\&C samples (test runs 13, 20, 30, 32, 34, and 36). Two of these tests (20 and 36) were done at elevated temperature. Four tests (test runs 17, 44, 50 and 52) were conducted using "Pu Cake," which is a mixture of about $30 \% \mathrm{PuO}_{2}$ and $70 \%$ plutonium tetrafluoride $\left(\mathrm{PuF}_{4}\right)$. The 
Table 2-SS\&C Test Content and Set-up Data

\begin{tabular}{|c|c|c|c|c|c|c|c|}
\hline $\begin{array}{c}{ }^{*} \text { Run } \\
\#\end{array}$ & $\begin{array}{l}\text { Description } \\
\text { 2/20/99 Start - Set } 1\end{array}$ & $\begin{array}{l}\text { Time } \\
\text { (days) }\end{array}$ & $\begin{array}{l}\text { Container } \\
\text { Volume }\end{array}$ & $\begin{array}{l}\text { "Grams } \\
\text { PuO22 }\end{array}$ & $\begin{array}{c}\text { Bulk } \\
\text { Weight }(g)\end{array}$ & $\begin{array}{l}\text { Measured } \\
\text { Volume }\end{array}$ & $\begin{array}{l}\text { Temp } \\
\text { (degC) }\end{array}$ \\
\hline 1 & PuO2+ RF MgO sand \& crucible & 8.83 & $250 c$ & 9.59 & 37.83 & 34.11 & ambient \\
\hline 2 & $\mathrm{PuO} 2+$ calcined $\mathrm{CaO}+\mathrm{Ca}(\mathrm{OH}) 2$ & 8.92 & $50 c c$ & 8.85 & 35.80 & 63.86 & ambient \\
\hline 3 & PuO2 Stored over desiccant & 9.65 & $5 c c$ & 7.65 & 7.65 & 30.50 & ambient \\
\hline 4 & PuO2 stored in $76 \%$ RH humidor & 9.71 & $50 \mathrm{c}$ & 8.54 & 8.54 & 30.90 & ambient \\
\hline 5 & $\mathrm{PuO} 2 \sim 10 \% \mathrm{H} 2 \mathrm{O}$ added & 6.66 & $50 c$ & 7.57 & 7.57 & 29.81 & ambient \\
\hline 6 & Standard Gas & 3.73 & $50 c c$ & 0.00 & 0.00 & 62.33 & ambient \\
\hline \multicolumn{8}{|c|}{ 3/1/99 Start - Set 2} \\
\hline 7 & Standard Gas + Heat & 6.31 & $500 c$ & 0.00 & 0.00 & 49.71 & 90 \\
\hline 8 & $\# 2$ stored at $100 \%$ RH & 6.14 & $50 c c$ & 7.73 & 31.30 & 64.10 & ambient \\
\hline 9 & $\mathrm{PuO} 2+30 \mathrm{~g} \mathrm{CaF} 2$ & 6.83 & $50 c c$ & 9.83 & 39.85 & 62.91 & ambient \\
\hline 10 & PuO2+Ca(OH)2 \& MgO Crucible & 5.75 & $25 c c$ & 7.90 & 15.80 & 43.46 & ambient \\
\hline 11 & $\# 1$ stored at $100 \% \mathrm{RH}$ & 6.12 & $25 c c$ & 9.32 & 36.76 & 38.51 & ambient \\
\hline 12 & \multicolumn{7}{|l|}{ 3/8199 Start - Set 3} \\
\hline 13 & $44 \mathrm{~g}$ of RF SS\&C sample $\mathrm{H} 6$ & 7.88 & $500 \mathrm{c}$ & 15.50 & 43.84 & 51.66 & ambient \\
\hline 14 & \# heated & 7.88 & $50 \circ c$ & 9.83 & 39.85 & 64.37 & 90 \\
\hline 15 & $\$ 8$ heated & 8.16 & $500 c$ & 7.73 & 31.30 & 65.63 & 90 \\
\hline 16 & PuO2 stored at $100 \% R H+$ Heat & 7.77 & $5 \propto c$ & 7.26 & 7.26 & 30.78 & 90 \\
\hline 17 & Pu Cake & 7.61 & $25 c c$ & 32.01 & 35.66 & 42.04 & ambient \\
\hline \multicolumn{8}{|c|}{ 3/17/99 Start-Set 4} \\
\hline 19 & CaF2 at RT repeat \#14 and \#9 & 6.8 & $50 \propto$ & 9.83 & 39.85 & 52.40 & ambient \\
\hline 20 & \#13 heated & 6.8 & $50 c c$ & 15.50 & 43.84 & 53.82 & 90 \\
\hline 21 & \#10 heated & 6.81 & $100 c$ & 7.50 & 15.00 & 25.98 & 90 \\
\hline 22 & PuO2+MgO 1:1 ratio & 6.81 & $25 c c$ & 9.73 & 19.45 & 43.03 & ambient \\
\hline 23 & \#11 heated & 6.78 & $100 c$ & 4.66 & 20.00 & 31.95 & 90 \\
\hline 24 & $\mathrm{PuO} 2+\mathrm{Mg}(\mathrm{OH}) 2$ & 6.79 & $250 c$ & 7.26 & 17.26 & 43.83 & ambient \\
\hline \multicolumn{8}{|c|}{ 3/26/99 Start-Set 5} \\
\hline 25 & $\mathrm{PuO2}+\mathrm{MgO}$ with lo water & 10.11 & $10 \propto c$ & 6.60 & 25.00 & 14.43 & 90 \\
\hline 26 & $\begin{array}{l}\text { PuO2+ MgO with med water } \\
\qquad 46 / 99 \text { Start-Set } 6\end{array}$ & 9.74 & $10 c c$ & 6.24 & 23.43 & 25.67 & 90 \\
\hline 30 & RFETSH2 & 7.69 & $500 c$ & 8.18 & 43.10 & 63.26 & ambient \\
\hline 31 & PuO2+MgO w/ hi watertheat & 8.83 & $10 c c$ & 6.15 & 23.09 & 26.22 & $90 \mathrm{C}$ \\
\hline 32 & RFETS H7 & 7.71 & $1000 c$ & 6.77 & 14.60 & 91.65 & ambient - \\
\hline 33 & \#18 repeated & 7.71 & $10 c c$ & 4.65 & 6.60 & 38.54 & ambient :- \\
\hline 34 & RFETS H8 & 7.69 & $100 c$ & 8.49 & 10.80 & 38.98 & ambient \\
\hline \multicolumn{8}{|c|}{ 4/16/99 Start - Set 7 } \\
\hline 36 & RFETS Sample H2 & 5.61 & $500 c$ & 8.18 & 43.10 & 61.32 & 90 \\
\hline 37 & \#31 repeated & 5.66 & $10 \circ c$ & 6.15 & 23.09 & 26.49 & 90 \\
\hline 38 & $\mathrm{PuO} 2+5 \%+12 \mathrm{O}$ & 5.69 & $25 c c$ & 9.66 & 10.29 & 44.90 & ambient \\
\hline \multicolumn{8}{|c|}{ 4/23/99 Start - Set 8} \\
\hline 41 & PuO2+100\%RH -2weeks & 5.6 & $10 \propto c$ & 10.08 & 10.08 & 19.25 & ambient \\
\hline 44 & PuCake - like \#17 & 5.77 & $100 c c$ & 27.65 & 30.80 & 123.67 & ambient \\
\hline 45 & PuO2 + $2.5 \%$ water & 5.77 & $10 \propto c$ & 12.17 & 12.50 & 37.51 & ambient \\
\hline 46 & PuO2+ $2.5 \%$ water & 5.84 & $100 c$ & 9.83 & 10.32 & 38.12 & ambient \\
\hline \multicolumn{8}{|c|}{ 4/29/99 Start - Set 9} \\
\hline 47. & PuO2+2.5\%+12O+Heat & 6.77 & 1000 & 12.17 & 12.50 & 18.96 & 90 \\
\hline 50 & PuCake - replicate1 & 6.76 & $100 c c$ & 27.34 & 30.46 & 122.76 & ambient \\
\hline 51 & \#41 repeated & 6.76 & $100 c$ & 10.08 & 10.08 & 18.70 & ambient \\
\hline 52 & PuCake - replicate \#2 & 6.77 & $25 c c$ & 14.98 & 16.69 & 45.15 & ambient \\
\hline \multicolumn{8}{|c|}{ 5/18/99 Start - Set 10} \\
\hline 53 & \#1 heated & 7.95 & $100 c$ & 10.08 & 10.08 & 18.74 & 90 \\
\hline 54 & Blank+Heat & 7.95 & $10 c c$ & 0.00 & 0.00 & 31.56 & 90 \\
\hline 55 & $\mathrm{PuO} 2+130 \mathrm{mg} \mathrm{H}_{2} \mathrm{O}$ & 7.95 & $50 c c$ & 12.57 & 12.70 & 71.49 & ambient \\
\hline 56 & PuO2+150mg H2O & 7.95 & $10 \propto c$ & 10.42 & 10.57 & 37.50 & ambient \\
\hline \multicolumn{8}{|c|}{ 5/26/99 Start - Set 11} \\
\hline 57 & PuO2+150mg H2O & 7.75 & $10 c c$ & 10.42 & 10.57 & 18.49 & 90 \\
\hline 58 & Blank & 8 & $100 c$ & 0.00 & 0.00 & 31.27 & ambient \\
\hline 59 & PuO2+130 mg H2O & 7.78 & $50 \mathrm{cc}$ & 12.57 & 12.70 & 59.55 & 90 \\
\hline
\end{tabular}

* Test runs 17, 44, 50 and 52 were conducted using "Pu Cake", a mixture of about $30 \% \mathrm{PuO}_{2}$ and $70 \% \mathrm{PuF}_{4}$. The data were adjusted to represent the $\mathrm{Pu}$ content in "Pu Cake" as $\mathrm{PuO}_{2}$.

** Test runs $28,29,35,40,42,43,48$, and 49 contained materials that do not conform to the content description of SS\&C residue. These test runs were not included in this report. 
$\mathrm{PuO}_{2}$ mass data, presented in Table 2 for the $\mathrm{Pu}$ Cake samples, have been adjusted to correct for the change in $\mathrm{Pu}$ composition. The $\mathrm{Pu}$ Cake was used to investigate the impact of $\mathrm{PuF}_{4}$ on gas generation rates. SRTC measurements have not found $\mathrm{PuF}_{4}$ in RFETS SS\&C residue samples ${ }^{13}$, but process history suggests $\mathrm{PuF}_{4}$ could be present.

The second issue that had to be addressed in creating SS\&C surrogates was selection of an appropriate source of $\mathrm{PuO}_{2}$. There are two likely sources of $\mathrm{PuO}_{2}$ in $\mathrm{SS} \& \mathrm{C}$. In the first case, the $\mathrm{PuO}_{2}$ is formed from air oxidization of small Pu metal fragments that did not coalesce during formation of the $\mathrm{Pu}$ metal button. The second case includes $\mathrm{PuO}_{2}$ present in the $\mathrm{PuF}$ as an impurity prior to production of $\mathrm{Pu}$ metal and $\mathrm{PuO}_{2}$ created in the initial stages of $\mathrm{Pu}$ metal production from hydrolysis of $\mathrm{PuF}_{4}$. The $\mathrm{PuO}_{2}$ present in the process prior to metal production was heated to temperatures in excess of $1000^{\circ} \mathrm{C}$ as part of the production process. Evidence from attempts to dissolve RFETS SS\&C suggests that greater than $90 \%$ of the $\mathrm{PuO}_{2}$ present in this SS\&C is "high fired." This is similar to what has been observed for processing SS\&C at the Savannah River Site ${ }^{14}$.

The surface area of $\mathrm{PuO}_{2}$ decreases linearly as the material is heated over the range of $50^{\circ} \mathrm{C}$ to $900^{\circ} \mathrm{C}$, and this trend is anticipated to continue for higher processing temperatures. Since the amount of moisture adsorbed by $\mathrm{PuO}_{2}$ is a function of surface area, ${ }^{15,16} \mathrm{PuO}_{2}$ from low temperature corrosion of Pu metal will adsorb more moisture than "high fired" material. The larger surface area $\mathrm{PuO}_{2}$ can adsorb more moisture and should provide the highest gas generation rates from radiolysis of $\mathrm{H}_{2} \mathrm{O}$. The $\mathrm{PuO}_{2}$ from corrosion of $\mathrm{Pu}$ metal was selected for use in creating SS\&C surrogates.

\section{Isotopic Analysis of Test Materials}

Isotopic analysis of selected samples was obtained following dissolution of the material in nitric acid. The solutions were analyzed using gamma spectroscopy and Inductively Coupled Plasma - Mass Spectroscopy (ICP-MS). ${ }^{17}$ These isotopic values were subsequently used as input for the analytical radiolysis model. No impurities were identified in the $\mathrm{PuO}_{2}$ using $\mathrm{x}$-ray diffraction, and ICP-MS identified only trace metals normally associated with Pu metal production. The isotopic data and associated decay energy are provided based on the gamma ray spectroscopy data in Table 3 .

Table 3 - Isotopic Data and Decay Energy for RFETS SS\&C and SRS PuO

\begin{tabular}{|c|c|c|c|c|c|c|}
\hline \multirow[b]{2}{*}{ Isotope } & \multirow{2}{*}{$\begin{array}{l}\text { Specific } \\
\text { Activity }\end{array}$} & \multirow{2}{*}{$\begin{array}{c}\text { MeV per } \\
\text { decay }\end{array}$} & \multicolumn{2}{|c|}{$\underline{\text { SRS } \mathrm{PuO}_{2}}$} & \multicolumn{2}{|c|}{ RFETS H6 } \\
\hline & & & mass fraction & eV/day/g Pu & mass fraction & eV/day/g Pu \\
\hline $\mathrm{Pu}-238$ & $1.99864 E+19$ & 5.49 & 0.00013 & $3.91 E+19$ & 0.00007 & $2.10 E+19$ \\
\hline Pu-239 & $7.24294 E+16$ & 5.1 & 0.9439 & $9.55 E+20$ & 0.9447 & $9.56 \mathrm{E}+20$ \\
\hline $\mathrm{Pu}-240$ & $2.64688 E+17$ & 5.16 & 0.0542 & $2.03 E+20$ & 0.0534 & $2.00 E+20$ \\
\hline$P u-241$ & $1.20263 E+20$ & 0.0053 & 0.0016 & $2.79 E+18$ & 0.0016 & $2.79 \mathrm{E}+18$ \\
\hline Pu-242 & $4.58677 E+15$ & 4.89 & 0.002 & $1.23 E+17$ & 0.0023 & $1.41 E+17$ \\
\hline Am-241 & $3.99949 E+18$ & 5.48 & 0.00106 & $6.37 E+19$ & 0.00239 & $1.44 E+20$ \\
\hline & Totals $=$ & & 1.002890 & $1.26 E+21$ & 1.00446 & $1.32 E+21$ \\
\hline
\end{tabular}


Based on the samples analyzed, there is less than $5 \%$ difference in the energy output of a representative RFETS sample and the $\mathrm{PuO}_{2}$ used in SS\&C surrogates. This small difference in radiation dose is anticipated based on the isotopic tolerances for "weapons grade" $\mathrm{Pu}$. The worst case isotopic data provided by RFETS suggests the decay energy could be as much as $25 \%$ higher than what was found in sample $\mathrm{H} 6$ or about $30 \%$ higher than found in the SRS $\mathrm{PuO}_{2}$. The reason for this difference in measured and worst case decay energy is the inclusion of $0.5 \% \mathrm{Pu}-238$ and a large amount of $\mathrm{Am}-241$ from $\mathrm{Pu}-241$ decay.

\section{Gas Generation Test Standards}

Several tests were conducted to confirm the capability to sample and analyze the gas in test vessels accurately. Test runs $6,7,54$ and 58 were conducted without $\mathrm{PuO}_{2}$ present in the vessels. Tests 6 and 7 used a $4 \% \mathrm{H}_{2}$ standard in unheated and heated configurations, and tests 54 and 58 used air as an $\mathrm{O}_{2}$ standard in heated and unheated configurations. The $\mathrm{H}_{2}$ standard also contained $76 \%$ nitrogen and nominally $4 \%$ of each of the following gases $\mathrm{O}_{2}, \mathrm{CO}_{2}, \mathrm{CO}$, methane and ethane. Tests 6 and 7 demonstrated the ability to analyze for $\mathrm{H}_{2}$ and confirmed that rapid recombination of $\mathrm{H}_{2}$ and $\mathrm{O}_{2}$ was not catalyzed by the sample vessel surfaces. Tests 54 and 58 demonstrated the ability to analyze for $\mathrm{O}_{2}$ and confirmed the vessel walls are not rapidly oxidized under the test conditions. Test results for these standards are presented in Table 4.

Table 4 - Measurement of Gas Standards from Test Vessels

\begin{tabular}{cccccc} 
Run & Vessel & \multicolumn{2}{c}{$\mathrm{H}_{2}$ Vol\% } & \multicolumn{2}{c}{$\mathrm{O}_{2}$ Vol\% } \\
$\#$ & Temperature & Standard & Measured & Standard & Measured \\
\hline 6 & ambient & 4.0 & 4.2 & 4.0 & 3.9 \\
7 & $90 \mathrm{C}$ & 4.0 & 3.7 & 4.0 & 3.6 \\
54 & $90 \mathrm{C}$ & 0.0 & 0.0 & 20.9 & 20.0 \\
58 & ambient & 0.0 & 0.0 & 20.9 & 20.5
\end{tabular}

The concentration of nitrogen gas $\left(\mathrm{N}_{2}\right)$ in ambient air is 78.08 vol\%. The $\mathrm{N}_{2}$ concentration results from measurement of these gas standards are found in Table 5, along with GC measurement data for all the SS\&C tests. The $\mathrm{N}_{2}$ values for tests 6 and 7 are larger than expected based on measurement statistics, but the measurements for $\mathrm{H}_{2}$ and $\mathrm{O}_{2}$ in the standard are accurate. The $\mathrm{N}_{2}$ values for tests 54 and 58 are within the anticipated 2 sigma standard deviation of the known value. The error bars for GC concentration data, based on measurement of standards over a 30 -day period, at the $95 \%$ confidence interval are $\pm 9.4 \%$ for $\mathrm{H}_{2}, \pm 1.5 \%$ for $\mathrm{O}_{2}$, and $\pm 7.1 \%$ for $\mathrm{N}_{2}{ }^{7}$

Some consideration has been given to scaling sample results using $\mathrm{N}_{2}$ as an internal standard. However, the greater degree of statistical uncertainty in the $\mathrm{N}_{2}$ value and evidence for $\mathrm{N}_{2}$ being consumed in radiolysis of air has limited efforts to correct data based on $\mathrm{N}_{2}$ recovery. Argon gas (Ar) is present in air at about 0.93 vol\%. The inert nature of Ar suggests that it could be used as an internal standard to correct the GC results for sample recovery. However, the GC 
Table 5 - Gas Measurement Data for SS\&C Residue Testing

\begin{tabular}{|c|c|c|c|c|c|c|c|c|}
\hline $\begin{array}{c}\text { Run } \\
\#\end{array}$ & $\begin{array}{c}\text { Sample \# } \\
\text { 2/20199 Start - Set } 1 \\
\end{array}$ & $\begin{array}{c}\mathrm{H} 2 \\
(\mathrm{vol} \%)\end{array}$ & $\underset{(\mathrm{vol} \%)}{\mathrm{O}}$ & $\begin{array}{c}N 2 \\
(v o l \%)\end{array}$ & $\begin{array}{c}\mathrm{CO} 2 \\
(\mathrm{vol} \%)\end{array}$ & $\begin{array}{l}\mathrm{N} 2 \mathrm{O} \\
(\mathrm{Vol} \%)\end{array}$ & $\underset{(\mathrm{vol} \%)}{\infty}$ & $\begin{array}{c}\text { sum } \\
\text { (vol\%) }\end{array}$ \\
\hline 1 & $3-123637$ & 0.55 & 18.8 & 84 & 0 & 0 & 0 & 103.35 \\
\hline 2 & $3-123636$ & 0.00 & 17.9 & 84.5 & 0 & 0 & 0 & 10240 \\
\hline 3 & $3-123635$ & 0.00 & 21.1 & 82.3 & 0.05 & 0 & 0 & 103.45 \\
\hline 4 & $3-123634$ & 0.00 & 20.1 & 82.5 & 0.16 & 0 & 0 & 10276 \\
\hline 5 & $3-123633$ & 10.80 & 22.8 & 61.7 & 0.1 & 0 & 0 & 95.40 \\
\hline 6 & $\begin{array}{c}3-123638 \\
3 / 1 / 99 \text { Start - Set } 2\end{array}$ & 4.20 & 3.9 & 81.6 & 1.8 & 0.5 & 1.2 & 93.20 \\
\hline 7 & $3-123539$ & 3.70 & 3.6 & 87 & NR & NR & 4.06 & 98.36 \\
\hline 8 & $3-123640$ & 0.05 & 19.6 & 86 & 0.1 & 0 & 0 & 105.75 \\
\hline 9 & $3-123641$ & 0.08 & 20.2 & 85.1 & 0.09 & 0.02 & 0 & 105.49 \\
\hline 10 & $3-123642$ & 0.62 & 20.2 & 83.8 & 0.06 & 0 & 0 & 104.68 \\
\hline 11 & $3-123643$ & 0.26 & 19.7 & 88.1 & 0.05 & 0.04 & 4.28 & 11243 \\
\hline 12 & $\begin{array}{c}\text { 3-123644 } \\
\text { 3/8199 Start - Set 3 }\end{array}$ & 0.54 & 20 & 84.8 & 0.12 & 0.12 & 0 & 105.58 \\
\hline 13 & $3-123645$ & 6.19 & 3.1 & 90.8 & 0.03 & 1.6 & 0 & 101.72 \\
\hline 14 & $3-123646$ & 0.89 & 16.7 & 80 & 5.2 & 0.25 & 0 & 103.04 \\
\hline 15 & $3-123647$ & 0.00 & 11.7 & 82.6 & 0 & 0 & 0 & 94.30 \\
\hline 16 & $3-123648$ & 0.22 & 15.5 & 78.2 & 0.48 & 0.04 & 0 & 94.44 \\
\hline 17 & $3-123649$ & 1.64 & 20.6 & 79.6 & 0.06 & 0.05 & 0 & 101.95 \\
\hline 18 & $\begin{array}{c}3-123650 \\
3 / 17 / 99 \text { Start-Set } 4\end{array}$ & 24.15 & 15.5 & 53.1 & 0.03 & 0 & 0 & 92.78 \\
\hline 19 & $3-123651$ & 0.00 & 18.2 & 83.8 & 0.37 & 0.08 & 0 & 10245 \\
\hline 20 & $3-123652$ & 80.00 & 0 & 23.6 & 0 & 0 & 0 & 103.60 \\
\hline 21 & $3-123653$ & 260 & 6 & 95.6 & 0.16 & 0.2 & 0 & 104.56 \\
\hline 22 & $3-123654$ & 0.13 & 15.4 & 86.3 & 0.09 & 0.11 & 0 & 102.03 \\
\hline 23 & $3-123655$ & 1.60 & 11.9 & 88.6 & 0.22 & 0.17 & 0 & 10249 \\
\hline 24 & $\begin{array}{c}\text { 3-123656 } \\
3 / 26 / 99 \text { Start-Set } 5\end{array}$ & 5.00 & 19.7 & 76.6 & 0.03 & 0.09 & 0 & 101.42 \\
\hline 25 & $3-123658$ & 217 & 12.6 & 82.7 & $<1$ & $<.1$ & $<1$ & 97.47 \\
\hline 26 & $\begin{array}{c}\text { 3-123659 } \\
4 / 699 \text { Start-Set } 6\end{array}$ & 1.19 & 16.2 & 79.4 & $<1$ & $<.1$ & $<1$ & 96.79 \\
\hline 30 & $3-125514$ & 1.27 & 16.5 & 75.8 & $<1$ & $<1$ & $<1$ & 93.57 \\
\hline 31 & $3-125515$ & 0.03 & 20.5 & 76 & $<1$ & $<1$ & $<1$ & 96.53 \\
\hline 32 & $3-125516$ & 8.13 & 12.9 & 78.5 & $<1$ & $<1$ & $<1$ & 99.53 \\
\hline 33 & $3-125517$ & 1.6 & 20.2 & 76.4 & $<1$ & $<1$ & $<1$ & 98.20 \\
\hline 34 & $\begin{array}{c}3-125518 \\
4 / 16199 \text { Start }- \text { Set } 7\end{array}$ & 0.2 & 20.2 & 76.9 & $<1$ & $<1$ & $<1$ & 97.30 \\
\hline 36 & $3-125520$ & 74.70 & 1.3 & 17.9 & 0.02 & $<.1$ & $<1$ & 93.92 \\
\hline 37 & $3-125521$ & 0.40 & 20 & 64.2 & 0.03 & 0.02 & $<.1$ & 84.65 \\
\hline 38 & $\begin{array}{c}3-125522 \\
4 / 23199 \text { Start - Set } 8\end{array}$ & 7.40 & 14.1 & $\pi 7.7$ & 0.08 & 0.04 & $<1$ & 99.32 \\
\hline 41 & $3-125525$ & 0.7 & 19.9 & 81.2 & NR & NR & 8.1 & 101.80 \\
\hline 44 & $3-125528$ & 0.2 & 18.6 & 82.4 & 0.32 & $<0.1$ & $\infty .1$ & 101.52 \\
\hline 45 & $3-125529$ & 23 & 21 & 76.8 & $\infty .1$ & $\infty .1$ & $\infty .1$ & 100.10 \\
\hline $46^{\star *}$ & 3-125530 & 1.2 & 21.1 & 62.1 & $<.1$ & $\varnothing .1$ & $<.1$ & 84.40 \\
\hline & $4 / 29 / 99$ Start - Set 9 & & & & & & & \\
\hline 47 & $3-125531$ & 3.4 & 7.3 & 81.8 & $\infty .1$ & $\varnothing .1$ & 8.1 & 92.50 \\
\hline 50 & $3-125534$ & 0.4 & 18.9 & 79.2 & $\infty .1$ & $<0.1$ & $<.1$ & 98.50 \\
\hline 51 & $3-125535$ & 1.5 & 19.9 & 73.4 & $\infty .1$ & $\infty .1$ & $<.1$ & 94.80 \\
\hline $52^{\text {*k }}$ & $\begin{array}{c}3-125536 \\
5 / 18 / 99 \text { Start }-\operatorname{Set} 10\end{array}$ & 0.55 & 20.14 & 78.36 & $\infty .1$ & 0.05 & $<0.1$ & 99.10 \\
\hline 53 & $3-127169$ & 1.32 & 13 & 85 & 4.1 & $\infty .1$ & 8.1 & 99.32 \\
\hline 54 & $3-127170$ & 0 & 20 &, 74 & $<0.1$ & $\infty .1$ & $\infty .1$ & 94.00 \\
\hline 55 & $3-127171$ & 0.36 & 19 & 84 & $\infty .1$ & $\infty .1$ & $\infty .1$ & 103.36 \\
\hline 56 & $3-127172$ & 0.25 & 20 & 84 & $\infty .1$ & $\infty .1$ & $\$ .1$ & 104.25 \\
\hline & $5 / 26 / 99$ Start - Set 11 & & & & & & & \\
\hline 57 & $3-127173$ & 1.8 & 10.1 & 81.5 & $\infty .1$ & 4.1 & 4.1 & 93.40 \\
\hline 58 & $3-127174$ & 0 & 20.5 & 78.1 & $\infty .1$ & $<.1$ & $<0.1$ & 98.60 \\
\hline 59 & $3-127175$ & 0.7 & 16.2 & 81.6 & 2.8 & 0.31 & $\infty .1$ & 101.61 \\
\hline
\end{tabular}

**Measurement problems during GC analysis noted for test runs 46 and 52 . 
uses Ar as a carrier gas, which prevents it from being measured in the samples. Samples noted to have measurement recovery problems during $\mathrm{GC}$ analysis include test runs 46 and 52 . The largest source of sample recovery problems stemmed from having insufficient sample volume for some of the tests.

\section{Gas Generation Rate Calculations}

The results from GC measurements are expressed as volume percent (vol\%). Because the gas volume, pressure and temperature of each sample vessel were different, the vol\% measurement was converted to micromoles ( $\mu \mathrm{mol}$ ) of gas to support comparison between tests. Using PVT measurements, the volume of each vessel and test stand volume was measured by expanding gas from a calibrated volume. For tests at elevated temperature, this measurement was made before and after the vessel had returned to ambient temperature. The PVT data from the end of each test run were used to calculate the total $\mu$ mols of gas in the system using the ideal gas law. Because the heated containers are not at uniform temperature, the average temperature for the gas is calculated based on the difference in system volume at ambient and elevated temperature.

The $\mu$ mols of $\mathrm{H}_{2}$ in a selected test vessel were calculated as the product of measured $\mathrm{vol} \% \mathrm{H}_{2}$ and the calculated total $\mu$ mols of gas in the vessel and associated test stand. These calculations have been completed using a spreadsheet format and were expanded to include changes in the $\mu$ mols of $\mathrm{O}_{2}$ present in the system. For $\mathrm{O}_{2}$ the only change from the above procedure required taking into account the initial $\mu$ mols of $\mathrm{O}_{2}$ in the system. The above calculation was done twice using initial and final $\mathrm{O}_{2}$ concentrations. The first time used the initial pressure, initial temperature, constant volume and the reference value of $20.946 \%$ vol $\% \mathrm{O}_{2}$ in air. ${ }^{18}$ The second calculation is for the end of test conditions and uses final pressure, final temperature, $=$ constant volume and the measured value for vol\% $\mathrm{O}_{2}$. The final result is expressed as delta $\mathrm{O}_{2}$ and is calculated as the difference between end and initial moles of $\mathrm{O}_{2}$. These calculations are presented in Table 6.

\section{Chemical Reactions in SS\&C Surrogate Materials and Residue Samples}

The potential of chemical reactions in SS\&C residues is important to transportation and storage safety because these reactions generate heat, pressure and potentially flammable mixtures of gases. The elevated temperatures possible during transportation of $\mathrm{Pu}$ residue materials could be a contributing factor to initiation of acceleration of potential chemical reactions. Calcium metal was used as a reductant in the production of Pu metal at RFETS, and a fraction of the unreacted calcium metal remains in the SS\&C residue. The amount of calcium metal present in SS\&C has been estimated by measuring the volume of gas produced when SS\&C residue was allowed to react with water. These water reactivity tests to determine reactive metal content of RFETS SS\&C have been done both at SRS and RFETS. ${ }^{19,20}$ The amount of calcium remaining was estimated to be as high as $11 \%$ in some samples. 
Table 6 - Spreadsheet Calculation of Initial and Final Gas Compositions

\begin{tabular}{|c|c|c|c|c|c|c|c|c|c|c|c|c|c|}
\hline $\begin{array}{c}\text { Run } \\
\#\end{array}$ & $\begin{array}{l}\text { Volume ini } \\
\text { (cc) }\end{array}$ & $\begin{array}{l}\text { itial P } \\
\text { (tom) }\end{array}$ & $\begin{array}{l}\text { initial t } \\
(\operatorname{deg} K)\end{array}$ & $\begin{array}{l}\text { start gas } \\
\text { (umols) }\end{array}$ & $\begin{array}{l}\text { start } \mathrm{O}^{2} \\
\text { (umols) }\end{array}$ & $\begin{array}{l}\text { Final P } \\
\text { (torr) }\end{array}$ & $\begin{array}{c}\text { Final } t \\
(\operatorname{deg} K)\end{array}$ & $\begin{array}{l}\text { end gas } \\
\text { (umols) }\end{array}$ & $\begin{array}{c}\text { H2 } \\
\text { (vol\%) }\end{array}$ & $\begin{array}{c}02 \\
\text { (vol\%) }\end{array}$ & $\begin{array}{l}\text { end } \mathrm{H} 2 \\
\text { (umols) }\end{array}$ & $\begin{array}{l}\text { end } \mathrm{O} 2 \\
\text { (umois) }\end{array}$ & $\begin{array}{l}\text { delta } 02 \\
\text { (umols) }\end{array}$ \\
\hline \multicolumn{14}{|c|}{ 2/20199 Start - Set 1} \\
\hline 1 & 34.1 & 752.2 & 296.6 & 1388.0 & 290.7 & 743.2 & 295.7 & 1375.5 & 0.6 & 18.8 & 7.6 & 258.6 & -32.1 \\
\hline 2 & 63.9 & 741.9 & 294.7 & 2579.5 & 540.3 & 711.8 & 297.2 & 2454.0 & 0.0 & 17.9 & 0.0 & 439.3 & -101.0 \\
\hline 3 & 30.5 & 740.9 & 296.6 & 1222.4 & 256.1 & 741.3 & 295.9 & 1226.0 & 0.0 & 21.1 & 0.0 & 258.7 & 2.6 \\
\hline 4 & 30.9 & 748.3 & 298.5 & 1242.9 & 260.3 & 751.5 & 295.4 & 1261.3 & 0.0 & 20.1 & 0.0 & 253.5 & -6.8 \\
\hline 5 & 29.8 & 755.5 & 297.3 & 1215.5 & 254.6 & 891.3 & 295.5 & 1442.7 & 10.8 & 22.8 & 155.8 & 328.9 & 74.3 \\
\hline 6 & 62.3 & 775.7 & 295.5 & 2625.3 & 549.9 & $\pi 74.7$ & 294.5 & 2630.8 & 4.2 & 3.9 & 110.5 & 102.6 & NA \\
\hline \multicolumn{14}{|c|}{ 3/1/99 Start - Set 2} \\
\hline 7 & 49.7 & 649.4 & 296.2 & 1748.7 & 366.3 & 808.1 & 331.0 & 1947.4 & 3.7 & 3.6 & 72.1 & 70.1 & $\overline{N A}$ \\
\hline 8 & 64.1 & 750.2 & 295.6 & 2610.2 & 546.7 & 735.1 & 295.7 & 2556.8 & 0.1 & 19.6 & 1.3 & 501.1 & -45.6 \\
\hline 9 & 62.9 & 734.5 & 299.1 & 2478.8 & 519.2 & 733.3 & 298.2 & 2482.2 & 0.1 & 20.2 & 2.0 & 501.4 & -17.8 \\
\hline 10 & 43.5 & 746.5 & 298.5 & 1743.9 & 365.3 & 746.5 & 295.8 & 1759.8 & 0.6 & 20.2 & 10.9 & 355.5 & -9.8 \\
\hline 11 & 38.5 & 755.7 & 296.4 & 1575.4 & 330.0 & 749.7 & 295.9 & 1565.5 & 0.3 & 19.7 & 4.1 & 308.4 & -21.6 \\
\hline 12 & 30.7 & 756.6 & 297.5 & 1253.5 & 262.6 & 753.7 & 296.1 & 1254.6 & 0.5 & .20 .0 & 6.8 & 250.9 & -11.6 \\
\hline \multicolumn{14}{|c|}{ 3/8/99 Start - Set 3} \\
\hline 13 & 51.7 & 762.3 & 302.1 & 2091.6 & 438.1 & 655.9 & 295.9 & 1837.3 & 6.2 & 3.1 & 113.7 & 57.0 & -381.1 \\
\hline 14 & 64.4 & 765.1 & 296.3 & 2666.9 & 558.6 & 975.2 & 329.5 & 3057.0 & 0.9 & 16.7 & 27.2 & 510.5 & -48.1 \\
\hline 15 & 65.6 & 754.1 & 299.6 & 2650.5 & 555.2 & 806.3 & 327.6 & 2591.6 & 0.0 & 11.7 & 0.0 & 303.2 & -252.0 \\
\hline 16 & 30.8 & 760.2 & 296.1 & 1267.9 & 265.6 & 753.2 & 314.3 & 1183.7 & 0.2 & 15.5 & 2.6 & 183.5 & -82.1 \\
\hline 17 & 42.0 & 762.2 & 298.0 & 1725.3 & 361.4 & $\pi 9.1$ & 297.2 & 1768.3 & 1.6 & 20.6 & 29.0 & 364.3 & 2.9 \\
\hline 18 & 30.3 & 760.0 & 298.0 & 1241.5 & 260.0 & 1179.8 & 296.4 & 1937.7 & 24.2 & 15.5 & 468.0 & 300.3 & 40.3 \\
\hline \multicolumn{14}{|c|}{ 3/17/99 Start-Set 4} \\
\hline 19 & 52.4 & 751.7 & 298.4 & 2118.0 & 443.6 & 744.5 & 297.4 & 2104.7 & 0.0 & 18.2 & 0.0 & 383.1 & -60.6 \\
\hline 20 & 53.8 & 753.4 & 297.6 & 2186.1 & 457.9 & 1178.3 & 321.3 & 3166.9 & 80.0 & 0.0 & 2533.5 & 0.0 & -457.9 \\
\hline 21 & 26.0 & 744.0 & 298.4 & 1039.3 & 217.7 & 803.2 & 323.0 & 1036.6 & 26 & 6.0 & 27.0 & 62.2 & -155.5 \\
\hline 22 & 43.0 & 749.4 & 298.3 & 1734.5 & 363.3 & 742.1 & 298.0 & 1719.3 & 0.1 & 15.4 & 2.2 & 264.8 & -98.5 \\
\hline 23 & 32.0 & 758.2 & 299.0 & 1299.9 & 272.3 & 806.3 & 307.8 & 1342.9 & 1.6 & 11.9 & 21.5 & 159.8 & -112.5 \\
\hline 24 & 43.8 & 764.4 & 298.1 & 1803.3 & 377.7 & 764.3 & 297.8 & 1804.9 & 5.0 & 19.7 & 90.2 & 355.6 & -222 \\
\hline \multicolumn{14}{|c|}{$3 / 26 / 99$ Start-Set 5} \\
\hline 25 & 14.4 & 749.5 & 295.9 & 586.5 & 122.8 & 8002 & 324.7 & 570.5 & 2.2 & 12.6 & 124 & 71.9 & -50.9 \\
\hline 26 & 25.7 & 752.6 & 296.2 & 1046.5 & 219.2 & 789.2 & 317.1 & 1025.2 & 1.2 & 16.2 & 12.2 & 166.1 & -53.1 \\
\hline \multicolumn{14}{|c|}{$4 / 6 / 99$ Start-Set 6} \\
\hline 30 & 63.3 & 755.8 & 297.8 & 2576.0 & 539.6 & 724.6 & 297.6 & 2471.3 & 1.3 & 16.5 & 31.4 & 407.8 & -131.8 \\
\hline 31 & 26.2 & 733.8 & 369.5 & 835.5 & 175.0 & 738.8 & 367.5 & 845.7 & 0.0 & 20.5 & 0.3 & 173.4 & -1.6 \\
\hline 32 & 91.7 & 753.9 & 297.5 & 3726.5 & 780.5 & $\pi 72.2$ & 296.9 & 3824.6 & 8.1 & 12.9 & 310.9 & 493.4 & -287.2 \\
\hline 33 & 38.5 & 760.0 & 298.8 & 1572.9 & 329.5 & 751.8 & 296.8 & 1566.4 & 1.6 & 20.2 & 25.1 & 316.4 & -13.0 \\
\hline 34 & 39.0 & 768.9 & 298.9 & 1608.9 & 337.0 & 760.5 & 296.9 & 16020 & 0.2 & 20.2 & 3.2 & 323.6 & -13.4 \\
\hline \multicolumn{14}{|c|}{$4 / 16199$ Start $-\operatorname{Set} 7$} \\
\hline 36 & 61.3 & 748.5 & 297.9 & 2472.1 & 517.8 & 3843.2 & 324.5 & 11652.5 & 74.7 & $\overline{1.3}$ & 8704.4 & 151.5 & $\overline{-366.3}$ \\
\hline 37 & 26.5 & 741.6 & 297.4 & 1059.9 & 222.0 & 813.1 & 316.1 & 1093.3 & 0.4 & 20.0 & 4.4 & 218.7 & -3.3 \\
\hline 38 & 44.9 & 744.9 & 297.4 & 1804.4 & 378,0 & 802.2 & 297.9 & 1940.0 & 7.4 & 14.1 & 143.6 & 273.5 & -104.4 \\
\hline \multicolumn{14}{|c|}{ 4/23/99 Start - Set 8} \\
\hline 41 & 19.3 & 750.0 & 298.2 & 776.9 & 162.7 & 742.3 & 296.4 & 773.6 & 0.7 . & 19.9 & 5.4 & 153.9 & -8.8 \\
\hline 44 & 123.7 & 750.5 & 300.6 & 4954.2 & 1037.7 & 722.7 & 297.4 & 4822.0 & 0.2 & 18.6 & 9.6 & 896.9 & -140.8 \\
\hline 45 & 37.5 & 756.9 & 298.5 & 1526.0 & 319.6 & 782.5 & 297.4 & 1583.5 & 2.3 & 21.0 & 36.4 & 332.5 & 12.9 \\
\hline 46 & 38.1 & 763.9 & 298.9 & 1563.3 & 327.4 & 788.3 & 296.9 & 1624.1 & 1.2 & 21.1 & 19.5 & 342.7 & 15.2 \\
\hline \multicolumn{14}{|c|}{$4 / 29 / 99$ Start - Set 9} \\
\hline 47 & 19.0 & 749.7 & 297.9 & 765.4 & 160.3 & 31197.3 & $370.0^{\circ}$ & 984.2 & 3.4 & 7.3 & 33.5 & 71.8 & -88.5 \\
\hline 50 & 122.8 & 748.8 & 298.2 & 4945.9 & 1036.0 & 736.0 & 298.4 & 4858.1 & 0.4 & 18.9 & 19.4 & 918.2 & -117.8 \\
\hline 51 & 18.7 & 755.7 & 298.1 & 762.3 & 159.7 & 753.4 & 298.1 & 759.9 & 1.5 & 19.9 & 11.4 & 151.2 & -8.4 \\
\hline 52 & 45.1 & 762.5 & 298.8 & 1848.5 & 387.2 & 747.9 & 298.4 & 1815.5 & 0.6 & 20.1 & 10.0 & 365.6 & -21.5 \\
\hline \multicolumn{14}{|c|}{ 5/18/99 Start - Set 10} \\
\hline 53 & 18.7 & 754.9 & 297.6 & 762.7 & 159.8 & 872.6 & 338.2 & 775.8 & 1.3 & 13.0 & 10.2 & 100.9 & -58.9 \\
\hline 54 & 31.6 & 754.7 & 298.1 & 1282.2 & 268.6 & 775.2 & 315.6 & 1244.0 & 0.0 & 20.0 & 0.0 & 248.8 & -19.8 \\
\hline 55 & 71.5 & 743.3 & 298.4 & 2857.4 & 598.5 & 744.9 & 298.1 & 2866.5 & 0.4 & 19.0 & 10.3 & 544.6 & -53.9 \\
\hline 56 & 37.5 & 759.8 & 298.4 & 1532.1 & 320.9 & 774.6 & 297.5 & 1566.7 & 0.3 & 20.0 & 3.9 & 313.3 & -7.6 \\
\hline \multicolumn{14}{|c|}{$5 / 26 / 99$ Start - Set 11} \\
\hline 57 & 18.5 & 774.9 & 298.3 & 770.7 & 161.4 & 41048.9 & 300.6 & 1035.1 & 1.8 & 10.1 & 18.6 & 104.5 & -56.9 \\
\hline 58 & 31.3 & 750.4 & 298.5 & 1261.3 & 264.2 & 750.3 & 299.3 & 1257.8 & 0.0 & 20.5 & 0.0 & 257.8 & -6.4 \\
\hline 59 & 59.6 & 742.4 & 298.2 & 2378.8 & 498.3 & $3 \quad 1019.0$ & 322.6 & 3018.4 & 0.7 & 16.2 & 21.1 & 489.0 & -9.3 \\
\hline
\end{tabular}


Test run number 18 contained a sample of $S S \& C$ surrogate created by mixing moist $\mathrm{PuO}_{2}$ (from test \#5 and \#12) and small pieces of calcium metal. Test 18 showed a rapid pressure rise at ambient temperature immediately upon sealing the sample vessel. Results indicate that the pressure increase is primarily due to $\mathrm{H}_{2}$ probably from the reaction of calcium metal with $\mathrm{H}_{2} \mathrm{O}$. It was recognized that this test with freshly cut calcium metal was not representative of RFETS SS\&C conditions. The test sample was re-measured after several weeks and the gas generation rate was much smaller. However, these test results provided an indication of the pressure increase that should be anticipated with a reaction of calcium metal in SS\&C residue.

Figures 3 and 4 show the pressure data for a RFETS sample with and without heating (Tests 30 and 36 respectively). When heated to $90^{\circ} \mathrm{C}$ this sample, which had demonstrated a pressure decrease at ambient temperature, rapidly increased in pressure. Analysis of the gas mixture at the end of test 36 showed an elevated $\mathrm{H}_{2}$ concentration, similar to test run number 18 . The initial pressure rise observed for test run 36 (Figure 4) is approximately 100 times greater than expected for radiolysis of water. During days $2-7$ of test run 36 , the pressure increase is still more that 10 times what is expected for radiolysis of water. The most probable cause for the observed $\mathrm{H}_{2}$ production in test 36 is the reaction of calcium metal with water vapor.

Even though the calcium metal content of SS\&C was expected to have a heavily oxidized surface and react slowly at ambient temperature in room air, the transport conditions for SS\&C residues may cause the calcium to react with adsorbed moisture in the sealed container. The subsequent pressure rise and $\mathrm{H}_{2}$ generation rate is far greater than what is predicted for radiolysis of adsorbed moisture. Furthermore, chemical reactions that produce $\mathrm{H}_{2}$ are not considered as part of the analytical radiolysis model. 
Figure 3 - RFETS Sample Test Run 30 at Ambient Temperature

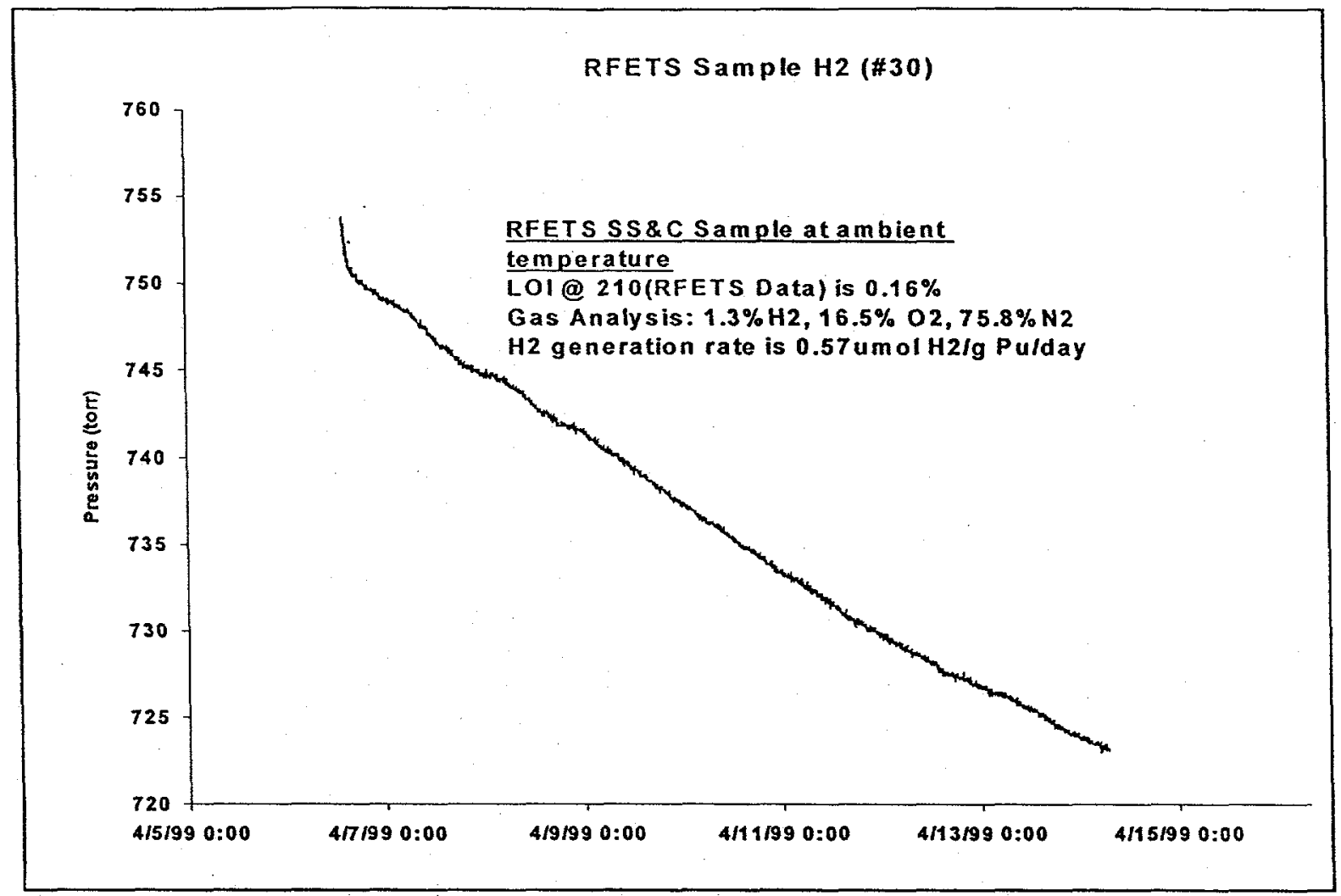

Figure 4-RFETS Sample Test Run 36 at Elevated Temperature

$$
\text { RFETS H2 + Heat (\#36) }
$$

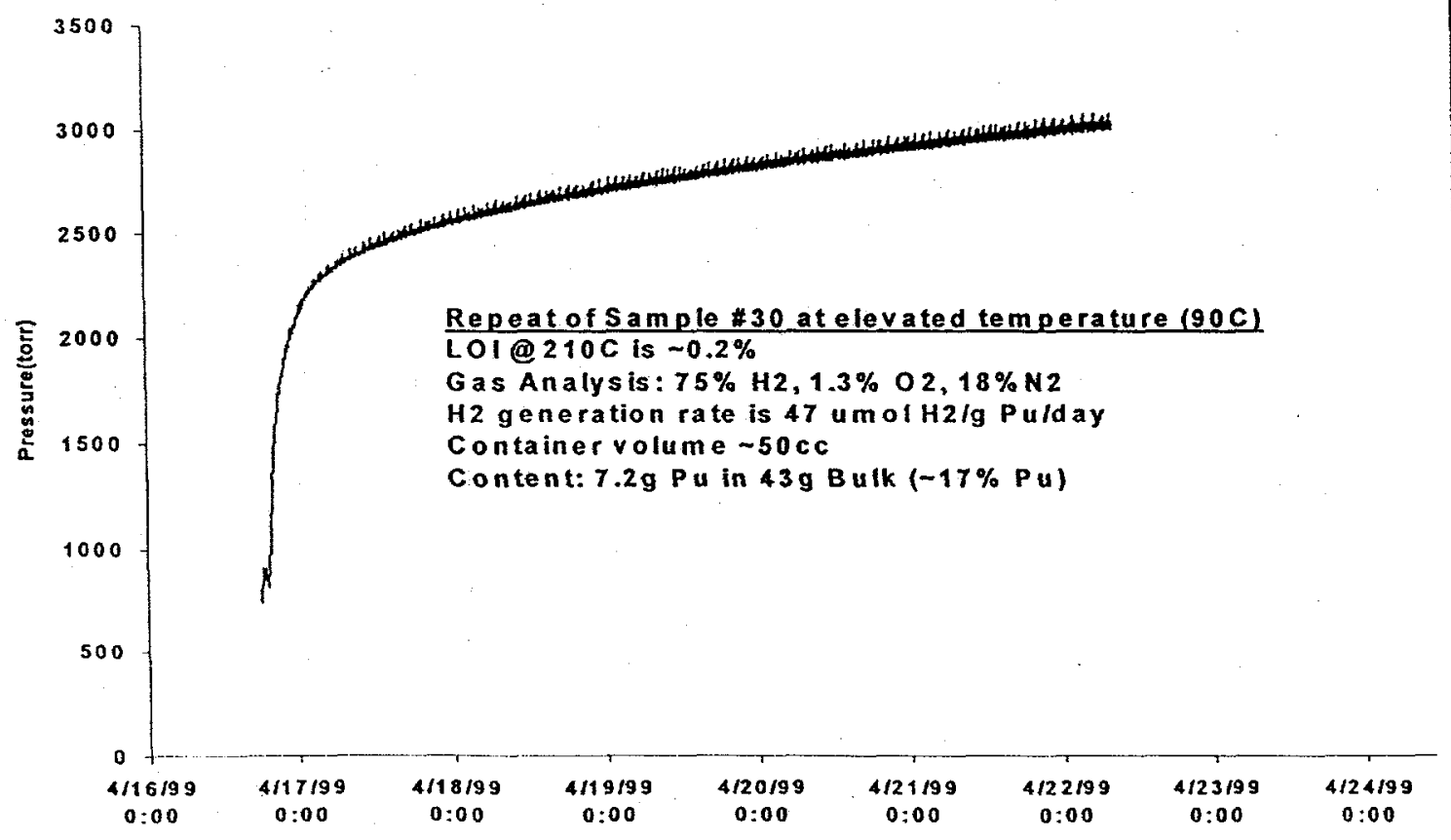




\section{Section III - Gas Generation Modeling}

\section{Description of the Analytical Radiolysis Model}

The analytical radiolysis model developed by N.M. Askew, ${ }^{4}$ as an adaptation of earlier work by M.L. Hyder, ${ }^{20}$ uses a spreadsheet format to calculate the rates of $\mathrm{H}_{2}$ and $\mathrm{O}_{2}$ formation from the radiolysis of water. The key assumptions documented by Askew in describing this model are given below:

- All materials are finely divided and homogeneously mixed so the effects of self-shielding are neglected

- Gas phase recombination was neglected

- The effect of the substrate on radiolysis was neglected

- A G-value of 1.6 molecules per $100 \mathrm{eV}$ was used for $\mathrm{H}_{2}$ formation

- Oxygen is generated at half of the $\mathrm{H}_{2}$ molar generation rate

The model calculates gas production rates by first estimating the amount of energy deposited into the water, assuming that radiation absorbed by other materials, such as the matrix components, does not lead to gas production. The estimated amount of energy absorbed by the residue is based upon the energy released by decay of radioactive materials present. The relative stopping power (SP) of each matrix component determines the energy absorbed by that component. The range of stopping powers for non-radioactive components in SS\&C residue is very small, so the stopping power of $\mathrm{MgO}$ was used to represent the bulk matrix. The ratio of water stopping power to matrix stopping power is then used to determine the effective dose absorbed by water. The G-value, or molecules per 100 electron volts (eV), is = then applied to compute the $\mathrm{H}_{2}$ generation rate. The equation for $\mathrm{H}_{2}$ generation rate could be represented:

$$
\begin{aligned}
& \mathrm{H}_{2} \text { Generation Rate }=\mathrm{F} * \mathrm{E} * \mathrm{G} * \mathrm{C} \\
& \text { Where: } \quad \begin{aligned}
\mathrm{F} & =\mathrm{SP}_{\mathrm{H} 2 \mathrm{O}^{*} \text { mass }} \mathrm{H} 2 \mathrm{~d} / \Sigma\left(\mathrm{SP}_{\text {matrix }} *\right. \text { mass } \\
\mathrm{E} & =\text { total decay energy rate in } \mathrm{eV} / \text { day } \\
\mathrm{G} & =\mathrm{G} \text {-value for } \mathrm{H}_{2} \text { production or } \mathrm{G}\left(\mathrm{H}_{2}\right) \\
\mathrm{C} & =\text { Constant used for unit conversions }
\end{aligned}
\end{aligned}
$$

The analytical radiolysis model includes a term to correct for decreasing water content as a result of radiolysis.

\section{Predictions of $\mathrm{H}_{2}$ Generation Rate using the Analytical Radiolysis Model}

To compare observed $\mathrm{H}_{2}$ generation rates with output from the analytical radiolysis model, the data are expressed as $\mu \mathrm{mol} / \mathrm{g} \mathrm{PuO}_{2} /$ day. This comparison is provided in Table 7 for several samples that cover a range of matrix contents, and moisture and temperature conditions. The weight loss of the sample at $210^{\circ} \mathrm{C}$ is used as the moisture input to the model. The model does not accurately predict the gas generation rate observed experimentally when using this weight loss value as an estimate of moisture content. Run number 10 shows that weight gains 
can occurr for materials that adsorb gas or react with air at elevated temperature. This is a problem associated with using this technique to estimate moisture content.

Table 7 - Comparison of Model Predictions with Measured $\mathrm{H}_{2}$ Generation Rates

\begin{tabular}{|ccccc|}
\hline Run \# & $\begin{array}{c}\text { Model Prediction } \\
\text { (umol H2/g Pu/day) }\end{array}$ & $\begin{array}{c}\text { Measured Rate } \\
\text { (umol H2/g Pu/day) }\end{array}$ & $\begin{array}{c}\text { Surrogate Content } \\
\text { PuO2 plus matrix: }\end{array}$ & $\begin{array}{c}\text { \%Wt Loss @ } \\
\text { 210 deg C }\end{array}$ \\
\hline 10 & 0.00 & 0.27 & $\mathrm{CaO}+\mathrm{MgO}$ & -0.33 \\
11 & 0.06 & 0.08 & $\mathrm{MgO}$ & 0.11 \\
14 & 0.07 & 0.40 & $\mathrm{CaF2} @ 90 \mathrm{deg} \mathrm{C}$ & 0.30 \\
21 & 0.39 & 0.70 & $\mathrm{Ca}(\mathrm{OH}) 2+\mathrm{MgO}$ & 0.33 \\
22 & 0.25 & 0.04 & $\mathrm{MgO}$ & 0.29 \\
23 & 0.06 & 0.78 & $\mathrm{MgO} \mathrm{@} \mathrm{90} \mathrm{deg} \mathrm{C}$ & 0.11 \\
24 & 0.31 & 2.09 & $\mathrm{Mg}(\mathrm{OH}) 2$ & 0.65 \\
\hline
\end{tabular}

\section{Limitations of Modeling $\mathrm{H}_{2}$ Generation}

Two principal limitations have been identified for the analytical radiolysis model when used for SS\&C residue materials. The first is the inaccuracy associated with using a G-value for bulk liquid water for moisture adsorbed on a matrix. The model assumes that the radiation dose absorbed by the SS\&C matrix does not result in $\mathrm{H}_{2}$ production and there is no energy transfer. But some materials like $\mathrm{SiO}_{2}$ and $\mathrm{MgO}$ are observed to promote energy transfer to adsorbed species on the material surface. ${ }^{21,22}$ For these materials that support energy transfer, the Gvalue can be 10 to 100 times the $G$-value associated with radiolysis of homogeneous materials like an aqueous solution. G-values that reflect $\mathrm{H}_{2}$ generation rates in the presence of matrix materials are necessary to fully correct for the energy transfer phenomena. These G-values could be used, based on bounding estimates of residue content, to more accurately predict $\mathrm{H}_{2}$ generation rate.

Samples 22 and 23 contain $\mathrm{MgO}$ at ambient temperature and $90^{\circ} \mathrm{C}$ respectively. For the sample at ambient temperature, the measured $\mathrm{H}_{2}$ generation rate is less than predicted by the analytical radiolysis model. In test run 23 the sample has a lower weight moisture content than sample 22 , but the measured $\mathrm{H}_{2}$ generation rate is a factor of 13 greater than the model result. The variation in $\mathrm{H}_{2}$ generation rate that may result from the temperature difference between these samples is not understood. One possibility is the formation of $\mathrm{Mg}(\mathrm{OH})_{2}$ at elevated temperature. Test run 24 showed a $\mathrm{H}_{2}$ generation rate about 7 times larger than predicted by the analytical radiolysis model.

The second limitation identified for the analytical radiolysis model is the inaccuracy associated with estimating moisture based on weight loss measurements at $210^{\circ} \mathrm{C}$. An extreme example of this problem is found in Table 7. Run number 10 generated $\mathrm{H}_{2}$ although the weight loss measurement at $210^{\circ} \mathrm{C}$ shows a weight gain. This type of weight gain was observed with numerous samples known to contain $\mathrm{CaO}$ or $\mathrm{Ca}(\mathrm{OH})_{2}$. The weight gain was attributed to the reactions of calcium metal with air or water and the reactions of $\mathrm{CaO}$ with $\mathrm{H}_{2} \mathrm{O}$ to form $\mathrm{Ca}(\mathrm{OH})_{2}$ or $\mathrm{Ca}(\mathrm{OH})_{2}$ with $\mathrm{CO}_{2}$ to form $\mathrm{CaCO}_{3}{ }^{27}$ A more detailed evaluation of moisture adsorption and weight loss measurements is provided in the following sections. 


\section{Section IV - SS\&C Moisture Content}

RFETS has characterized much of the SS\&C residues for moisture content using the $210^{\circ} \mathrm{C}$ weight loss measurement. A similar analysis was setup at SRTC to determine the utility of the analytical radiolysis model using weight loss measurements at $210^{\circ} \mathrm{C}$ as the moisture input. ${ }^{23}$ The use of a $210^{\circ} \mathrm{C}$ weight loss method has been continued in an attempt to achieve maximum benefit from the existing RFETS data. This section discusses the factors that influence moisture adsorption in SS\&C residues and shows the effect of moisture content on the $\mathrm{H}_{2}$ generation rate. Use of the $210^{\circ} \mathrm{C}$ weight loss method is sufficient to determine physically adsorbed moisture and can be used as an indicator of the gas composition for SS\&C residues.

\section{Moisture Measurements based on Weight Loss}

One of the most frequently used laboratory techniques for measuring the moisture content of a solid is based on weight loss after drying. Weight loss measurements are made frequently by weighing a sample, heating the sample to remove adsorbed moisture, and then weighing the dried sample. The moisture content is calculated as the difference between initial and final weights and reported as a percentage of sample mass. Selection of the proper drying temperature, to determine moisture content of a material by the weight loss method, requires specific understanding of the materials' weight loss properties. The weight loss properties of a material are determined using Thermogravimetric Analysis (TGA) to measure weight loss as a function of time and temperature. The TGA data are used to select the proper drying temperature for a simple weight loss determination of moisture. Weight loss measurements are not specific for $\mathrm{H}_{2} \mathrm{O}$ and subsequently report any volatile compound as moisture content.

Based on TGA data for SS\&C residues over a temperature range of 30 to $900^{\circ} \mathrm{C}$, it is evident that the SS\&C components continue to lose weight above $210^{\circ} \mathrm{C}$. The primary components of $\mathrm{SS} \& \mathrm{C}$ are $\mathrm{MgO}$, Ca metal, $\mathrm{CaF}_{2}, \mathrm{CaO}, \mathrm{Ca}(\mathrm{OH})_{2}, \mathrm{CaCO}_{3}, \mathrm{Pu}$ metal, $\mathrm{PuO}_{2}$, and a possible trace of $\mathrm{Mg}(\mathrm{OH})_{2}$. In the case of $\mathrm{Ca}(\mathrm{OH})_{2}$ and $\mathrm{Mg}(\mathrm{OH})_{2}$, these compounds begin to decompose and lose $\mathrm{H}_{2} \mathrm{O}$ around $400^{\circ} \mathrm{C}$. For $\mathrm{PuO}_{2}$ the weight loss appears to be nearly continuous as temperature increases. For samples of $\mathrm{PuO}_{2}$ containing less than $2 \% \mathrm{H}_{2} \mathrm{O}$, about half of the adsorbed water is removed at $210^{\circ} \mathrm{C}^{24}$ Figures 5 through 7 show the TGA plots for some materials found in SS\&C residue. Figure 8 is the TGA data for an actual SS\&C sample.

Weight loss measurements at $210^{\circ} \mathrm{C}$ estimate moisture content based on the assumption that weight loss is caused by desorption of $\mathrm{H}_{2} \mathrm{O}$. The weight loss measurement at RFETS used an automated weight loss balance with a sample size of about 5 grams $(\mathrm{g})$. The TGA analysis uses about $0.020 \mathrm{~g}$ of sample. Both systems were set-up to heat the sample at $210^{\circ} \mathrm{C}$ until the sample weight was constant. The TGA accomplished this by holding the sample at $210^{\circ} \mathrm{C}$ for 30 minutes. The weight loss balance at RFETS was set to stop heating once the weight loss achieved a slope of less than $0.05 \%$. In cases where the sample contains calcium or plutonium metals that react with air to form the heavier oxides, the weight loss measurement is offset by potential weight gains. Other sources of error in this type measurement include chemical reactions that increase the sample weight, such as conversion of $\mathrm{Ca}(\mathrm{OH})_{2}$ to $\mathrm{CaCO}_{3}$, and problems caused by sample handling. When samples have equilibrated to adsorb moisture in a 
Figure 5 - TGA Plot of $\mathrm{PuO}_{2}$

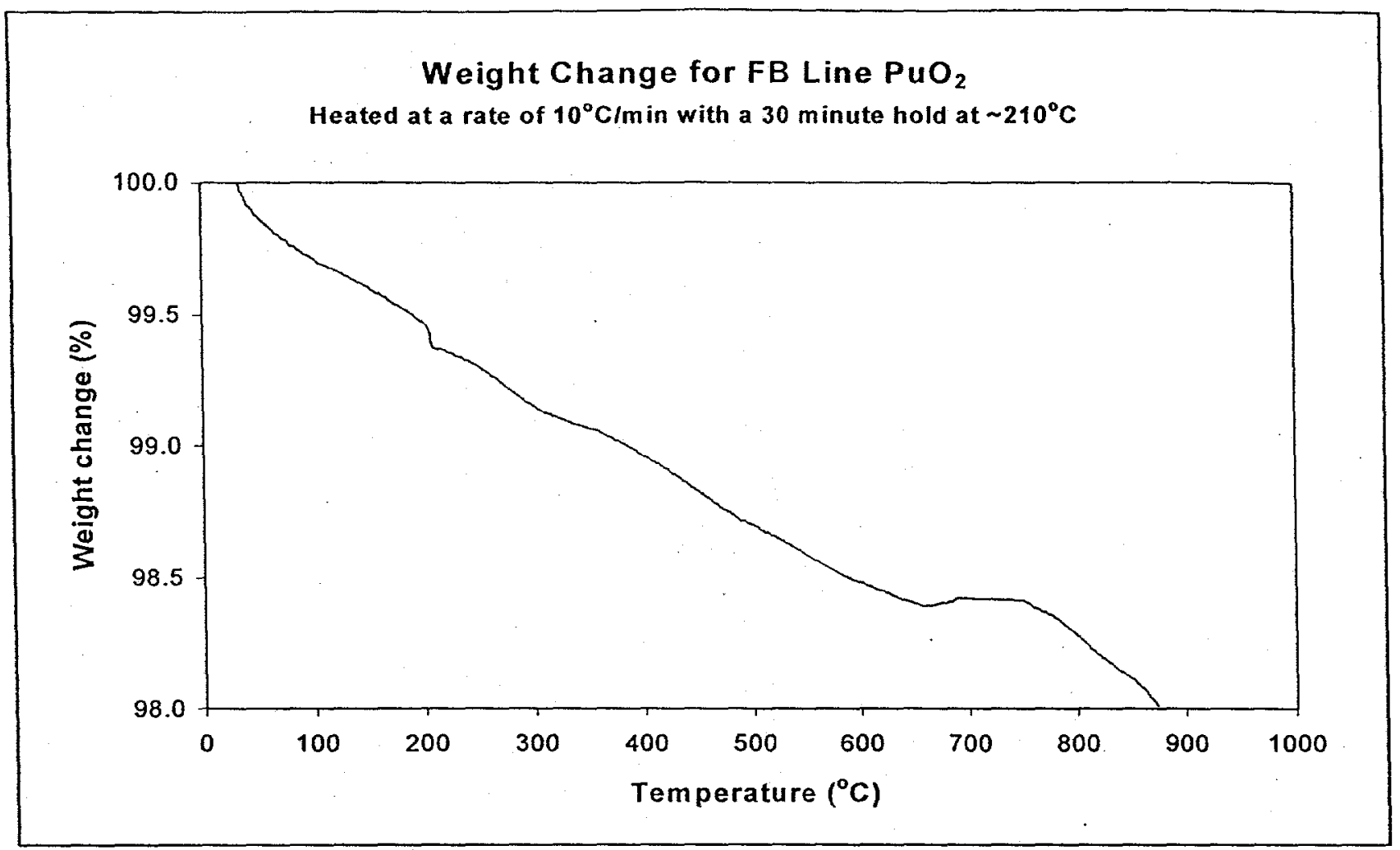

Figure 6 - TGA Plot of $\mathrm{Ca}(\mathrm{OH})_{2}$




Figure 7 - TGA Plot of $\mathrm{Mg}(\mathrm{OH})_{2}$

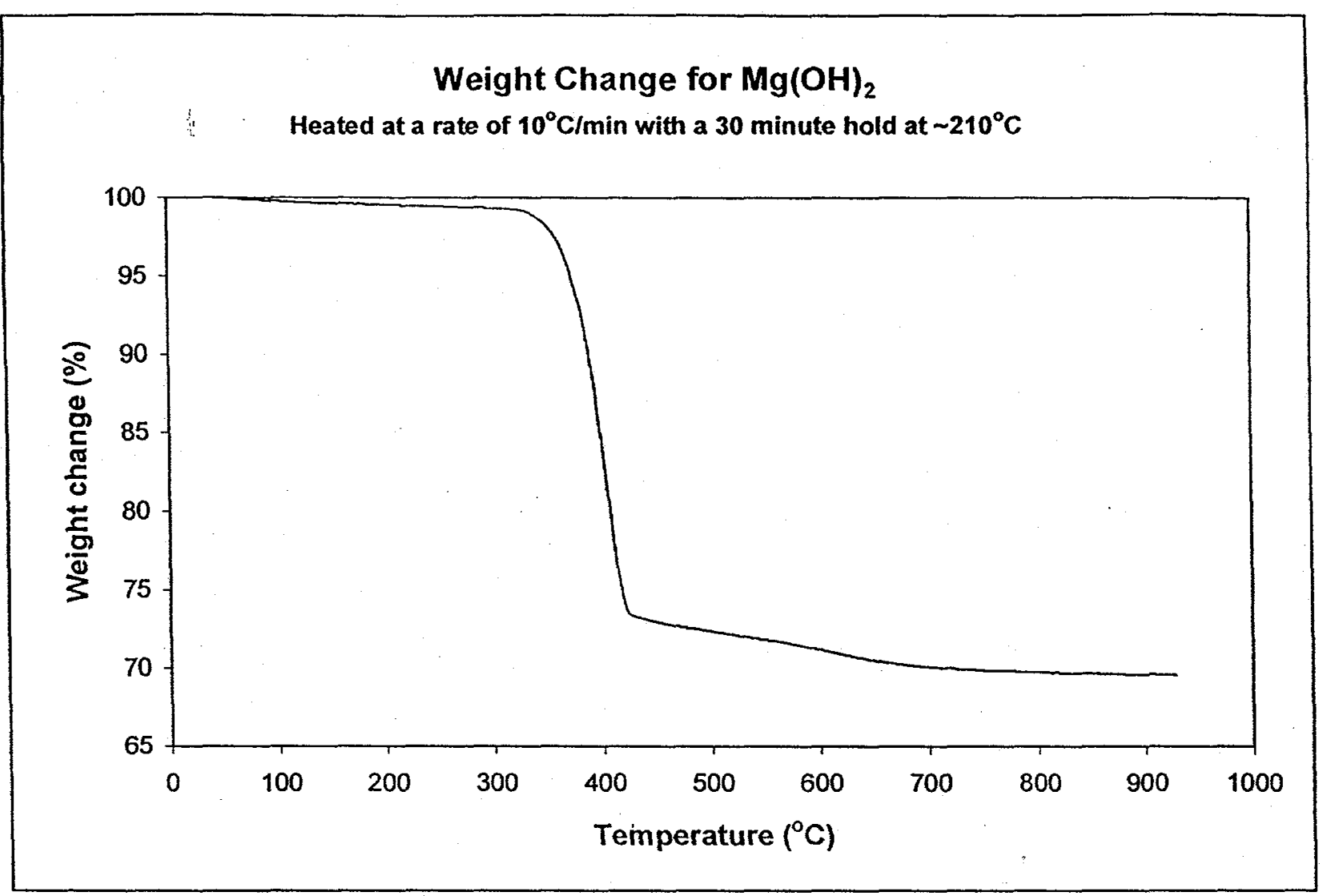

Figure 8 - TGA Plot of RFETS Sample H2

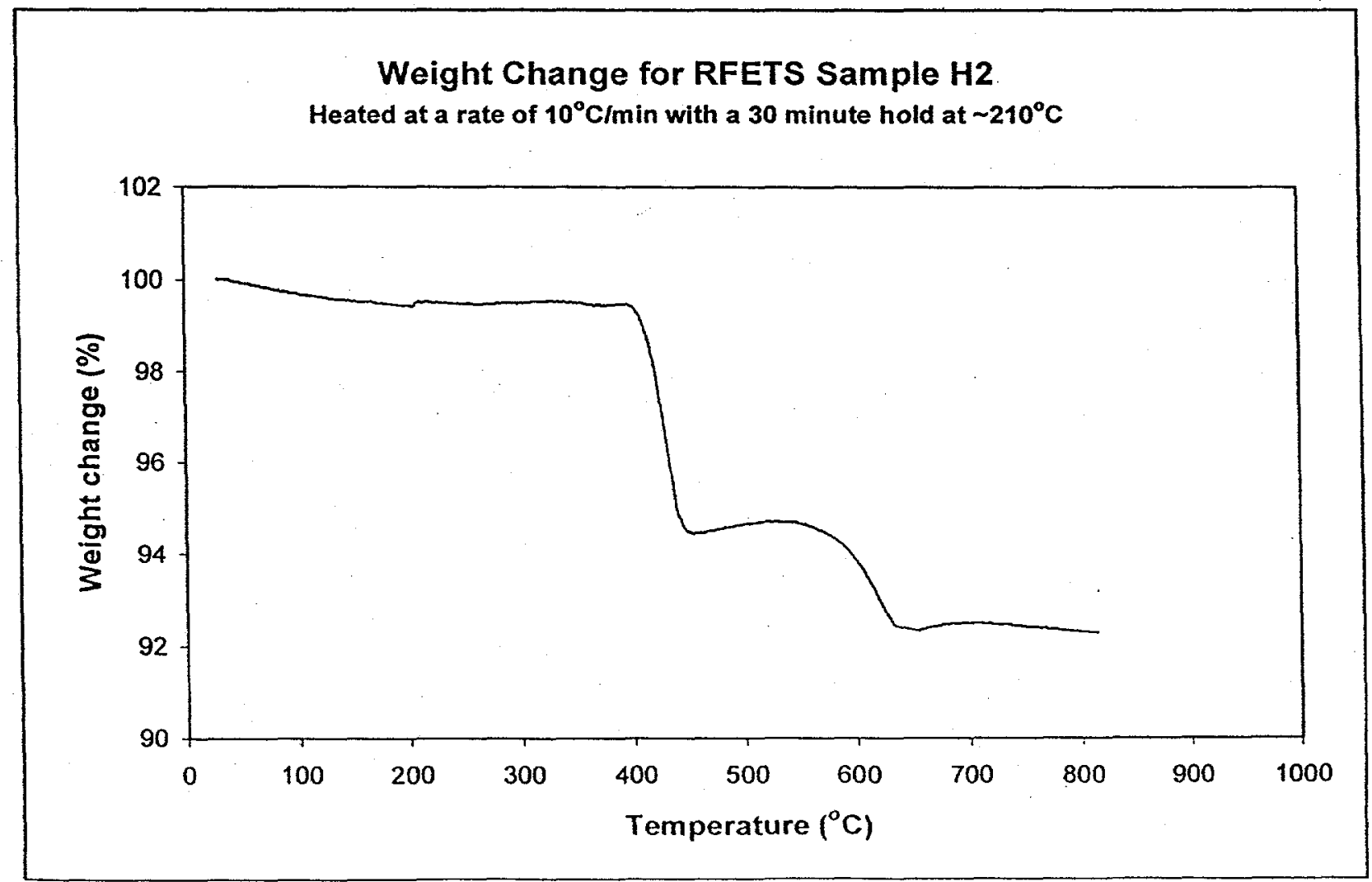


high humidity environment, storing the samples in a dry environment prior to the weight loss measurements may cause the samples to lose a fraction of the adsorbed moisture. Thus the actual moisture content would be underestimated. The opposite is possible if "dry" samples are stored in a humid environment prior to analysis. Adsorbed moisture is defined as the quantity of $\mathrm{H}_{2} \mathrm{O}$ that has condensed on a solid surface and has not penetrated within the solid.

It is evident that additional information about the chemical composition of SS\&C can be obtained from Figures 5-8. The RFETS sample shown in Figure 8, for example, contains $\mathrm{Ca}(\mathrm{OH})_{2}$ and $\mathrm{CaCO}_{3}$ based on the TGA curve and the transition temperatures for decomposition of these species. The presence of $\mathrm{CaCO}_{3}$ and $\mathrm{Ca}(\mathrm{OH})_{2}$ have been confirmed using $\mathrm{x}$-ray diffraction measurements. Based on measurement of the weight change at each transition, a quantitative analysis of the species could be accomplished. The error associated with the SRTC TGA weight loss measurements has been estimated by looking at the reproducibility of measurements on a reagent grade surrogate. The relative standard deviation of this measurement is $\pm 3.2 \%$ at the $95 \%$ confidence interval. For actual SS\&C and surrogate materials, the difficulty associated with obtaining a representative sample would add to the measurement uncertainty. Obtaining representative samples can be difficult because the dense $\mathrm{PuO}_{2}$ tends to settle to the bottom of a container. Accurate sampling is also hindered by materials at the surface of a filled storage container adsorbing moisture more rapidly than materials at the center of the container. The impact of these effects on moisture analysis methods for SS\&C residues has not been evaluated.

\section{Adsorption of Moisture on $\mathrm{PuO}_{2}$}

As part of the efforts associated with testing the analytical radiolysis model, various components of the SS\&C residue were exposed to high humidity environments to monitor the adsorption of moisture: $\mathrm{PuO}_{2}$ was found to adsorb a significant quantity of $\mathrm{H}_{2} \mathrm{O}$. The $\mathrm{PuO}_{2}$ used for these tests was obtained from the air oxidation of $\mathrm{Pu}$ metal buttons and has never been intentionally heated above approximately $110^{\circ} \mathrm{C}$. Thermal calculations on storage conditions of the Pu metal suggest the $\mathrm{PuO}_{2}$ may have been heated to about $170^{\circ} \mathrm{F}\left(\sim 77^{\circ} \mathrm{C}\right)$ during storage. $^{25}$ Based on literature reports, this oxide should have a surface area of about $7 \mathrm{~m}^{2} / \mathrm{g}$, which would decrease in nearly a straight line fashion to about $2 \mathrm{~m}^{2} / \mathrm{g}$ on heating to $900^{\circ} \mathrm{C}^{12}$ Because the $\mathrm{PuO}_{2}$ used in these tests has a higher surface area than $\mathrm{PuO}_{2}$ anticipated to be in SS\&C, the moisture content of this material will be higher and provide conservative estimates of moisture adsorption. Increasing moisture content is expected to provide a conservative estimate of gas generated from radiolysis.

Figure 9 shows the weight gained by $\mathrm{PuO}_{2}$ from adsorption of moisture in humid atmospheres over an extended period of time. This $\mathrm{PuO}_{2}$ was originally generated by air oxidation of plutonium metal. The $100 \%$ humidity environment was produced by filling the bottom of a standard glass desiccator with water, and samples containing about $10 \mathrm{~g}$ of $\mathrm{PuO}_{2}$ were stored in a beaker in the upper section of the desiccator. The $76 \%$ constant humidity was created by keeping an excess of sodium acetate in contact with a saturated solution of sodium acetate. ${ }^{26}$ The initial weight loss at $210^{\circ} \mathrm{C}$ for the samples of $\mathrm{PuO}_{2}$, before exposure to elevated humidity, was about $0.6 \%$, and the total weight loss by this sample at $900^{\circ} \mathrm{C}$ was about $1.6 \%$. 
Figure 9 - Weight Gain of $\mathrm{PuO}_{2}$ in Humid Environments

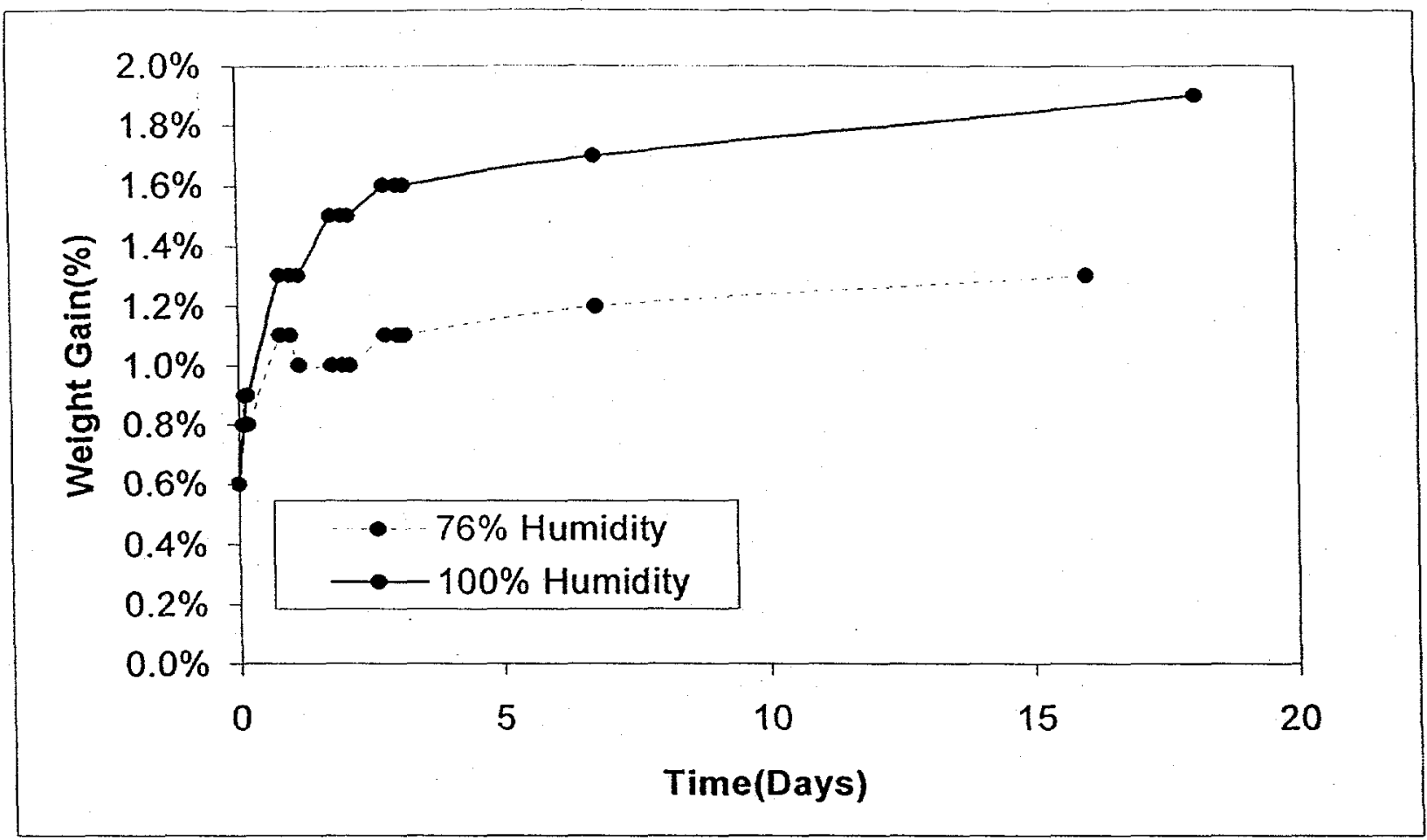

Figure 9 plots the percent weight gained for the samples stored in $76 \%$ and $100 \%$ humidity environments. A similar sample of $\mathrm{PuO}_{2}$ (not shown in Figure 9) was maintained in the $100 \%$ humidity environment for about two weeks and showed an average weight loss at $210^{\circ} \mathrm{C}$ of approximately $2.3 \%$. The difference between these results suggests the estimate of starting moisture content for Figure 9 may be low.

\section{Adsorption of Moisture on SS\&C Residue Components}

Moisture adsorption tests were also conducted on SS\&C residue components including MgO (both sand and crucible), $\mathrm{CaF}_{2}$, and $\mathrm{CaO}$. The $\mathrm{CaO}$ and $\mathrm{CaF}_{2}$ are reagent grade laboratory chemicals and the $\mathrm{MgO}$ components were obtained from RFETS. The test was conducted by first drying the materials to constant weight using a muffle furnace at $800^{\circ} \mathrm{C}$. No appreciable weight loss was observed during the drying step except for the $\mathrm{CaO}$ sample. The samples were placed in constant humidity storage as described above for about 100 hours. Humidity levels of $100 \%, 76 \%$, and $52 \%$ were used along with a desiccator containing $\mathrm{CaSO}_{4}$ desiccant. The $52 \%$ humidity level was achieved using magnesium nitrate as described above for the $76 \%$ humidity environment.

These tests showed that $\mathrm{CaF}_{2}$ and $\mathrm{MgO}$ adsorb less than $0.1 \%$ moisture over the course of 100 hours even at $100 \%$ relative humidity. Although $\mathrm{MgO}$ with a very low density can adsorb $\mathrm{H}_{2} \mathrm{O}$ and $\mathrm{CO}_{2}$, the sand and crucible in this application are refractory materials with a high density that do not readily adsorb significant quantities of $\mathrm{H}_{2} \mathrm{O}$ or $\mathrm{CO}_{2}{ }^{27}$ The $\mathrm{CaO}$ sample demonstrated that it is a far better desiccant than even $\mathrm{CaSO}_{4}$ and was able to readily adsorb moisture under "dry" conditions. The moisture adsorbed by $\mathrm{CaO}$ is chemically reacted to form 
$\mathrm{Ca}(\mathrm{OH})_{2}$. Calcium metal was not tested under these conditions but is known to form a protective layer of calcium oxide which breaks down in the presence of humid air to allow additional formation of $\mathrm{CaO}$ and $\mathrm{Ca}(\mathrm{OH})_{2} .{ }^{28}$

Each of the primary non-radioactive components of SS\&C has been shown either not to adsorb appreciable amounts of moisture or to adsorb moisture that can not be recovered at $210^{\circ} \mathrm{C}$. One exception to this statement is $\mathrm{Ca}(\mathrm{OH})_{2}$ formed from oxidation of calcium metal. The adsorption of moisture on $\mathrm{Ca}(\mathrm{OH})_{2}$ was evaluated and shown to be on the order of $2 \%$ from air at uncontrolled humidity levels. ${ }^{29}$ The moisture content of reagent grade $\mathrm{Ca}(\mathrm{OH}) 2$, from this same set of tests, was limited to about $1 \%$ under similar conditions. Based on these observations, the weight loss at $210^{\circ} \mathrm{C}$ for $\mathrm{SS} \& \mathrm{C}$ residue is expected to provide primarily information on the moisture adsorbed by $\mathrm{PuO}_{2}$ and $\mathrm{Ca}(\mathrm{OH})_{2}$. Heating $\mathrm{Ca}(\mathrm{OH})_{2}$ to $210^{\circ} \mathrm{C}$ does not remove $\mathrm{H}_{2} \mathrm{O}$ to form $\mathrm{CaO}$, but simply removes the adsorbed moisture.

\section{Moisture Measurement Data for Actual Samples of SS\&C}

For actual SS\&C samples, some of the $\mathrm{PuO}_{2}$ is expected to have been heated above $1000^{\circ} \mathrm{C}$ and will have a smaller surface area than the $\mathrm{PuO}_{2}$ used for these tests. So, the $\mathrm{PuO}_{2}$ in actual SS\&C should adsorb less moisture from the storage environment than described by the SRTC studies. Calcium hydroxide is not initially present in SS\&C residues, but is formed as excess calcium metal is oxidized to $\mathrm{CaO}$, which then reacts with water to form $\mathrm{Ca}(\mathrm{OH})_{2}$. Calcium hydroxide can also be formed directly from the reaction of calcium metal with water vapor. ${ }^{28}$ The other components of SS\&C have been shown to physically adsorb only small amounts of moisture. With the foregoing background information on the compounds present in RFETS. SS\&C, the limit for moisture adsorption in SS\&C should be about $2 \%$, since this is the approximate moisture limit for both $\mathrm{PuO}_{2}$ and $\mathrm{Ca}(\mathrm{OH})_{2}$.

The statistical analysis of moisture determinations, made by RFETS for about 700 cans of SS\&C residue, shows a mean weight loss at $210^{\circ} \mathrm{C}$ of $1.3 \%{ }^{30}$. The upper bound, at the $95 \%$ confidence interval for the moisture content on all SS\&C samples in this statistical study, was about $1.9 \%$. This observed upper limit for the actual moisture measurements matches the $2 \%$ estimate determined by evaluating weight gain of individual SS\&C components. A comparison of TGA data from SRS, with data on the same samples analyzed at RFETS is presented in Table 8. The RFETS measurements used an automated moisture balance to determine moisture content.

Table 8 - Comparison of SRS TGA and RFETS Weight Loss Data

\begin{tabular}{|c|c|c|c|}
\hline $\begin{array}{c}\text { Sample } \\
\text { ID }\end{array}$ & $\begin{array}{c}\text { RFETS initial } \\
\text { Value }\end{array}$ & $\begin{array}{c}\text { Sister Can } \\
\text { Value }\end{array}$ & $\begin{array}{l}\text { TGA Value } \\
@ 210 \mathrm{C}\end{array}$ \\
\hline $\mathrm{H} 2$ & 0.16 & 0.29 & 0.5 \\
\hline H6 & 1.08 & 0.44 & 0.5 \\
\hline $\mathrm{H} 7$ & 0.86 & 0.3 & 0.3 \\
\hline H8 & 1.87 & -- & 0.7 \\
\hline
\end{tabular}


The SS\&C materials identified in Table 8 were crushed then sieved through a $1 / 4$ inch screen at RFETS prior to packaging in produce cans. The volume of SS\&C in the original storage container may require packaging in multiple produce cans after processing. Each of the cans packaged from the original container are called "sister cans." The samples for moisture measurement were originally pulled from only one of the sister cans. As part of the effort to understand the difference between SRS TGA values and RFETS weight loss at $210^{\circ} \mathrm{C}$ the sister cans from each of the Table 8 samples were analyzed by RFETS where possible. ${ }^{31}$

Samples from the sister cans were only exposed to the ambient air for about one day. Handling of the initial samples at RFETS is uncertain, but may have included storage in the lab for up to 30 days. Exposure of the samples to humid air could explain the observed difference in weight loss values presented in Table 8. The sister can values are much closer to the SRS data than the initial data points. The SRS weight loss values appear conservative with respect to the RFETS measurements with the exception of sample H2. The statistical analysis of the RFETS weight loss measurement may help interpret these results.

Based on statistical analysis of 178 sister cans, the two sigma standard deviation of the RFETS weight loss method is about $0.6 \%^{32}$ The statistical analysis further demonstrated that the SS\&C moisture results are normally distributed with an average moisture content of $1.3 \%$. With all SS\&C considered to represent a single population, $95 \%$ of the RFETS results are within a range of $1.3 \pm 0.6 \%$ based on analysis at $210^{\circ} \mathrm{C}$.

The RFETS replicate weight loss values for sample $\mathrm{H} 2$, from Table 8 , are outside the normal statistical distribution for SS\&C residues. Based on the composition of sample $\mathrm{H} 2$, there is no evident reason for this difference in results. The average difference between RFETS replicate measurements presented in Table 8 is $0.44 \%$ moisture, which is consistent with the $\pm 0.6 \%$ standard deviation associated with replicate measurements. The SRS TGA values are within the $\pm 0.6 \%$ window attributed to normal variation for the RFETS analysis.

\section{Addition of Liquid Water to $\mathrm{PuO}_{2}$}

Several of the gas generation test runs with $\mathrm{PuO}_{2}$ were designed to help evaluate the effect of elevated moisture content on $\mathrm{H}_{2}$ generation rate. Weight loss measurements at $210^{\circ} \mathrm{C}$ measured typically only a fraction of the anticipated moisture content when $\mathrm{H}_{2} \mathrm{O}$ was added directly to the test vessel. Table 9 shows the variation between added water and measured values at $210^{\circ} \mathrm{C}$.

Table 9 - Comparison of TGA Data with Known Water Addition to $\mathrm{PuO}_{2}$

\begin{tabular}{|c|c|c|c|c|}
\hline $\begin{array}{c}\text { Run } \\
\#\end{array}$ & $\begin{array}{c}\text { Added } \mathrm{H}_{2} \mathrm{O} \\
\text { Content }\end{array}$ & $\begin{array}{c}\text { Total } \mathrm{H}_{2} \mathrm{O} \\
\text { Content }\end{array}$ & $\begin{array}{c}\text { Wt Loss @ } \\
210{ }^{\circ} \mathrm{C}\end{array}$ & $\begin{array}{c}\text { Fraction } \\
\text { Recovered }\end{array}$ \\
\hline 5 & $10 \%$ & $10.6 \%$ & $4.5 \%$ & $42 \%$ \\
\hline 38 & $5 \%$ & $5.6 \%$ & $3.3 \%$ & $59 \%$ \\
\hline 47 & $2.5 \%$ & $3.1 \%$ & $1.8 \%$ & $58 \%$ \\
\hline
\end{tabular}


Water in these instances was added directly to the $\mathrm{PuO}_{2}$ using a pipette to obtain elevated levels of moisture. The weight of the test vessels was measured before and after $\mathrm{H}_{2} \mathrm{O}$ addition to confirm $\mathrm{H}_{2} \mathrm{O}$ content of the sample. Plotting the TGA curves for $\mathrm{PuO}_{2}$ samples, measured as part of the GGTP, shows that any moisture content greater than approximately $1.5 \%$ was lost by heating to approximately $60^{\circ} \mathrm{C}$ and only about $1 \%$ moisture remains after heating to $210^{\circ} \mathrm{C}$. Several TGA plots for these $\mathrm{PuO}_{2}$ samples, normalized to the dry $\mathrm{PuO}_{2}$ mass at $500^{\circ} \mathrm{C}$, are shown in Figure 10.

Figure 10 - TGA Plots of Normalized Moisture Content on $\mathrm{PuO}_{2}$

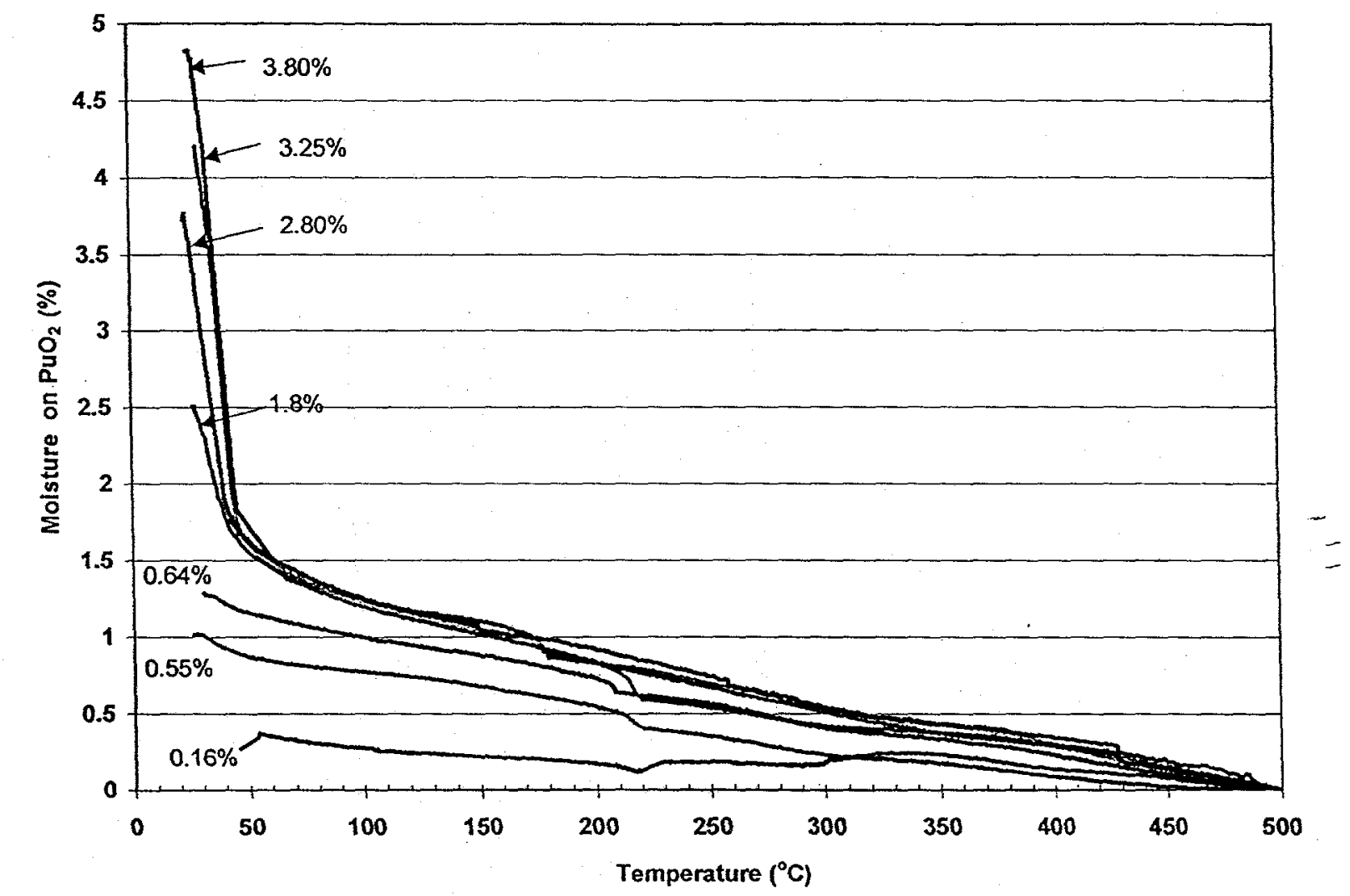

The fraction of water that is easily removed from $\mathrm{PuO}_{2}$ could desorb in dry air. An example of how easily excess water can be removed from $\mathrm{PuO}_{2}$ was observed when storing the $\mathrm{PuO}_{2}$ for test run 3 in a desiccator containing a $\mathrm{CaSO}_{4}$ desiccant. The moisture content of this $\mathrm{PuO}_{2}$ dropped from $0.56 \%$ to $0.14 \%$ based on weight loss at $210^{\circ} \mathrm{C}$. This behavior explains why samples loaded with high percentages of water for test runs like numbers 5,38 and 45 could have lost water to the environment prior to measurement by TGA.

Published Data for Adsorption of $\mathrm{H}_{2} \mathrm{O}$ on $\mathrm{PuO}_{2}$ 
Published data ${ }^{16,33}$ on the adsorption of water vapor show similar results to those obtained by the SRTC efforts. These two publications demonstrate that much of the adsorbed moisture above about $1 \%$ is physically adsorbed and can be removed under vacuum without heating. The remaining water is removed in a stepwise fashion that requires heating to remove water that is contained in chemically adsorbed layers. The first chemically adsorbed layer forms by dissociation of the water molecules to form hydroxyl groups on the $\mathrm{PuO}_{2}$ surface, and the second layer of water molecules is hydrogen bonded to these surface hydroxyls.

These publications show that at $95 \%$ humidity, the equilibrium moisture content of low fired $\mathrm{PuO}_{2}$ was about $3.2 \%$. At $75 \%$ humidity, the equilibrium moisture content was about $1.7 \%$. Achieving the equilibrium moisture content required up to eight repeated adsorption and desorption cycles with the moisture content of the $\mathrm{PuO}_{2}$ increasing after each cycle. These publications also reported that about $0.7 \%$ of the adsorbed $\mathrm{H}_{2} \mathrm{O}$ will remain on the $\mathrm{PuO}_{2}$ at $200^{\circ} \mathrm{C}$. This is comparable to the $1 \%$ found in the SRTC measurements shown in Figure 10. From the literature reports, we can calculate the expected weight loss at $200^{\circ} \mathrm{C}$, for a sample of $\mathrm{PuO}_{2}$ repeatedly exposed to $95 \%$ humidity, to be $2.5 \%$. The SRTC sample of $\mathrm{PuO}_{2}$ stored at $100 \%$ humidity for two weeks showed a $2.3 \%$ weight loss at $210^{\circ} \mathrm{C}$. This sample was not cycled to remove and re-adsorb moisture, which possibly accounts for the $0.2 \%$ difference between the SRTC data and the literature reports.

\section{Effect of Moisture and Matrix Content on $\mathrm{H}_{2}$ Generation}

Figure 11 is a plot of $\mathrm{H}_{2}$ production rate as a function of moisture content on $\mathrm{PuO}_{2}$. The curve

Figure $11-\mathrm{H}_{2}$ Generation Rate as a Function of Adsorbed $\mathrm{H}_{2} \mathrm{O}$ on $\mathrm{PuO}_{2}$

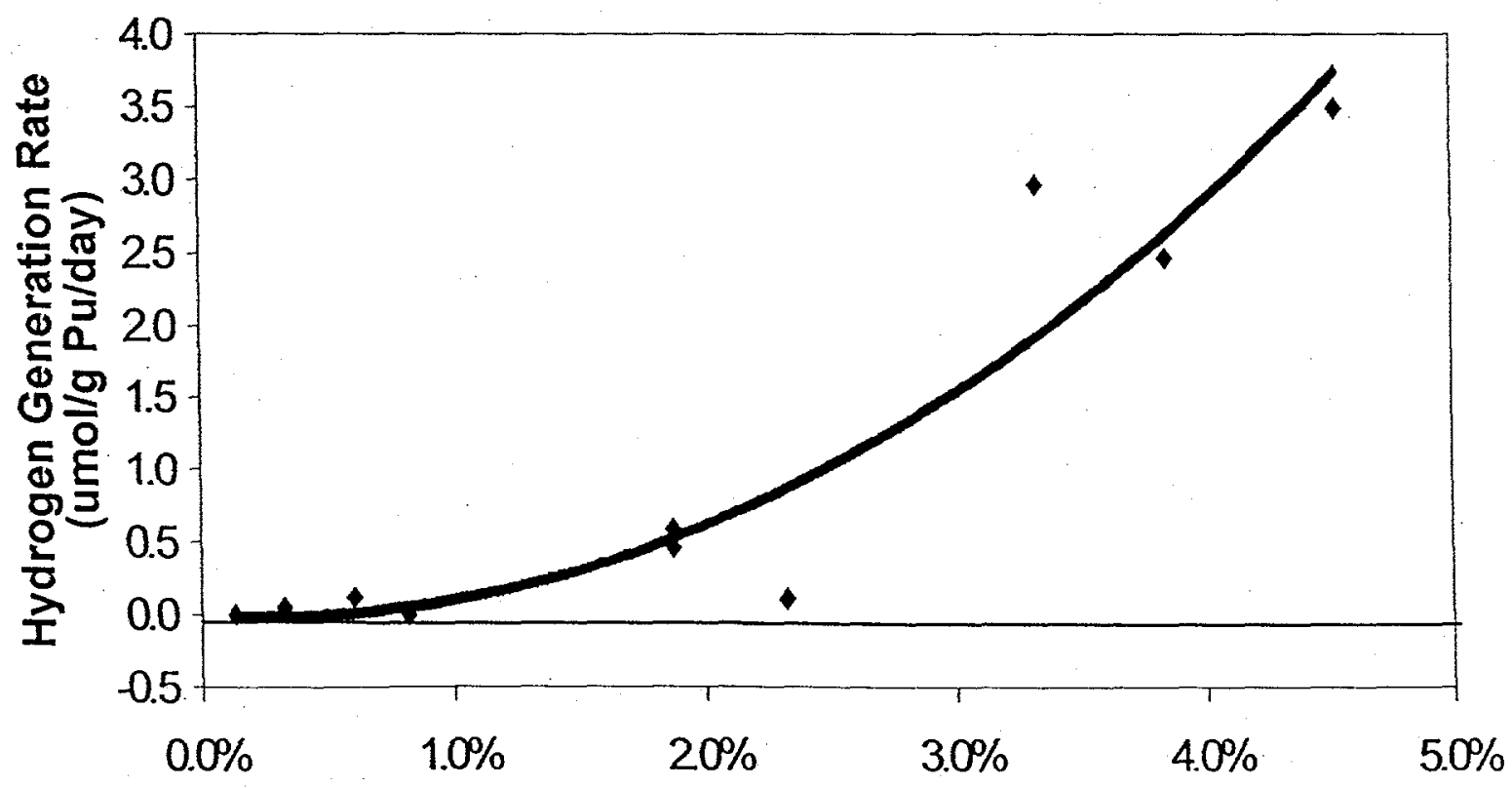

Weight Loss at $210 \mathrm{C}(\%)$ 
added to Figure 11 was done using Microsoft ${ }^{\oplus}$ Excel $^{\circledR}$ and is intended only to help guide the eye, not provide an accurate fit to support data interpolation. The moisture value is from TGA data providing weight loss at $210^{\circ} \mathrm{C}$. Similar increases in $\mathrm{H}_{2}$ generation rate as a function of moisture content have been reported for irradiation of other systems such zeolite and ion exchange rèsin..$^{34,35,36}$

The $\mathrm{H}_{2}$ generation rate for $\mathrm{SS} \& \mathrm{C}$ surrogate materials as a function of moisture content are plotted in Figure 12. Samples containing calcium metal and $\mathrm{PuO}_{2}$ with greater than $0.7 \%$ weight loss at $210^{\circ} \mathrm{C}$ are not included. The calcium metal samples are excluded to emphasis the effects of radiolysis. The data for $\mathrm{PuO}_{2}$ at greater than $0.7 \%$ weight loss at $210^{\circ} \mathrm{C}$ were presented in Figure 11. Figure 12 shows a marked increase with elevated temperature for three of the surrogate materials. The mechanism leading to the increased $\mathrm{H}_{2}$ production rate is uncertain, but the results indicate that a thermally sensitive reaction to produce $\mathrm{H}_{2}$ is possible.

Figure 12 - Hydrogen Gas Generation Rate for SS\&C Surrogate Materials

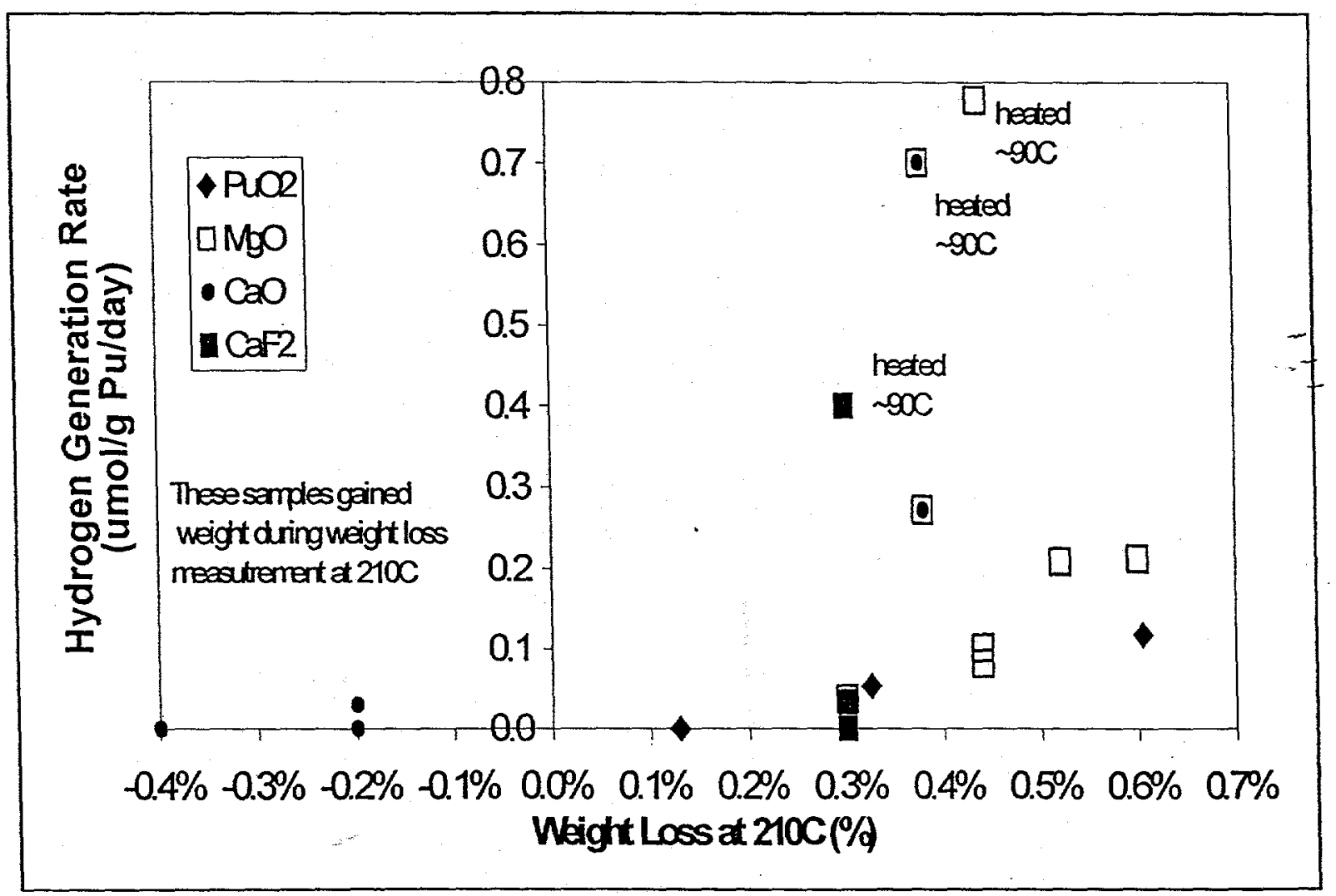

\section{Additional Observations on $\mathrm{H}_{2}$ generation}

Several additional interesting observations can be made in review of the $\mathrm{H}_{2}$ generation data for SS\&C residues. Perhaps most relevant to packaging of $\mathrm{Pu}$ bearing residue materials is the fact that flammable mixtures of $\mathrm{H}_{2}$ and $\mathrm{O}_{2}$ can be present in sealed containers. Such mixtures were observed in test runs $5,18,24$ and 32 . Tests 5,18 and 24 are surrogate materials while test run 32 was an actual SS\&C sample. Because $5 \%$ oxygen is considered sufficient to support 
combustion ${ }^{37}$ there is anticipated to be a transition period in many sealed systems where potentially flammable mixtures of $\mathrm{H}_{2}$ and $\mathrm{O}_{2}$ are formed.

In many of the tests, $\mathrm{O}_{2}$ was slowly depleted from the gas phase of these sealed systems by some mechanism (see further discussion in Section VI). Because $\mathrm{H}_{2}$ generation rate is a function of moisture content and radiation dose, the $\mathrm{H}_{2}$ concentrations increased fastest with a high moisture content. The potentially flammable mixture of $\mathrm{H}_{2}$ and $\mathrm{O}_{2}$ would be present once the $\mathrm{H}_{2}$ concentration exceeded $4 \%$ and remain until the $\mathrm{O}_{2}$ content is depleted to less than $5 \%$. Because the rate of $\mathrm{O}_{2}$ depletion in these systems is uncertain, the best way to minimize the time frame, where a flammable mixture of gases may coexist, is to reduce the moisture content of the $\mathrm{Pu}$ residue. With the use of produce cans to store $\mathrm{Pu}$ residue, this problem is compounded by potential leaks that allow air to enter the container and replenish depleted $\mathrm{O}_{2}$ or allow $\mathrm{H}_{2}$ to leak into a secondary container filled with air.

Significant $\mathrm{H}_{2}$ concentrations have been found both in test vessels that pressurize and those which remain at ambient pressure. So, it is clear from this data set that pressure is not a good indicator of gas composition and facilities should not rely on observation of container pressurization to detect flammable mixtures.

One interesting observation from the GGTP was that mixtures of $\mathrm{Ca}(\mathrm{OH})_{2}$ and $\mathrm{PuO}_{2}$ had much slower $\mathrm{H}_{2}$ generation rates than anticipated. Three tests were run with mixtures of $\mathrm{PuO}_{2}$ and $\mathrm{CaO}$ plus $\mathrm{Ca}(\mathrm{OH})_{2}$ and the observed $\mathrm{H}_{2}$ generation rate was very small when compared with a similar mixture of $\mathrm{PuO}_{2}$ and $\mathrm{Mg}(\mathrm{OH})_{2}$. This suggests that $\mathrm{CaO}$ could be added as a desiccant to $\mathrm{Pu}$ residue with elevated moisture content to reduce the $\mathrm{H}_{2}$ generation rate.

These test results showing formation of flammable $\mathrm{H}_{2}$ mixtures are substantially different from data in recent reports published by Los Alamos National Laboratory (LANL). ${ }^{38,39,40}$ The LANL reports postulate that $\mathrm{H}_{2}$ is produced primarily by chemical reaction of adsorbed $\mathrm{H}_{2} \mathrm{O}$ on $\mathrm{PuO}_{2}$ to produce $\mathrm{H}_{2}$ and the super-stoichiometric oxide, $\mathrm{PuO}_{2+x}$. The recombination of $\mathrm{H}_{2}$ and $\mathrm{O}_{2}$ by radiolytic and chemical catalytic mechanisms is reported to be faster than the $\mathrm{H}_{2}$ production. Based on LANL's observations, less than $2 \% \mathrm{H}_{2}$ would be anticipated to build up in the storage container until all the $\mathrm{O}_{2}$ is consumed. There are substantial differences in the amount of $\mathrm{H}_{2} \mathrm{O}$ and the quality of $\mathrm{PuO}_{2}$ used by LANL and what is found in SS\&C residue materials.

The LANL work was done using $\mathrm{PuO}_{2}$ processed to meet the 3013 standard. ${ }^{41}$ This standard requires heating the $\mathrm{PuO}_{2}$ at $950^{\circ} \mathrm{C}$ for 2 hours in an oxidizing atmosphere and maintaining the total moisture content at less than $0.5 \%$. The moisture content for many of the 3013 quality $\mathrm{PuO}_{2}$ materials is less than $0.1 \%$. This suggests that there may be a competing mechanism that changes as a function of moisture content. At low moisture content, surface chemistry is the dominant component of $\mathrm{H}_{2}$ generation. As moisture content increases, radiolytic gas generation becomes a larger component of the observed gas production. 


\section{Section V - Radiolysis Effects In Residue Materials}

\section{Brief Presentation of Radiolysis Theory}

There are a substantial number of published reports that suggest radiolysis of adsorbed $\mathrm{H}_{2} \mathrm{O}$ will not necessarily generate $\mathrm{O}_{2}$. The primary reason for this is found in reviewing the primary reaction pathways associated with radiolysis of $\mathrm{H}_{2} \mathrm{O}$. The following explanation for the lack of $\mathrm{O}_{2}$ observed during radiolysis of water in a heterogeneous environment is an excerpt from A.S. Wagh et.al. ${ }^{42}$

For water, the primary reaction pathways for $\mathrm{H}_{2}$ generation in the radiolytic decomposition of water are shown below.

$$
\begin{aligned}
& 2 \mathrm{e}_{\mathrm{aq}}^{-}+2 \mathrm{H}_{2} \mathrm{O} \rightarrow 2 \mathrm{H}+2 \mathrm{OH}^{-}, \\
& \mathrm{e}_{\mathrm{aq}}^{-}+\mathrm{H}+\mathrm{H}_{2} \mathrm{O} \rightarrow \mathrm{H}_{2}+\mathrm{OH}^{-}, \\
& \mathrm{H}+\mathrm{H} \rightarrow \mathrm{H}_{2}
\end{aligned}
$$

$\mathrm{O}_{2}$ is not a primary radiolytic product, but is generated by secondary reactions of oxygen-containing intermediates and products such as the reaction of perhydroxyl radicals. Significantly less $\mathrm{O}_{2}$ should be generated relative to $\mathrm{H}_{2}$ because oxygen-containing transients will react with other ... constituents before they can build high-enough concentrations in solution to form $\mathrm{O}_{2}$.

In this study, Wagh et al were evaluating the radiation effects on chemically bonded phosphate ceramics. Their work showed that no $\mathrm{O}_{2}$ was produced in samples containing $5 \% \mathrm{Pu}$ and $\mathrm{H}_{2} \mathrm{O}$ concentrations that ranged from about $1 \%$ to $19 \%$. The lack of $\mathrm{O}_{2}$ production suggests that matrix materials are scavenging the $\mathrm{O}_{2}$ precursors. Under conditions that allow $\mathrm{OH}$ radicals to be produced faster than the matrix scavenges them, intermediates like $\mathrm{H}_{2} \mathrm{O}_{2}$ and $\mathrm{HO}_{2}$ are formed that may subsequently react to form $\mathrm{O}_{2}$.

Other reports have also identified the lack of $\mathrm{O}_{2}$ production associated with radiolysis of moisture on adsorbed species. These include the work of Nakashima and Aratono ${ }^{36}$, who studied the gamma radiolysis of water adsorbed on zeolites. They observed that $\mathrm{O}_{2}$ was produced only at sufficiently high rates of absorbed energy. Bibler, Wallace and Ebra demonstrated $\mathrm{O}_{2}$ depletion during gamma radiolysis of zeolite with $5 \%$ and $16 \%$ adsorbed water $^{35}$. The radiolysis of water on silica gel was studied in the early $1960 \mathrm{~s}$ at Oak Ridge National Lab. They report no $\mathrm{O}_{2}$ detected for adsorbed water up to about $16 \%$ during gamma radiolysis. ${ }^{43}$ In studying the alpha radiolysis of moisture in concrete waste forms, Bibler identified that at $7.4 \% \mathrm{H}_{2} \mathrm{O}$ in cement radiolysis yielded no $\mathrm{O}_{2}$ and pressure of the storage containers dropped. ${ }^{44} \mathrm{He}$ notes that the water used as part of the cement structure is evidently more stable than water driven off by heating at $200^{\circ} \mathrm{C}$ 


\section{Radiolysis of Moist Air}

The radiolysis of moist air has been demonstrated in numerous instances to result in the production of $\mathrm{N}_{2} \mathrm{O}$ and $\mathrm{NO}_{3}{ }^{-}$. The $\mathrm{NO}_{3}{ }^{-}$is readily adsorbed on metal oxide surfaces to form up to 10 monolayers ${ }^{21} . \mathrm{N}_{2} \mathrm{O}$ is present as a non-condensable gas and is readily measured in air systems. Argonne National Laboratory has studied both alpha and gamma radiolysis of moist and dry air systems to support storage of High Level Waste in an underground repository. ${ }^{45,46}$ Reed and Konynenburg provide a review of several reports on radiolysis in moist air systems. ${ }^{47,48}$ Included in this review are data from the following authors. Primak and Fuchs demonstrate the formation of $\mathrm{HNO}_{3}$ in a moist air system and the subsequent corrosion of nickel wire. Corrosion of the wire continued until water was depleted from the air. Jones used spectroscopic techniques (infrared absorption) to monitor the gas composition of an irradiated gas cell. This effort demonstrated that $\mathrm{HNO}_{3}$ and $\mathrm{O}_{3}$ are the major products formed until all the water was consumed. A final study, Tokunaga and Suzuki, suggested that $\mathrm{HNO}_{3}$ is formed by reaction of $\mathrm{OH}$. This mechanism is proposed to explain the observation in each instance that $\mathrm{HNO}_{3}$ formation is dependent on the presence of water.

The following excerpt from Reed and Konynenburg provides a good summary of anticipated products from the radiolysis of moist and dry air:

In dry air systems, the primary radiolytic products formed upon irradiation are nitrogen dioxide and nitrous oxide (minor amounts of ozone, nitric oxide and nitrogen pentoxide are also formed). Irradiation in a closed system resulted in the formation of a steady-state concentration of the nitrogen oxides that depended on the dose rate, temperature, total pressure, and initial nitrogen/oxygen ratio....

The addition of water to the dry air system resulted in the formation of nitric acid in place of nitrogen dioxide with nitrous oxide being generated to a lesser extent. Initial rate data indicated that nitrogen dioxide was formed first and subsequently oxidized to nitric acid by reaction with the $\mathrm{OH}$ free radical. In high dose experiments, nitric acid was preferentially formed until the water in the gas phase was depleted...

Since $\mathrm{O}_{2}$ is not produced by radiolysis of water except via very reactive intermediates like $\mathrm{OH}$ radicals, the production of oxygen in Pu bearing residue materials should only be anticipated at very high moisture levels and dose rates. Additionally, the radiolysis of air in a residue storage container is expected to result in production of $\mathrm{NO}_{3}{ }_{3}$, which is readily absorbed by many metal oxides. Without $\mathrm{O}_{2}$ being produced from the radiolysis of $\mathrm{H}_{2} \mathrm{O}$, the radiolysis of air should subsequently deplete the $\mathrm{O}_{2}$ content of a residue storage container.

Los Alamos National Laboratory has recently performed headspace gas analysis on multiple cans of $\mathrm{PuO}_{2}$ that have been in storage for as long as 18 years ${ }^{38}$. Each of these cans which had been packaged in air showed extensive oxygen depletion when the can did not leak. Four of the cans were at least 13 years old and had $0.1 \% \mathrm{O}_{2}$ or less. One can was 1 year old and contained $4.9 \% \mathrm{O}_{2}$. Each of the materials had a moisture content of less than $1.3 \%$ moisture 
based on interstitial gas analysis. These materials ranged in composition from a mixed uranium-plutonium oxide to reactor grade $\mathrm{PuO}_{2}$ and included "weapons grade" $\mathrm{PuO}_{2}$ from RFETS. The loss of $\mathrm{O}_{2}$ in the headspace of these containers offers external support for the observation that $\mathrm{O}_{2}$ content is depleted in sealed containers of $\mathrm{Pu}$ residue that have sufficiently low moisture content.

Recent efforts to "understand fundamentally the radiolytic processes occurring on metal oxide surfaces," have led the authors of a recent publication ${ }^{49}$ to conclude that, "...one cannot make reliable predictions of the course of radiolytic reactions under nonhomogeneous conditions using yields and rate data acquired in homogeneous systems." Similarly, radiolysis of moisture adsorbed on residue surfaces is a nonhomogeneous condition and should be anticipated to produce quite different results from radiolysis of aqueous solutions.

Other mechanisms for the depletion of $\mathrm{O}_{2}$ in the sealed system have been proposed. These include oxidation of metal storage container surfaces and adsorption of $\mathrm{O}_{2}$ on the active sites created by radiation damage to matrix materials. However; the fate of $\mathrm{O}_{2}$ removed from the air of these sealed systems remains uncertain. Some of the mechanisms anticipated to remove $\mathrm{O}_{2}$ from the air can be reversed at sufficiently high temperature or produce other gases, such as $\mathrm{N}_{2} \mathrm{O}$, that support combustion of $\mathrm{H}_{2}$. Evaluating the entire range of mechanisms for $\mathrm{O}_{2}$ depletion is beyond the scope of this report, but has been recently addressed by Graham et al. ${ }^{50}$ 


\section{Section VI - Oxygen Content in SS\&C Gas Generation Tests}

The $\mathrm{O}_{2}$ content of residue containers has a big impact on determining the gas pressure for shipping and storage packages. The assumption of simple stoichiometric production of $\mathrm{H}_{2}$ and $\mathrm{O}_{2}$ from radiolysis of $\mathrm{H}_{2} \mathrm{O}$ would yield only a $33 \%$ increase in gas pressure. However, combustion of stoichiometric $\mathrm{H}_{2}$ and $\mathrm{O}_{2}$ mixtures at elevated pressures is considered far more dangerous than an equivalent amount of $\mathrm{H}_{2}$ mixed with air. Oxygen generation is not expected from radiolysis of adsorbed moisture and potential mechanisms for $\mathrm{O}_{2}$ depletion have been identified. By demonstrating "no net increase" of $\mathrm{O}_{2}$ for $\mathrm{SS} \& \mathrm{C}$ residues with sufficiently low moisture content, the possibility of stoichiometric $\mathrm{H}_{2}$ and $\mathrm{O}_{2}$ mixtures at $\mathrm{H}_{2}$ concentrations greater than about $30 \%$ is eliminated.

\section{Contributors to $\mathrm{O}_{2}$ Depletion}

Several investigators have measured the $\mathrm{O}_{2}$ content of the headspace gas in sealed containers of $\mathrm{PuO}_{2}$ and identified reduced $\mathrm{O}_{2}$ concentrations. ${ }^{51,38} \mathrm{SS} \& \mathrm{C}$ residues show $\mathrm{O}_{2}$ depletion similar to what has been identified for storage of pure $\mathrm{PuO}_{2}$. The mechanism associated with $\mathrm{H}_{2}$ generation and $\mathrm{O}_{2}$ consumption may change as a result of increased $\mathrm{H}_{2} \mathrm{O}$ content in the containers. The net change in $\mathrm{O}_{2}$ content of the headspace gas is the sum of reactions that produce and consume $\mathrm{O}_{2}$. The design of the current tests does not allow us to determine the relative contribution from forward and reverse reactions. As described earlier, $\mathrm{O}_{2}$ is not produced directly from radiolysis of $\mathrm{H}_{2} \mathrm{O}$, but results from additional reactions involving $\mathrm{OH}$ and $\mathrm{OH}_{2}$ radicals. If $\mathrm{O}_{2}$ is not generated by radiolysis of adsorbed $\mathrm{H}_{2} \mathrm{O}$ (because the $\mathrm{PuO}_{2}$ or other materials present in the residue matrix rapidly scavenge $\mathrm{OH}$ and $\mathrm{OH}_{2}$ radicals) any radiation induced or chemical reaction that consumes $\mathrm{O}_{2}$ will result in $\mathrm{O}_{2}$ depletion.

To help identify the factors that influence net changes in $\mathrm{O}_{2}$ content, the available data for $\mathrm{O}_{2}$ content of the sealed containers in the GGTP are examined and presented in graphical form. These observations include the relationships between $\mathrm{O}_{2}$ content and $\mathrm{H}_{2}$ production rate, $\mathrm{H}_{2}$ concentration, moisture content, dose rate, sample temperature, and matrix content. Each of these relationships or factors seems to have some influence on $\mathrm{O}_{2}$ content of the vessel. The most evident controlling factor on sample net $\mathrm{O}_{2}$ content is moisture. If the moisture is limited to about $2.3 \%$, based on weight loss at $210^{\circ} \mathrm{C}$, no net increase of $\mathrm{O}_{2}$ was observed in the vessel headspace. A statistical evaluation of the change in $\mathrm{O}_{2}$ data was completed and supports the conclusion that no net $\mathrm{O}_{2}$ is produced when weight loss at $210^{\circ} \mathrm{C}$ is limited to $2.3 \%{ }^{52}$

\section{Observations on $\mathrm{O}_{2}$ Content of SS\&C Residues}

The change in $\mathrm{O}_{2}$ content for each sample in the GGTP is presented in Table 6 under the heading of "delta $\mathrm{O} 2$." Delta $\mathrm{O}_{2}$ is calculated as the final minus the initial moles of $\mathrm{O}_{2}$. The "Change in $\mathrm{O}_{2}(\%)$ ". was calculated as delta $\mathrm{O}_{2}$ divided by the initial moles of $\mathrm{O}_{2}$, then multiplied by 100 to represent the value as percent change. "Change in $\mathrm{O}_{2}(\%)$ " is used in Figures $13-17$ to show the impact of other measured or calculated parameters on $\mathrm{O}_{2}$ content from gas generation testing of SS\&C residue. In many of the figures, test number is used to identify some of the data points. Based on run number, the reader can find additional information on selected samples using Tables 2, 5, and 6. 
Figure 13 shows the change in moles of $\mathrm{O}_{2}$ for a given test versus the $\mathrm{H}_{2}$ concentration in the same test. Hydrogen concentrations are plotted on a log scale to allow observation of the full range of concentration values. The $\mathrm{GC}$ results for $\mathrm{H}_{2}$ have been used without any correction for vessel volume. Since the containers have measured gas volumes that range from about $14 \mathrm{cc}$ to $124 \mathrm{cc}$, the concentration data does not provide a good indication of how much $\mathrm{H}_{2}$ has been generated. Note however that $\mathrm{O}_{2}$ content is not increasing along with $\mathrm{H}_{2}$ concentrations as would be anticipated for stoichiometric production of $\mathrm{O}_{2}$ from radiolysis of aqueous solutions. Figure 13 includes all samples in this data set that do not contain calcium metal.

Figure 13 - Change in Oxygen v. Hydrogen Concentration

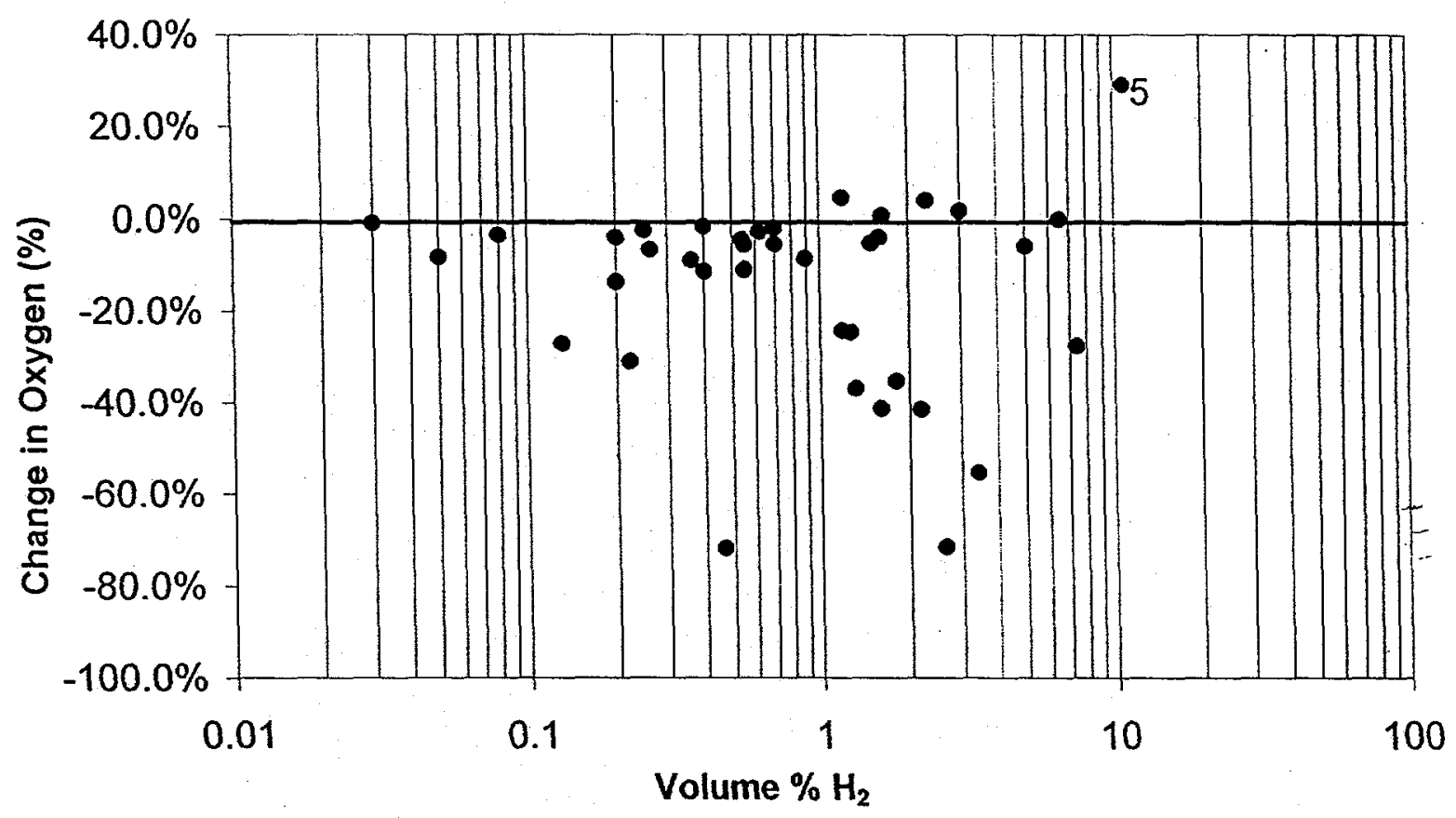

Also of interest in discussion of flammability issues is the observation that $\mathrm{O}_{2}$ in these tests was diminished as $\mathrm{H}_{2}$ concentration approached the lower flammable limit (LFL) of $4 \% \mathrm{H}_{2}$ in air. One clear exception to this observation is test run 5 , which generated about $10 \% \mathrm{H}_{2}$ and initially contained about $10 \% \mathrm{H}_{2} \mathrm{O}$ on $\mathrm{PuO}_{2}$. The other tests which have a positive change in $\mathrm{O}_{2}$ are experiments with $\mathrm{PuO}_{2}$ containing elevated moisture from the addition of liquid $\mathrm{H}_{2} \mathrm{O}$. No evidence was found for $\mathrm{O}_{2}$ increasing when samples were simply allowed to adsorb moisture from humidified air. In general, it was noted that samples with matrix content in addition to $\mathrm{PuO}_{2}$ had a more evident decrease in $\mathrm{O}_{2}$ content.

Figure 14 demonstrates little correlation between increasing $\mathrm{H}_{2}$ generation rates and the observed change in $\mathrm{O}_{2}$. Hydrogen gas generation rates should be a function of moisture content and dose rate for a particular material type. If the mechanism for $\mathrm{O}_{2}$ depletion was dependent on the same factors as $\mathrm{H}_{2}$ generation rate, good correlation between change in $\mathrm{O}_{2}$ content and $\mathrm{H}_{2}$ generation rate should be observed. If $\mathrm{O}_{2}$ is removed from the gas phase by 
radiolysis of air, the change in $\mathrm{O}_{2}$ content should correlate with radiation dose to the air and increase with higher dose rates. However, the actual effect of radiation dose on $\mathrm{O}_{2}$ depletion mechanism for SS\&C residues remains uncertain. Other factors expected to impact the rate of $\mathrm{O}_{2}$ depletion would include the volume of air irradiated and factors that control rates of $\mathrm{NO}_{3}{ }^{-}$ being deposited in the matrix. The dose rates to air in these vessels were expected to be nearly constant for the $\mathrm{PuO}_{2}$ samples because a single source of $\mathrm{PuO}_{2}$ was used and the material mass in each vessel covered a narrow range. Little change in $\mathrm{O}_{2}$ content for $\mathrm{PuO}_{2}$ samples, that were not heated, was seen in Figures 14 and 15. This slow rate for $\mathrm{O}_{2}$ depletion is consistent with the $\mathrm{O}_{2}$ depletion observed in long term storage of $\mathrm{PuO}_{2}$.

Figure 14 - Change in Oxygen v. Hydrogen Generation Rate

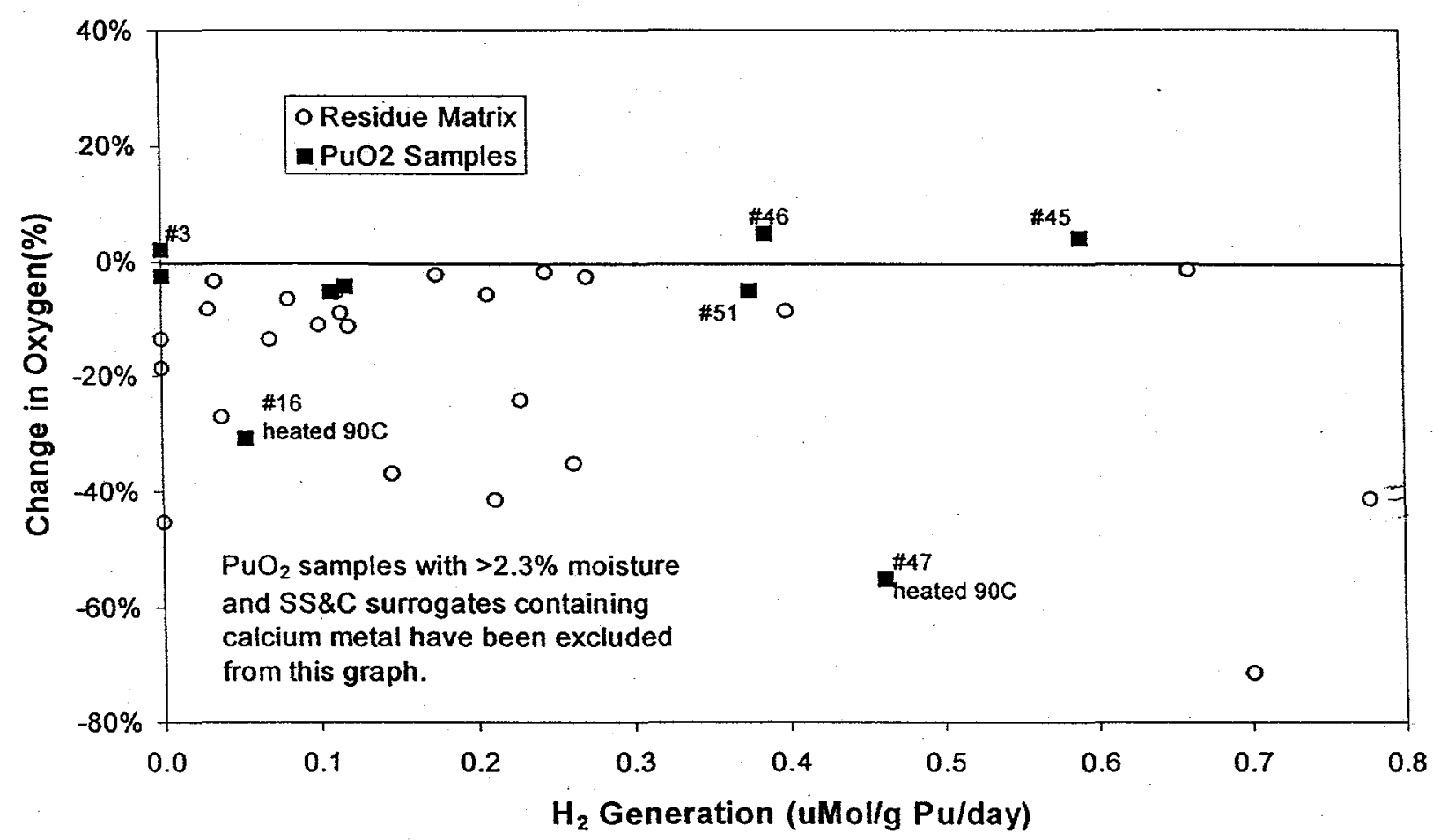

When the $\mathrm{PuO}_{2}$ was mixed with matrix materials to form the $\mathrm{SS} \& \mathrm{C}$ surrogates, there was a significant impact on the sample bulk density. $\mathrm{PuO}_{2}$ has the highest bulk density of materials used in these tests. The calcium salts in SS\&C have bulk densities on the order of 0.3 to $0.6 \mathrm{~g} / \mathrm{cc}$. Plutonium dioxide and $\mathrm{MgO}$ used in these tests have bulk densities of 1.9 and 1.8 respectively. The $\mathrm{PuO}_{2}$ that is not mixed with matrix components will irradiate an enclosed volume of air substantially smaller than $\mathrm{PuO}_{2}$ in $\mathrm{SS} \& \mathrm{C}$ surrogates. On the other hand, adding matrix components will adsorb some portion of the radiation and reduce the exposure to air. These are competing factors that make it difficult to estimate that actual radiation dose absorbed by air. 
Based on literature review, the factors identified for $\mathrm{O}_{2}$ production in the non-homogeneous system are high dose rate and high moisture (physically absorbed). The radiation dose to adsorbed water would be highest for $\mathrm{PuO}_{2}$ that is not mixed with additional matrix materials. When matrix materials are present, these absorb part of the radiation dose. $\mathrm{PuO}_{2}$ has been shown to have more physically adsorbed water than other SS\&C components. The water adsorbed by $\mathrm{CaO}$ is chemically reacted to form $\mathrm{Ca}(\mathrm{OH})_{2}$, which appears resistant to radiolytic decomposition in the SS\&C surrogates. So, the greatest dose to water will occur when $\mathrm{PuO}_{2}$ is the only matrix component in a sample. The application of literature reports, combined with observations for SS\&C residues, suggest that $\mathrm{PuO}_{2}$ is the matrix most likely to produce $\mathrm{O}_{2}$. Evaluating the change in $\mathrm{O}_{2}$ content as a function of moisture on $\mathrm{PuO}_{2}$ is expected to provide the most conservative moisture limit for establishing "no net increase" of $\mathrm{O}_{2}$ from radiolysis of adsorbed moisture.

\section{Selection of a Moisture Limit for "No Net Increase" in $\mathrm{O}_{2}$}

Figure 15 shows the change in $\mathrm{O}_{2}$ content for the $\mathrm{SS} \& \mathrm{C}$ materials as a function of weight loss at $210^{\circ} \mathrm{C}$. The values that have high weight loss are $\mathrm{PuO}_{2}$ (\# 5 and \#38) and one sample (\#17) of "Pu Cake". Test 5 is the only sample with $10 \%$ moisture, and the only sample that shows a statistically significant increase in $\mathrm{O}_{2}$ in this data set. Test 45 has a slight increase in $\mathrm{O}_{2}$ but is within the statistical confidence interval established for air $^{52}$. It should be noted that the sample

Figure 15 - Change in Oxygen v. Moisture Content for SS\&C Surrogates

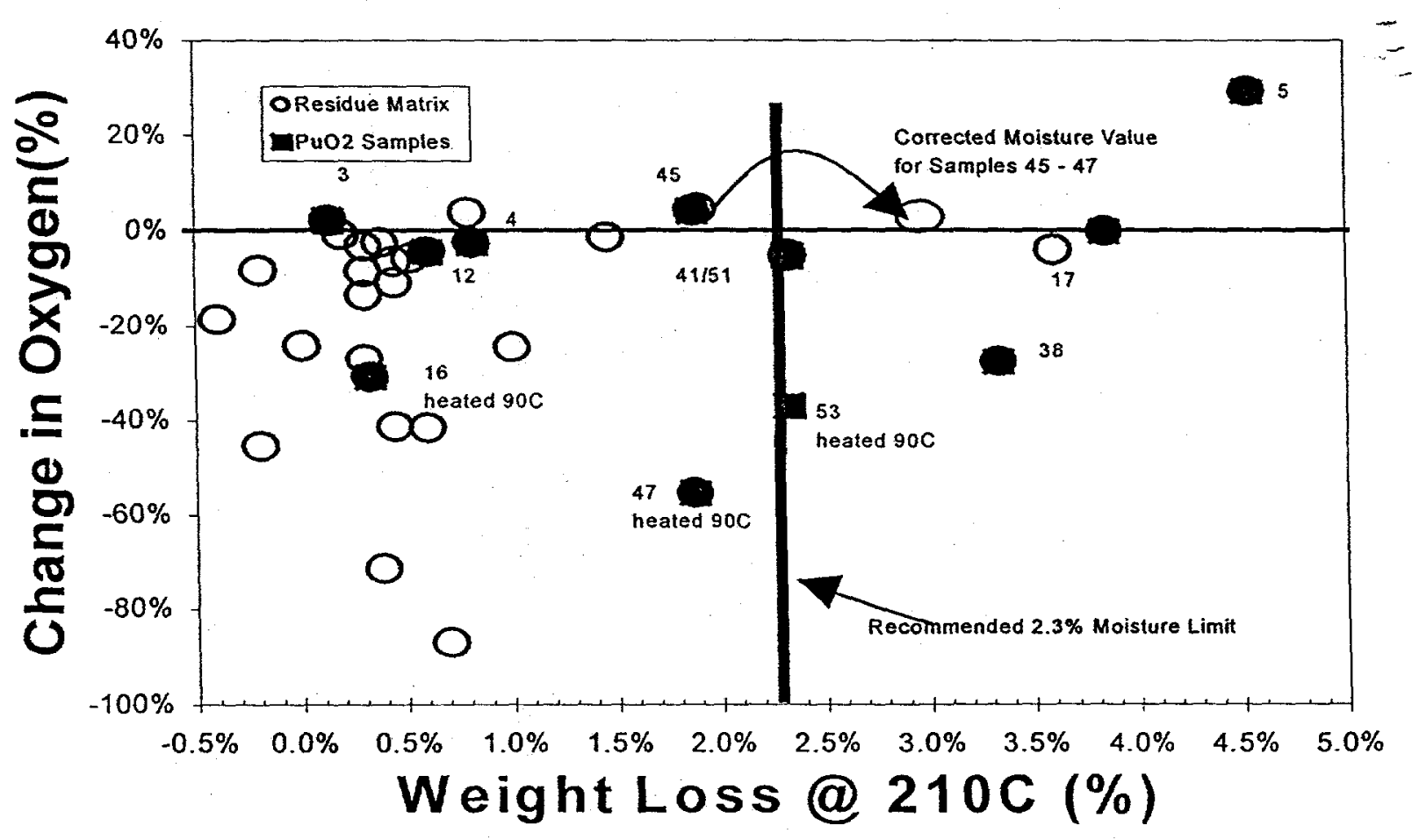


for test 45 was known to have started with greater than $3 \%$ moisture (as discussed in Section IV). The weight loss measurement for this sample was made after the sample was used for test 47. Realistic placement of this data point, and others with direct addition of liquid $\mathrm{H}_{2} \mathrm{O}$, would be at a higher moisture content.

Increasing the moisture content of the $\mathrm{PuO}_{2}$, represented by weight loss at $210^{\circ} \mathrm{C}$ above $2.3 \%$ suggests a change in the gas generation mechanism and the potential for a net increase of $\mathrm{O}_{2}$. This transition may have a curve shaped similar to what was presented for $\mathrm{H}_{2}$ generation rate as a function of moisture content (see Figure 11).

Sample 38 does not fit the general trends observed for $\mathrm{O}_{2}$ content in Figure 15. For this reason, the result for sample 38 has been discounted in selecting the moisture limit that is acceptable without a net increase in $\mathrm{O}_{2}$ content. Having additional data to define the shape of this curve for $\mathrm{O}_{2}$ generation would be helpful. However, after eliminating the data point for test 38 , there are duplicate gas generation tests for a sample that has $2.3 \%$ moisture. By establishing the moisture limit at $2.3 \%$ for "no net increase" in $\mathrm{O}_{2}, \mathrm{SS} \& \mathrm{C}$ residues with a measured weight loss of less that $2.3 \%$ will have a headspace $\mathrm{O}_{2}$ concentration less than or equal to air.

Statistical analysis of the SS\&C surrogate data supports the assertion that "no net oxygen" is produced at less than $2.3 \%$ weight loss at $210^{\circ} \mathrm{C} .^{51}$ The $2.3 \%$ value was the highest moisture content achieved for $\mathrm{PuO}_{2}$ without addition of liquid $\mathrm{H}_{2} \mathrm{O}$ to the test vessel. A weight loss of $2.3 \%$ is also near the $2.5 \%$ upper limit anticipated for water adsorption from $95 \%$ humidity in air at ambient temperatures reported in literature. There would seem to be little chance that SS\&C residue could exceed this moisture content based on weight loss at $210^{\circ} \mathrm{C}$. The surface area of the $\mathrm{PuO}_{2}$ is important to drawing this conclusion and should be limited to $\mathrm{PuO}_{2}=$ generated from oxidation of metal or other $\mathrm{PuO}_{2}$ sources which have a similar low surface area around $7 \mathrm{~m}^{2} / \mathrm{g}$ or less.

\section{Effects of Radiation Exposure, Matrix Content and Temperature on $\mathrm{O}_{2}$ Content}

Figures 16 and 17 are added to support the conclusion that net oxygen content of residue containers will decrease with storage time provided the moisture content is sufficiently low. Figure 16 demonstrates a possible decrease in $\mathrm{O}_{2}$ content as a function of exposure rate for each of the matrix materials present in SS\&C.

The decrease in $\mathrm{O}_{2}$ is a trend that can be observed in Figure 16 for each matrix component as exposure rate increases. Exposure values are computed as electron volts (eV) per hour, based on the $\mathrm{PuO}_{2}$ mass and isotopic distribution for each sample. This rate is then divided by the total gas volume of a sealed system to correct for the variations in gas volume and thus the $\mathrm{O}_{2}$ content of each test stand. The observed decrease in $\mathrm{O}_{2}$ content as a function of dose rate is consistent with radiation induced mechanisms for $\mathrm{O}_{2}$ depletion, such as radiolysis of moist air.

Figure 17 shows the impact of various SS\&C matrix components on the $\mathrm{O}_{2}$ content. In addition, the actual SS\&C samples measured as part of the GGTP are included in this graph. 
Figure 16-Change in Oxygen v. Dose Rate

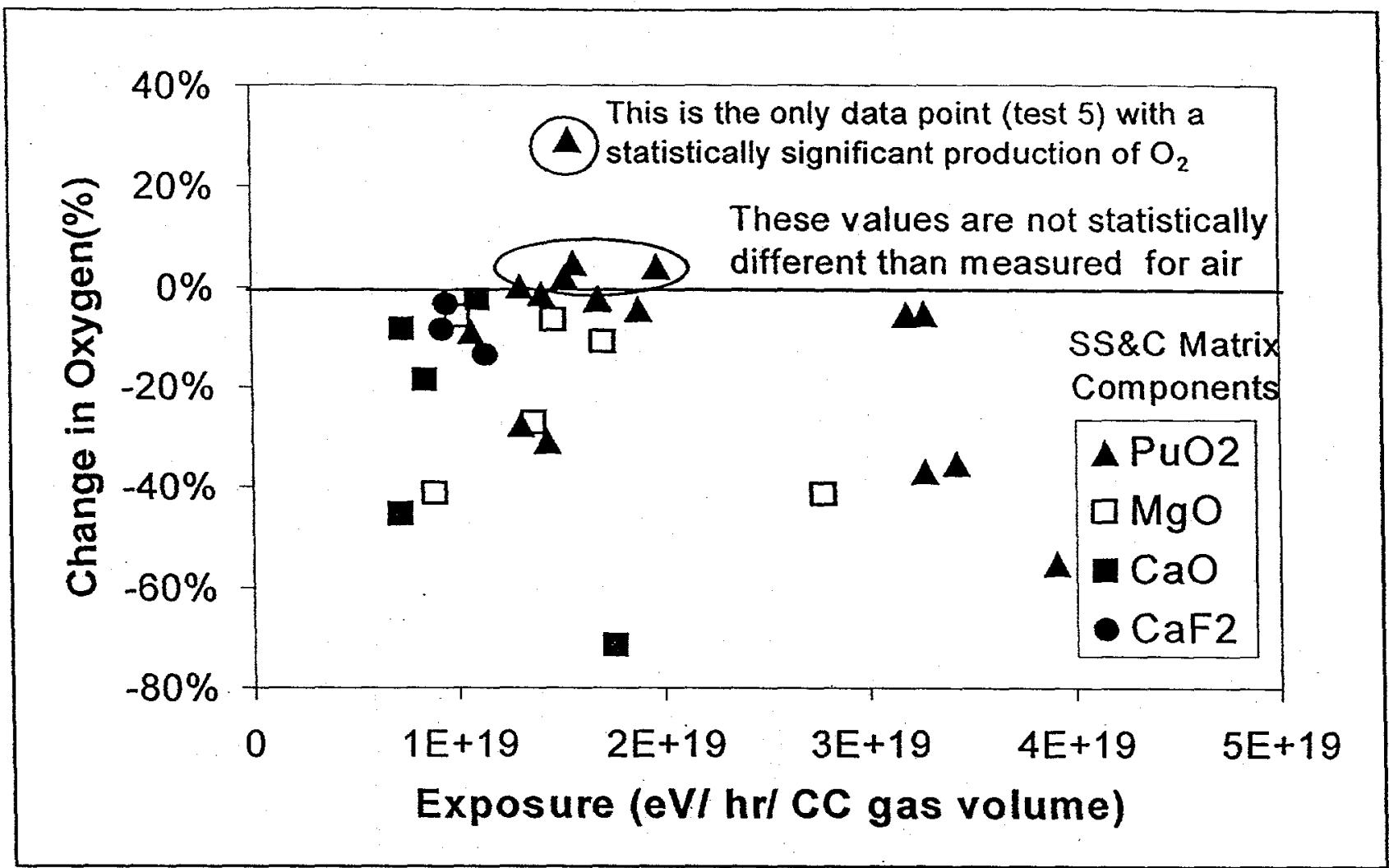

Figure 17 - Change in Oxygen v. SS\&C Matrix Contents

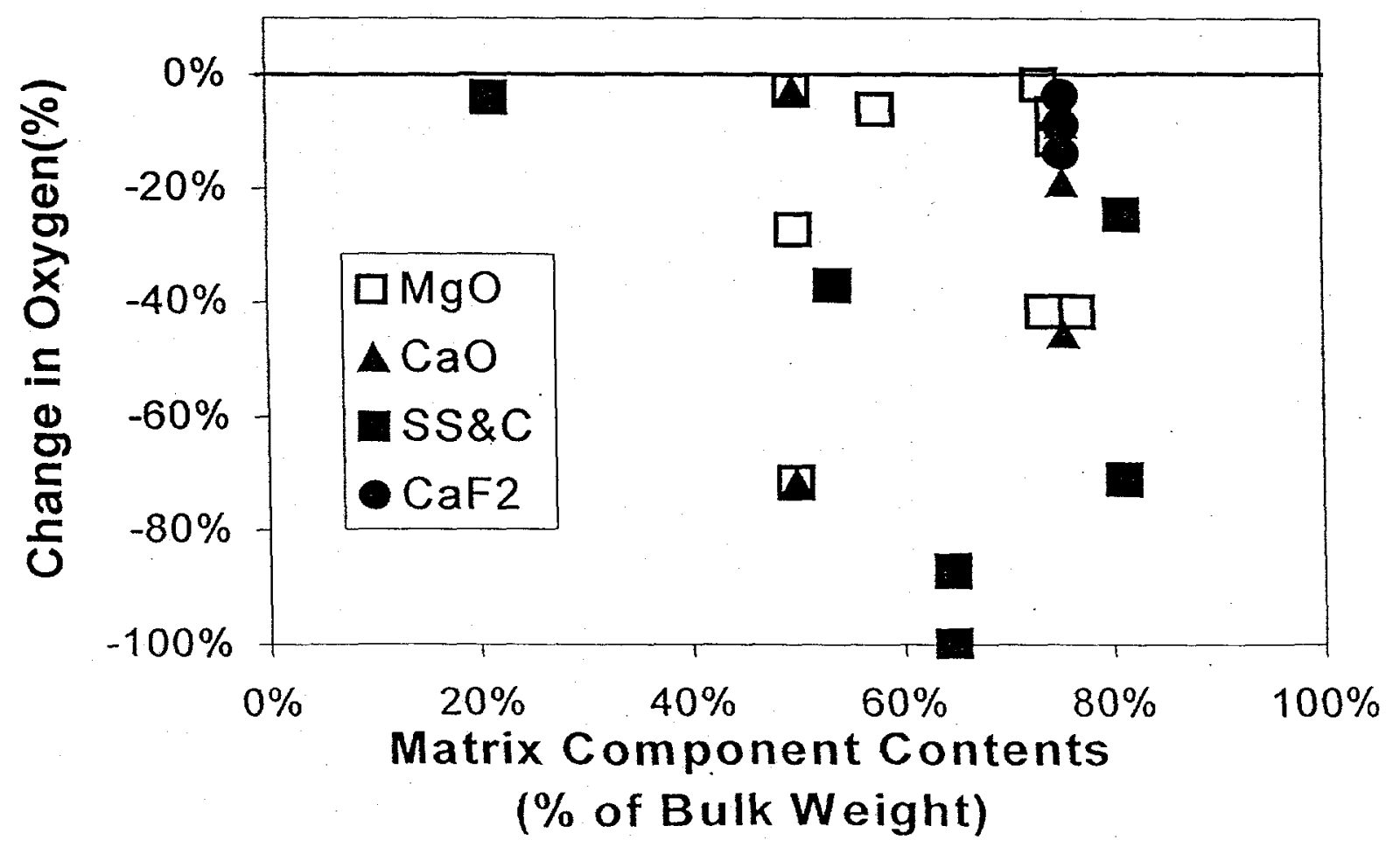


Other test runs that contain calcium metal (runs 18 and 33) have been excluded from Figure 17. None of the samples that include matrix components had a positive value for change in $\mathrm{O}_{2}$ content and many had statistically significant decreases in $\mathrm{O}_{2}$. However there are no evident trends for $\mathrm{O}_{2}$ content as a function of matrix content or percentage of gross weight.

Table 10 shows the change in $\mathrm{O}_{2}$ content of eight containers of surrogate SS\&C before and after heating. There were no changes in container, sample volume, moisture content, etc., between the heated and unheated tests. Each of the test vessels was removed from the apparatus prior to heating to ensure the sample vessel was re-equilibrated with air. The results shown in Table 10 for heating SS\&C residues demonstrate a dramatic change in the $\mathrm{O}_{2}$ content of the test vessels. Based on these observations, there is apparently a thermal reaction that depletes $\mathrm{O}_{2}$. The results for test runs 55 and 59 do not show the large decrease in $\mathrm{O}_{2}$ content found in the other samples. The reason for this difference is not known. On average (including runs 55 and 59), there was $549 \%$ or about 5.5 times more $\mathrm{O}_{2}$ removed from heated vessels than from vessels maintained at ambient temperature.

Table 10 - Effect of Elevated Temperature on $\mathrm{O}_{2}$ content of SS\&C Residue

\begin{tabular}{|c|c|c|c|c|c|}
\hline \multirow{2}{*}{$\begin{array}{c}\text { Sample } \\
\text { Description }\end{array}$} & \multicolumn{2}{|c|}{ Run Numbers } & \multicolumn{2}{|c|}{ O2 Content } & \multirow{2}{*}{$\begin{array}{c}\% \text { Change } \\
\text { when heated }\end{array}$} \\
\hline & Ambient & Heated(90C) & Ambient & Heated(90C) & \\
\hline $\mathrm{PuO} 2+\mathrm{CaF} 2$ & 9 & 14 & -18 & -48 & $267 \%$ \\
\hline $\mathrm{PuO} 2+100 \% \mathrm{RH}$ & 8 & 15 & -45 & -252 & $560 \%$ \\
\hline RFETSH6 & 13 & 20 & -381 & -457 & $120 \%=$ \\
\hline $\mathrm{PuO} 2+\mathrm{Ca}(\mathrm{OH}) 2+\mathrm{MgO}$ & 10 & 21 & -10 & -155 & $1550 \%$ \\
\hline $\mathrm{PuO2}+100 \% \mathrm{RH}$ & 11 & 23 & -22 & -112 & $509 \%$ \\
\hline PuO2 + $100 \%$ RH 2 weeks & $41 / 51$ & 53 & $-9 /-8$ & -59 & $694 \%$ \\
\hline $\mathrm{PuO2}+130 \mathrm{mg} \mathrm{H} 2 \mathrm{O}$ & 55 & 59 & -54 & -9 & $-17 \%$ \\
\hline \multirow[t]{2}{*}{$\mathrm{PuO2}+150 \mathrm{mg} \mathrm{H} 2 \mathrm{O}$} & 56 & 57 & -8 & -57 & $713 \%$ \\
\hline & & & & Average & $549 \%$ \\
\hline
\end{tabular}

To summarize these observations for change in $\mathrm{O}_{2}$ content, there have been no factors identified in the gas generation test data, other than moisture content, that cause significant $\mathrm{O}_{2}$ production. Many of the tests show that species are present that cause $\mathrm{O}_{2}$ depletion in SS\&C residues. 


\section{Statistical Evaluation of Oxygen in Gas Generation Tests}

A statistical evaluation of the $\mathrm{O}_{2}$ data $^{52}$ reported in this study has been completed and is provided as Attachment 1. The statistics associated with $\mathrm{O}_{2}$ data support the assertion that "no net $\mathrm{O}_{2}$ increase" is produced in test cases if moisture values were maintained below the established $2.3 \%$ weight loss limit recommended for SS\&C residues.

There are four important parts in the statistical review of $\mathrm{O}_{2}$ data from the GGTP needed to support transportation and storage of SS\&C residues. The first is a propagation of error to determine the normal variation expected from sampling and measuring errors. The second is application of the propagated errors. The propagated errors were used to determine if the change in $\mathrm{O}_{2}$ content for each sample is statistically different from values determined for measurement of room air. This allowed the tests to be categorized as " $\mathrm{O}_{2}$ Depleted," "No Difference," or " $\mathrm{O}_{2}$ Generated." The third aspect of the statistical evaluation was to determine how decreasing the measurement uncertainty impacted the initial categorization of tests. The final aspect of the statistical review was to select samples with $2.3 \%$ or less moisture and calculate the level of confidence for "no net increase" in $\mathrm{O}_{2}$ content.

The propagation of error provides an average uncertainty of $55 \mu \mathrm{mol}$ in the delta $\mathrm{O}_{2}$ measurement. This value can be as low as $8.3 \mu \mathrm{mol}$ after decreasing the estimated uncertainty for each input measurement (volume, temperature, vol\% $\mathrm{O}_{2}$ and pressure) by a factor of 5 . The reduced uncertainty increases the number of samples that fell into the category of "increased $\mathrm{O}_{2}$ " from 4 to 7 . The initial 4 samples that are suspected of producing $\mathrm{O}_{2}$ were from test runs $5,28,48$, and 49 . Test 5 was spiked at about $10 \%$ moisture and had a weight loss at $210^{\circ} \mathrm{C}$ of about $4.5 \%$. The Tests 28,48 and 49 were representative of the fluoride residue and not SS\&C. When the input measurement uncertainty used to propagate error was reduced by a factor of two, test run 18 was added to the group of samples which showed "increased $\mathrm{O}_{2}$." This test had a high moisture level, similar to Test 5 , but was not analyzed for weight loss. When the input measurement uncertainty was decreased by a factor of 5 , samples 45 and 46 were added to the group of samples that showed "increased $\mathrm{O}_{2}$." The $\mathrm{PuO}_{2}$ samples, used for runs 45 and 46 , were spiked with $2.5 \%$ water by adding an aliquot of water to each test vessel.

Based on our review of gas generation data for samples in the GGTP, an "operational window" was established for SS\&C residue materials. This "operational window" is used to exclude tests on matrix components such as NaF that are not expected in RFETS SS\&C residue and to limit moisture content to $2.3 \%$ based on weight loss at $210^{\circ} \mathrm{C}$. After eliminating tests that were outside the "operational window," the statistical evaluation shows there is less than 1 chance in 100,000 that the remaining samples come from a population whose mean change in $\mathrm{O}_{2}$ is zero or greater. This means that there is a very high probability that on average $\mathrm{O}_{2}$ is depleted. When input measurement uncertainty is reduced by a factor of 5 , as discussed above, about $80 \%$ of the test runs are categorized as " $\mathrm{O}_{2}$ Depleted." 


\section{Measurement of Other Gases in the Test Apparatus}

GC-MS measurements were made in parallel with the determinations of $\mathrm{H}_{2}, \mathrm{O}_{2}$, and $\mathrm{N}_{2}$ in each sample. These measurements were performed to provide an indication of other gases that may be present. The typical gases detected included $\mathrm{N}_{2} \mathrm{O}, \mathrm{CO}_{2}$, and $\mathrm{CO}$. Other gases were not observed in the headspace samples. The $\mathrm{N}_{2} \mathrm{O}, \mathrm{CO}_{2}$, and $\mathrm{CO}$ gases were generally a minor component of the overall gas content. The GC-MS gas measurement data is included in Table 6 along with $\mathrm{GC}$ results for $\mathrm{H}_{2}, \mathrm{O}_{2}$ and $\mathrm{N}_{2}$. The detection limits reported for this measurement were estimated at 0.1 vol\%.

There were two tests indicating that $\mathrm{CO}$ or $\mathrm{CO}_{2}$ was generated in significant quantities during the test period. The source of carbon for creating $\mathrm{CO}$ or $\mathrm{CO}_{2}$ is not known, but is assumed to be organic contamination from sample handling in the glovebox. Nitrous oxide $\left(\mathrm{N}_{2} \mathrm{O}\right)$ is produced from the radiolysis of nitrogen in air. Nitric oxide (NO) and nitrogen dioxide $\left(\mathrm{NO}_{2}\right)$ were not detected in the headspace gases. No clear correlation between $\mathrm{NO}_{\mathrm{x}}$ concentration and vessel contents was ever identified. 


\section{Section VII - Review of Gas Generation Test Program Findings}

\section{Conceptual Model for Gas Generation}

Review of the technical literature on radiolysis of adsorbed species, gas generation related to $\mathrm{PuO}_{2}$ storage, radiolysis of solutions, and the SRTC experience from gas generation testing has led to the conceptual model that is illustrated in Figure 18. This model suggests that as the water content of a heterogeneous Pu residue increases, the effects of bulk water and subsequent radiolysis increase while the surface effects decrease. Surface effects as previously noted would include adsorption of $\mathrm{OH}$ radicals, chemical decomposition of $\mathrm{H}_{2} \mathrm{O}$, and adsorption of $\mathrm{O}_{2}$. The bulk water effects include production of $\mathrm{OH}$ and $\mathrm{OH}_{2}$ radicals in proportion to absorbed dose to yield a positive net $\mathrm{O}_{2}$ production rate. As the bulk water in the system increases, a greater number of $\mathrm{OH}$ and $\mathrm{OH}_{2}$ radicals produced can exceed the capacity of material surfaces to scavenge the radicals. The radicals can then recombine and lead to $\mathrm{O}_{2}$ production. In concept, this explains the increased $\mathrm{H}_{2}$ production rate observed as moisture content of a heterogeneous material increases and the observed threshold value for $\mathrm{O}_{2}$ generation.

Figure 18 - Conceptual Model for Radiolysis of Adsorbed Species

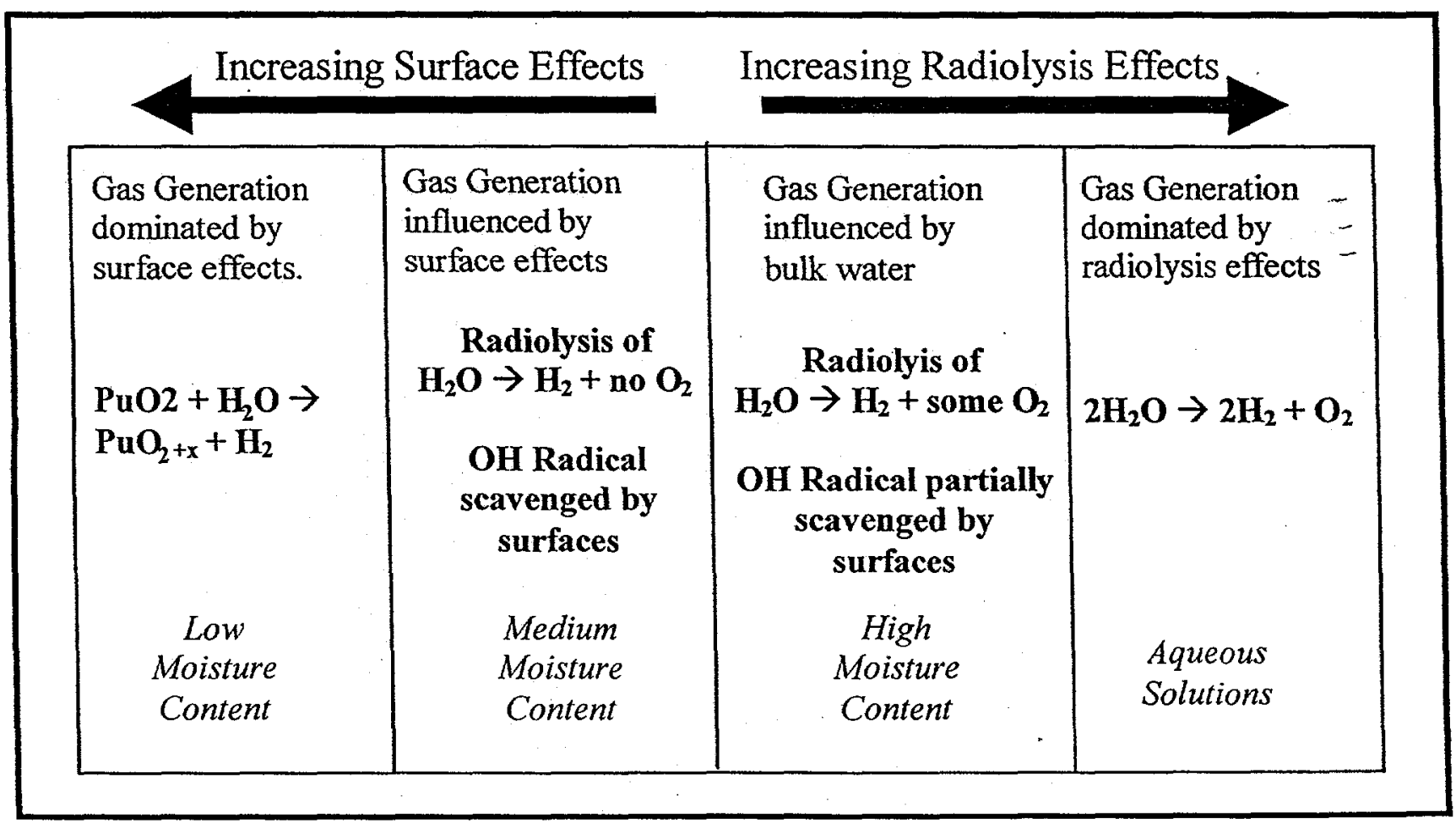




\section{Summary of GGTP Results for SS\&C}

Our current understanding of the transportation requirements for shipping Pu residue materials mandates that sufficient data is available for each material type to ensure that gas generation does not compromise package safety. The only means known, to provide the required level of information for gas generation of $\mathrm{Pu}$ residues, is laboratory testing to measure the gas generation from residue materials. SRTC established a GGTP to provide measurements for the RFETS SS\&C and fluoride residues. The testing competed on SS\&C residues used both actual samples and surrogate materials. The results of this test program have been presented in the foregoing sections along with a presentation of pertinent technical literature and potential reaction mechanisms. Several of the test program findings have significant impact on storage and transportation of $\mathrm{Pu}$ residue materials. These are enumerated below:

1) Hydrogen gas is generated from both chemical and radiation induced reactions in the $S S \& C$ residue. The reaction of calcium metal with moisture in $\mathrm{SS} \& \mathrm{C}$ residue produced $\mathrm{H}_{2}$ much faster than anticipated for radiolysis of $\mathrm{H}_{2} \mathrm{O}$.

2) The rate of $\mathrm{H}_{2}$ generation for adsorbed moisture on $\mathrm{Pu}$ residues varies based on the matrix composition. This change in $\mathrm{H}_{2}$ generation rate may result from energy transfer mechanisms.

3) The observed hydrogen generation rate increased with increased moisture contents. This is consistent with observations for radiolysis of adsorbed water in other systems.

4) The gas generation analytical model tested was inadequate for predicting $\mathrm{H}_{2}$ generation rates in $\mathrm{SS} \& \mathrm{C}$ surrogates when using moisture values estimated by weight loss at $210^{\circ} \mathrm{C}$. Moisture analysis, based on weight loss at $210^{\circ} \mathrm{C}$, underestimates the total adsorbed moisture of SS\&C residues.

5) Oxygen depletion was observed in most of the SS\&C surrogate gas generation tests. This observation is consistent with reports in the technical literature for irradiation of adsorbed moisture.

6) No net increase in oxygen is observed for SS\&C residues when moisture is maintained below $2.3 \%$ as indicated by weight loss at $210^{\circ} \mathrm{C}$. The decrease in $\mathrm{O}_{2}$ content is consistent with headspace gas measurements for long term storage of $\mathrm{PuO}_{2}$.

7) RFETS SS\&C residues exposed to $100 \%$ humidity at ambient temperature should not adsorb more than $2.3 \%$ moisture as measured by weight loss at $210^{\circ} \mathrm{C}$. This $\mathrm{H}_{2} \mathrm{O}$ would subsequently desorb when the $\mathrm{SS} \& \mathrm{C}$ residues are returned to a dry atmosphere. 


\section{References}

'UCRL-ID-125115, Bulging of Cans Containing Plutonium Residues - Summary Report, R.A. Van Konynenburg, Lawrence Livermore National Laboratory, March 1996.

${ }^{2}$ LA-UR-95-4415 Rev. 2, Plutonium Storage, J.M. Haschke and J.C. Martz, Los Alamos National Laboratory, 1995.

3 WSRC-SA-7 Rev. 7, Safety Analyis Report - Packages 9965,9968,9972-75 Packages(U), Westinghouse Savannah River Company, Savannah River Technology Center, Packaging and Transportation Group, January 1999.

${ }^{4}$ SRT-CHT-98-2020, Hydrogen and Oxygen Generation During Transport of Selected RFETS Residues in 9975 Packages(U), N.M. Askew, October 1998.

5 WSRC-RP-99-00164 Rev. 1, Task Technical and Quality Assurance Plan - Gas Generation Test Support for Revision of the 9975 SARP.

6 Non Destructive Testing Handbook, 2nd Edition, Volume 1, Leak Testing, ISBN 0-87170125-1, 1982.

${ }^{7}$ SRT-ADS-99-0260, Analysis Summary for 9975 Project Support, J.E. Young, 7/9/99

${ }^{8}$ SRT-CHT-98-1076 Rev. 1, Processing RF IDC\#398 S,S,\&C Material, J.H. Gray, 12/29/98

${ }^{9}$ SRT-CHT-98-1081 Rev. 0, Processing RF IDC\#390 S,S,\&C Material, J.H. Gray, 12/31/98

${ }^{10}$ SRT-CHT-99-1007 Rev. 0, Processing RF IDC\#395 S,S,\&C Material, J.H. Gray, 01/27/99

${ }^{11}$ SRT-CHT-99-1011 Rev. 0, Processing RF IDC\#392 S,S,\&C Material, J.H. Gray, 02/19/99

${ }^{12}$ Department of Energy Plutonium Sand, Slag, and Crucible Trade Study, Volume II, Section III.a.,Nuclear Materials Stabilization Task Group, 1/2/97.

${ }^{13}$ Personal Communication with J.H. Gray, 7/29/99.

14 WSRC-TR-97-00395, Flowsheet Modifications for Dissolution of Sand, Slag, and Crucible Residues in the F-Canyon Dissolvers, J.H. Gray, R.R. Livingston, E.A. Kyser, R.A. Pierce, D.B. Allen..., Westinghouse Savannah River Company, December 1997.

${ }^{15}$ LA-12999-MS, Plutonium Dioxide Storage: Conditions for Preparation and Handling, John M. Haschke and Thomas E. Ricketts, Los Alamos National laboratory, August 1995.

${ }^{16}$ A Thermal Desorption Study of the Surface Interactions between Water and Plutonium Dioxide, J.L: Stakebake, The Journal of Physical Chemistry, Vol 77, No. 5, 1973

${ }^{17}$ SRT-ADS-99-1235, David DiPrete, Pu Isotopics on CHTS Samples, 6/11/99.

${ }^{18}$ Chemistry: Principles and Practice, Reger, Goode, and Mercer, 1993, Saunders College Publishing, ISBN 0-3-73333-2, Page 10.

${ }^{19}$ RS-090-025, Rev. 0, Ash Residue Calcination Treatability Study Summary Report, P.J. Jossart, Rocky Flats Environemental Technology Site, September 1996.

${ }^{20}$ SRT-CTS-96-0090, M.L.Hyder, Gas Generation in Shipping Packages, August 1996.

${ }^{21}$ Radiolysis of adsorbed substances on oxide surfaces, A.B. Aleksandrov, et.al., Russian Journal of Physical Chemistry, 65 (6), pp. 847-889, 1991.

${ }^{22}$ Radiolysis and Energy Transfer in the Adsorbed State, J.G. Rabe et.al, Journal of Physical Chemistry, Vol 70, number 4, pp. 1098-1107, April 1966

${ }^{23}$ WSRC-TR-9900236, Thermal Analysis of RFETS SS\&C, P.S. Korinko, Westinghouse Savannah River Company, August 1999.

${ }^{24}$ SRT-MTS-99-3021, Thermal Analysis of Constituents Comprising SS\&C and Low Pu Containing SS\&C Samples, P.S. Korinko, 7/14/99.

${ }^{25}$ WSRC-TR-94-0418, J.W. Jerrell and Poh Sang Lam, Thermal Analysis of Storage Cans Containing Special Nuclear Materials, October 1994. 
${ }^{26}$ Handbook of Chemistry and Physics, $68^{\text {th }}$ Edition, CRC Press, ISBN 0-8493-0468-7, 1987, p. E-42

${ }^{27}$ The Merck Index, $10^{\text {th }}$ edition, Merck \& Co, ISBN 911910-27-1, 1983.

${ }^{28}$ The Low-Temperature Oxidation of Calcium by Water Vapor, D.A. Nissen, Oxidation of Metals, Vol. 11, No. 5, pp. $241-261,1977$.

${ }^{29}$ SRT-MTS-99-3021, Paul Korinko to John Gray, Thermal analysis of Constituents comprising SS\&C and Low Pu containing SS\&C samples, July 1999.

${ }^{30}$ TRG-018-99, Statistical Analysis of Sand, Slag, and Crucible (SS\&C) Moisture Content Data Obtained Since August 28, 1998,T.R. Gatliffe to G.S. Sprenger, Interoffice Correspondence, April 15,1999.

${ }^{31}$ Personal Communication, Fax from Beth Conrad to Jeff Schaade, July 1,1999.

${ }^{32}$ TRG-017-99, Statistical Analysis of Sand, Slag, and Crucible (SS\&C) Moisture Content Data, T.R. Gatliffe to G.S. Sprenger, Interoffice Correspondence, April 9, 1999.

${ }^{33}$ The Storage Behavior of Plutonium Metal, Alloys, and Oxide, J.L. Stakebake, Journal of Nuclear Materials, Vol. 38, pp 241-259, 1971.

${ }^{34}$ WSRC-MS-95-0013, Radiolytic Hydrogen Production During the Long Term Storage of Spent Organic Ion Exchange Resins, C.L. Crawford and N.E. Bibler, 1995.

${ }^{35}$ DP-MS-81-18, Effects of High Radiation Doses on Linde Ion Siv IE-95, N.E. Bibler et.al, 1981.

${ }^{36}$ Radiolytic Hydrogen Gas Formation From Water Adsorbed on Type A Zeolites, Mikio Nakashima and Yasukuki Aratono, Radiation Physical Chemistry, Vol 41, No. 3, pp. 461-465, 1993.

${ }^{37}$ GEND-052, Hydrogen Control in the Handling, Shipping, and Storage of Wet Radioactive Waste, J.O. Henrie et al, February 1986.

${ }^{38}$ LA-UR-99-3053, Materials Identification and Surveillance: June 1999 Characterization Status Report, Richard Mason et al, Los Alamos National Laboratory, 1999.

${ }^{39}$ LA-UR-98-5200, Preliminary Report on the Recombination Rates of Hydrogen and Oxygen over Pure and Impure Plutonium Oxides, Luis Morales, Los Alamos National Laboratory, 1998.

${ }^{40}$ LA-13597-MS, Kinetics of Reaction Between Plutonium Dioxide and Water at $25^{\circ} \mathrm{C}$ to $350^{\circ} \mathrm{C}$ : Formation and Properties of the $\mathrm{PuO}_{2+\mathrm{X}}$ Phase, L.A. Morales, J.M. Haschke, and T.H. Allen, Los Alamos National Laboratory, 1999.

${ }^{41}$ DOE-STD-3013-96, Criteria for Safe Storage of Plutonium Metals and Oxide, US Department of Energy, Washington, D.C. September 1996.

${ }^{42}$ Stabilization of Rocky Flats Pu-contaminated ash within chemically bonded phosphate ceramics, Journal of Nuclear Materials, A.S. Wagh et.al., vol 265, pp. 295-307, 1999.

${ }^{43}$ ORNL-3830, Chemical Technology Division Annual Progress Report, Section 10. Irradiation Effects on Heterogeneous Systems, pp. 233-235, November 1965.

${ }^{44}$ Radiolytic Gas Generation in Concrete Made with Incinerator Ash Containing Transuranium Nuclides, N.E. Bibler, Scientific Basis for Nuclear Waste Management, Vol 2, pp 585-592, 1980.

${ }^{45}$ ANL-97/15, Radiation Effects in Moist-Air Systems and the Influence of Radiolytic Product Formation on Nuclear Waste Glass Corrosion, D.J. Wronkiewicz et al, Argonne National Laboratory, July 1997. 
${ }^{46}$ D.T. Reed, Progress in Assessing the Effect of Ionizing Radiation on the Anticipated Waste Package Environment at the Yucca Mountain Potential Repository Site, Presentation for Focus '91 sponsored by American Nuclear Society, LasVegas, NV, 9/29-10/2/91.

${ }^{47}$ UCRL-97936, Effect of Ionizing Radiation on Moist Air Systems, D.T. Reed and R.A. Van Konynenburg, 1987.

${ }^{48}$ Effect of Ionizing Radiation on Moist Air Systems, D.T. Reed and R.A. Van Konynenburg, Material Research Society Proceedings, Vol 112, pp. 393-404, 1987.

${ }^{49}$ Radiation-Induced Catalysis on Oxide Surfaces: Degradation of Hexachlorobenzene on $\gamma$ Irradiated Alumina Nanoparticles, G.A. Zacheis, K.A. Gray, P.V. Kamat, Journal of Physical Chemistry B, Vol 103, No. 12, pp. 2142-2150, 1999.

${ }^{50}$ SRT-CHT-99-2009, Radiolysis of Adsorbed Water in Sand, Slag and Crucible Residues DRAFT, F.R. Graham (editor), Westinghouse Savannah River Co., July 1999.

${ }^{51}$ WSRC-RP-94-0629, Rev 1, Pu-Oxide Storage Issues - FB-Line Can C-39(U), R.A.Pierce, Westinghouse Savannah River Co., August 1994.

${ }^{52}$ WSRC-RP-99-00595, A Statistical Review of the Oxygen Data from the Gas Generation Test Supporting the Revision of the 9975 SARP(U), T.B. Edwards, July 1999. 
Attachment 1 - A Statistical Review of the Oxygen Data from the Gas Generation Tests Supporting the Revision of the 9975 SARP (U) 
WSRC-RP-99-00595

Revision 0

\section{A STATISTICAL REVIEW OF THE OXYGEN DATA FROM THE GAS GENERATION TESTS SUPPORTING THE REVISION OF THE 9975 SARP (U)}

T. B. Edwards

Westinghouse Savannah River Company

Savannah River Technology Center Aiken, SC 29808

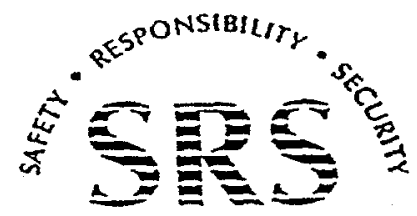

SAVANNAH RIVER SITE

PREPARED FOR THE U.S. DEPARTMENT OF ENERGY UNDER CONTRACT NO. DE-A C09-96SR18500 
WSRC-RP-99-00595

Revision 0

\section{DISCLAIMER}

This report was prepared by Westinghouse Savannah River Company (WSRC) for the United States Department of Energy under Contract No. DE-AC0996SR 18500 and is an account of work performed under that contract. Neither the United States Department of Energy, nor WSRC, nor any of their employees makes any warranty, expressed or implied, or assumes any legal liability or responsibility for the accuracy, completeness, or usefulness, of any information, apparatus, or product or process disclosed herein or represents that its use will not infringe privately owned rights. Reference herein to any specific commercial product, process, or service by trademark, name, manufacturer, or otherwise does not necessarily constitute or imply endorsement, recommendation, or favoring of same by WSRC or by the United States Government or any agency thereof. The views and opinions of the authors expressed herein do not necessarily state or reflect those of the United States Government or any agency thereof. 
WSRC-RP-99-00595

Revision 0

\section{A STATISTICAL REVIEW OF THE OXYGEN DATA FROM THE GAS GENERATION TESTS SUPPORTING THE REVISION OF THE 9975 $\operatorname{SARP}(\mathbf{U})$}

T. B. Edwards

July 15, 1999

Document Approvals

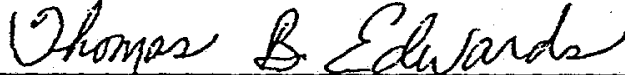

T. B. Edwards, Author Statistical Consulting Section

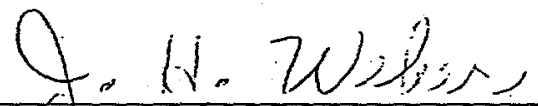

J. H. Weber, Technical Reviewer

Statistical Consulting Section

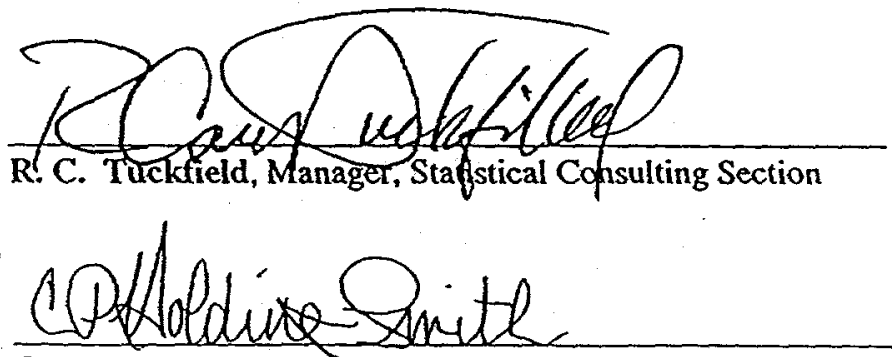

C. P. Holding-Smith, anager

Engineering Modeling \& Simulation Group Authorized Derivative Classifier
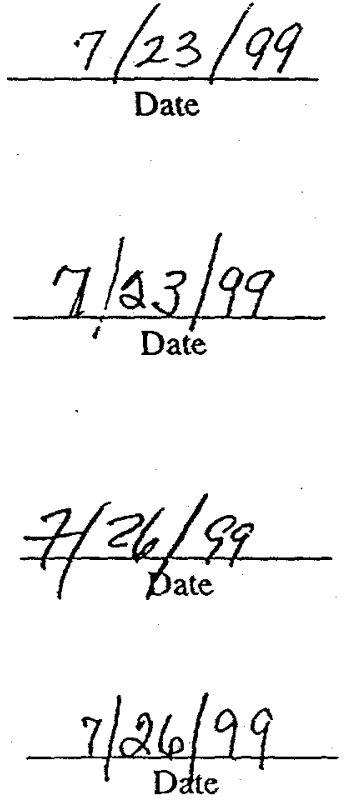
WSRC-RP-99-00595

Revision 0

This page intentionally left blank. 
WSRC-RP-99-00595

Revision 0

\section{INTRODUCTION}

The Chemical and Hydrogen Technology Section (CHT) of the Savannah River Technology Center (SRTC) has conducted a series of gas generation tests in support of the revision of the safety analysis report for packaging (SARP) for the 9975 container, developed at the Savannah River Site (SRS). The Packaging and Transportation Group of SRTC is coordinating the revision to this SARP. A Task Technical and Quality Assurance Plan directing this work was issued by CHT in February 1999 [1].

Initially, the primary interest in this testing was hydrogen generation. From [1], these gas "generation tests can be tracked in real-time by measuring the pressure of a sealed container of the materials being studied. Because multiple gas phase reactions are produced in the radiation field of the sample, material pressure measurements do not necessarily define the quantity of $\mathrm{H}_{2}$ generated. However, the change in total molecules of gas can be calculated using the ideal gas law from the pressure measurement, known container volume and sample temperature. A measurement of the actual headspace gases must be completed to calculate the $\mathrm{H}_{2}$ generation rate for a particular sample."

As the results from these tests were reviewed, however, questions arose regarding the oxygen in the headspace gases. Specifically, do the data from some tests indicate that oxygen was generated for those tests? And do the data for other tests indicate that the oxygen was depleted for them? A statistical analysis of the oxygen data derived from these tests is provided in this report to help answer these questions.

This analysis was conducted using JMP® Version 3.2.2, a commercial software package of the SAS Institute, Inc., in Cary, NC [2].

\section{DISCUSSION}

In this section various plots of the oxygen data are reviewed; the tests are grouped into similar types of experiments, which are then studied; measurement and analytical uncertainties are propagated through the equations used to determine the change in oxygen; and finally, the test results are judged for significant $\mathrm{O}_{2}$ changes based upon their corresponding uncertainties. As part of this final assessment, the results from those tests that are thought to be most representative of the operational window for the 9975 package are summarized.

The data from these tests are provided in Table Al of the Appendix. A test identifier is provided in the first column of this table. This identifier is used throughout this report to designate specific tests. Table A2 in the Appendix provides additional information for these tests designated using these same test identifying numbers. 
As described above for $\mathrm{H}_{2}$, the determination of interest for $\mathrm{O}_{2}$ is the change in total $\mathrm{O}_{2}$ molecules from the beginning to the end of each test in the sample vessel.

This determination is made using the following equation

$$
r=n_{2}-n_{1}=\frac{\mathrm{mP}_{2} \mathrm{~V}}{\mathrm{RT}_{2}}-\frac{\mathrm{aP}_{1} \mathrm{~V}}{\mathrm{RT}_{1}}
$$

where $\mathrm{n}_{1}$ is an estimate of the initial moles of $\mathrm{O}_{2}$ in the headspace gases of the container and $n_{2}$ is an estimate of the final moles of $\mathrm{O}_{2}$ in the headspace gases. Equation (1) also shows how these estimates are determined using the ideal gas law. In equation ( 1 ), the term "a" represents the initial $\mathrm{O}_{2}$ as a fraction of the headspace gas volume, $V$ (in cubic centimeters, $c c$ ), at an initial pressure of $P_{1}$ (in torr) and temperature of $T_{1}$ (in degrees Kelvin, ${ }^{\circ} \mathrm{K}$ ). $\mathrm{R}$ is the universal gas constant, $62324.73 \frac{\mathrm{torr} \cdot \mathrm{cc}}{\mathrm{K} \cdot \mathrm{mole}}$. The " $\mathrm{m}$ " term in equation (1) represents the final $\mathrm{O}_{2}$ concentration as a fraction of the headspace gases of volume $\mathrm{V}$ at a pressure of $\mathrm{P}_{2}$ (in torr) and temperature $\mathrm{T}_{2}\left({ }^{\circ} \mathrm{K}\right)$.

The value of " $a$ " for each experiment is the fraction of $\mathrm{O}_{2}$ in air, for which the reference value is 0.20946 . The value for " $\mathrm{m}$ " was determined by gas chromatography utilizing a sample of the headspace gases taken by syringe at the end of the test. These values along with results from equation (1) are provided in Table A1.

\section{INITIAL LOOK AT THE OXYGEN DATA}

Exhibit $\mathrm{Al}$ in the Appendix provides a plot of the initial $\mathrm{O}_{2}$ molar value versus the corresponding final value by test. Some of those tests with final $\mathrm{O}_{2}$ values larger than their initial values are labeled with their test number in this plot. Exhibit $A 2$ in the Appendix provides a plot of the change in $\mathrm{O}_{2}$ (final minus initial) by test number. A reference line at zero is also shown on this plot. Two questions of interest in this last plot are: "Which of these test results indicate a significant increase in $\mathrm{O}_{2}$ (if any)?" and "Which of these tests indicate a significant decrease in $\mathrm{O}_{2}$ (if any)?"

In order to answer these questions, an idea of the repeatability of the outcomes from similar tests must be determined. The test descriptions in Table A2 of the Appendix were used to group the tests into the categories indicated in Table 1.

Table 1: Types of Tests

\begin{tabular}{|c|c|}
\hline Type & Tests \\
\hline PuO2 $+\mathrm{MgO}$ & $1,11,23 \mathrm{H}, 25,26$ \\
\hline $\mathrm{PuO}+\mathrm{CaF}$ & $9,14,19$ \\
\hline $\mathrm{Pu} \mathrm{Cake}$ & $17,44,50,52$ \\
\hline $\mathrm{PuO} 2$ & $12,16 \mathrm{H}, 41,51$ \\
\hline PuO2 $+\mathrm{CaO}$ & $2,8,15 \mathrm{H}$ \\
\hline & $3,4,5,6,7,10,13,18,20,21,22,24,28,29,30,31,32$ \\
Other & $33,34,35,36,37,38,39,40,41,42,43,45,46,47,48$, \\
& $49,53,54,55,56,57,58,59$ \\
\hline
\end{tabular}


An " $\mathrm{H}$ " following a test number indicates that that particular test was heated, possibly differentiating it from the other tests in its group.

Exhibit A3 in the Appendix provides a look at the change in $\mathrm{O}_{2}$ by group type. Descriptive statistics for each of these groups are also provided in this exhibit. Note that the heated tests (those with the " $\mathrm{H}$ " suffix in Table 1) are labeled (in addition to those that were labeled earlier) in this exhibit and that they result in a change in $\mathrm{O}_{2}$ that appears to be different from their unheated counterparts. The average and standard deviation of each group containing a heated test are computed including and excluding this test.

The repeatability of a test of the 9975 package may be represented by the standard deviation in the measurements of set of identical experiments. Each of the first 5 groups from Table 1 (excluding the heated tests) is to be considered as a set of nearly identical experiments. Their standard deviations range from 0.000071 to 0.000002 moles of $\mathrm{O}_{2}$ with a pooled estimate of the standard deviation across all five groups of 0.00004 moles. When considered on a percentage basis as a relative (to the mean $\mathrm{O}_{2}$ change) standard deviation, they range from about $21 \%$ to about $101 \%$ of the average $\mathrm{O}_{2}$ change for the group with a pooled relative standard deviation of about $88 \%$ (using a one-way analysis of variance approach). In summary, a 2-sigma uncertainty determined from these results would be lead to a limit of $+/-0.00008$ moles and $+/-176 \%$ of reading for absolute and relative errors, respectively.' Obviously, assessing the $\mathrm{O}_{2}$ changes using the relative errors leads to insignificant differences between the initial and final oxygen for all of the tests. For those tests showing a potential $\mathrm{O}_{2}$ increase, the absolute error 2- sigma limit leads to only 28,48 , and 49 being significant at an approximate $95 \%=$ confidence level.

Part of the variation seen among the results for each of these groups is from measurement and analytical uncertainty and part is from differences in the conditions among each set of repeated tests (i.e., the conditions of the tests in each group may not have been as "identical" as desired). The next section looks at the variation due to the first of these two categories via the approach of error propagation. Before moving on to that topic, consider two additional looks at these data.

The first is a plot of the $\mathrm{O}_{2}$ change versus headspace volume (in cc) across all of the tests, which is provided in Exhibit A4 in the Appendix. The volume of headspace gases in the container of each test is plotted along the $\mathrm{x}$-axis. Along the $\mathrm{y}$-axis the initial moles of $\mathrm{O}_{2}$ are plotted as a solid light-gray line. The final moles of $\mathrm{O}_{2}$ are also plotted on the $y$-axis, and their values are indicated by the symbol " $x$ ". While several of the tests showing a potential increase in $\mathrm{O}_{2}$ have a headspace gas volume in the interval from 65 to $75 \mathrm{cc}$, other tests with volumes of only $30 \mathrm{cc}$ also show a potential increase in $\mathrm{O}_{2}$. Thus, there is no obvious

1 Absolute and relative errors are discussed later in this section. 
WSRC-RP-99-00595

Revision 0

relationship between the initial headspace gas volume and the generation or depletion of $\mathrm{O}_{2}$.

One of the key steps in measuring the final $\mathrm{O}_{2}$ value is injecting a sample from the headspace gas of the test container into a gas chromatogiaph. The recovery of this sample as reflected by its total sample volume percent determination is a critical measurement in this procedure. The target value for this determination is $100 \%$. Exhibit A5 in the Appendix provides a plot of the $\mathrm{O}_{2}$ changes versus the total sample volume percent determinations for these tests. There is no obvious relationship between the total sample volume percent determination and the generation or depletion of $\mathrm{O}_{2}$.

\section{Propagation of Measurement UnCertainties}

As evident in equation (1), the determination of $r$, the difference in moles of $\mathrm{O}_{2}$ from the beginning to the end of a test, is dependent on several measurements conducted over the course of the test. One question of interest as the results of these tests are evaluated is the potential impact of the uncertainties of these measurements on the derived values for $r$. Propagating the measurement uncertainties or errors afflicting the terms of equation (1) into the resultant $r$ reveals this potential impact.

The errors in experimental measurements fall into the two broad categories of bias errors and random errors. Bias is related to accuracy, the closeness of agreement between the measured value and the true value. ${ }^{2}$ Randomness of a measurement is related to the precision or repeatability of the measurement. Appropriatelytaken together, these two errors yield the uncertainty of the measurement. The ${ }^{-}$ error propagation for equation (1) conducted here follows the framework provided in reference [3]. This reference also provides a full discussion of the practice of and underlying theory for uncertainty analysis in an experimental setting. It is a linearized approach based on the use of a Taylor series expansion of equation (1).

Using the approach and terminology of [3], a 95\% coverage estimate of the uncertainty in the result $r, U_{r}$, can be expressed as

$$
\mathrm{U}_{\mathrm{r}}^{2}=\mathrm{B}_{\mathrm{r}}^{2}+\left(\mathrm{tS}_{\mathrm{r}}\right)^{2}
$$

where $B_{r}$ represents the $95 \%$ confidence bound of the bias limit for $r, S_{r}$ represents the estimate of the standard deviation of the random errors, and $t$ is the two-tailed, 95\% Student $t$ value (i.e., the $97.5^{\text {th }}$ percentile, with degrees of freedom equal to those associated with the estimate of $S_{r}$ ).

In the situation where bias errors are known, the corresponding measurements are frequently corrected for these biases. Some random errors may been induced into the measurement by this process, however. In addition, the durations of the biases often vary. Some bias or systematic errors may remain constant over only a few measurements while others may afflict an entire experimental study. For this study, the approach taken is to select bounding values (at a $95 \%$ confidence level) for the potential measurement biases 
The bias $\left(B_{r}\right)$ and precision $\left(S_{r}\right)$ errors for $r$ are estimated by propagating the bias $\left(B_{i}\right)$ and precision $\left(S_{i}\right)$ errors of each measurement term $i$ of equation (1) using a Taylor's series expansion as indicated in the following equations:

$$
B_{r}^{2}=\sum_{i=1}^{J} \theta_{i}^{2} B_{i}^{2}+2 \sum_{i=1}^{J-1} \sum_{j=i+1}^{j} \theta_{i} \theta_{j} \rho_{i j} B_{i} \dot{B}_{j}
$$

and

$$
\left(\mathrm{tS}_{\mathrm{r}}\right)^{2}=\sum_{\mathrm{i}=1}^{\mathrm{j}} \theta_{\mathrm{i}}^{2}\left(\mathrm{tS}_{\mathrm{i}}\right)^{2}+2 \sum_{\mathrm{i}=1}^{\mathrm{J}-1} \sum_{\mathrm{j}=\mathrm{i}+1}^{\mathrm{J}} \theta_{\mathrm{i}} \theta_{\mathrm{j}} \rho_{\mathrm{ij}}\left(\mathrm{tS} \mathrm{S}_{\mathrm{i}}\right)\left(\mathrm{tS} \mathrm{S}_{\mathrm{j}}\right)
$$

where the summations are over the $J(=7)$ terms of equation (1), which are listed in Table 2 and which contribute uncertainty to the resultant $r$, each $\theta_{i}=\frac{\partial r}{\partial_{i}{ }^{\text {th }} \text { term }}$ represents the partial derivative of equation (1) with respect to the $\mathrm{i}^{\text {th }}$ term of that equation, each $B_{i}$ represents the $95 \%$ confidence estimate of the bias for the $i^{\text {th }}$ such term, $S_{i}$ represents the standard deviation of the precision errors for this $i^{\text {th }}$ term, the corresponding Student $t$ value is chosen for $95 \%$ (two-tailed) confidence and reflecting the degrees of freedom associated with $S_{i}$, the $\rho_{i j}$ expression represents the correlation between the biases for terms $i$ and $j$, and the $\rho_{i j}$ expression represents the correlation between the random errors for terms $i$ and $j$.

For the approach being used here, the degrees of freedom associated with each estimated $S_{i}$ is assumed large enough to justify using $t=2$ in the analyses that follow.

Table 2 provides a list of the partial derivative of equation (1) with respect to each term of interest and provides initial estimates of the bias and precision errors for each of these terms. 
WSRC-RP-99-00595

Revision 0

Table 2: Information Associated with the Propagation of Errors

\begin{tabular}{|c|c|c|c|c|c|c|c|}
\hline \multicolumn{2}{|c|}{ Term } & Units & Partial Derivative & $\begin{array}{c}95 \% \text { Bound for } \\
\text { Bias, } B_{i} \\
\text { (relative) }\end{array}$ & $\begin{array}{c}\text { 95\% Bound for } \\
\text { Bias, } B_{i} \\
\text { (absolute) }\end{array}$ & $\begin{array}{c}\text { 1Standard } \\
\text { Deviation } \\
\text { Precision, } S_{\mathrm{i}} \\
\text { (relative) }\end{array}$ & $\begin{array}{c}\text { IStandard } \\
\text { Deviation } \\
\text { Precision, } S_{i} \\
\text { (absolute) }\end{array}$ \\
\hline 1 & $a^{\prime}$ & & $\frac{-P_{1} \cdot V}{R \cdot T_{1}}$ & $2 \%$ & 0.004 & $2 \%$ & 0.004 \\
\hline 2 & $\mathrm{~V}$ & $c c$ & $\frac{m \cdot P_{2}}{R \cdot T_{2}}-\frac{a \cdot P_{1}}{R \cdot T_{1}}$ & $3 \%$ & 1 & $3 \%$ & 1 \\
\hline 3 & m & & $\frac{P_{2} \cdot V}{R \cdot T_{2}}$ & $5 \%$ & 0.01 & $5 \%$ & 0.01 \\
\hline 4 & $P_{1}$ & torr & $\frac{-\mathrm{a} \cdot \mathrm{V}}{\mathrm{R} \cdot \mathrm{T}_{1}}$ & $1 \%$ & 7 & $1 \%$ & 7 \\
\hline 5 & $P_{2}$ & torr & $\frac{m \cdot V}{R \cdot T_{2}}$ & $1 \%$ & 7 & $1 \%$ & 7 \\
\hline 6 & $T_{1}$ & ${ }^{\circ} \mathrm{K}$ & $\frac{a \cdot P_{1} \cdot V}{R \cdot T_{1}^{2}}$ & $0.33 \%$ & 1 & $0.33 \%$ & 1 \\
\hline 7 & $T_{2}$ & ${ }^{\circ} \mathrm{K}$ & $\frac{-\boldsymbol{m} \cdot \mathbf{P}_{\mathbf{2}} \cdot \mathbf{V}}{\mathrm{R} \cdot \boldsymbol{T}_{\mathbf{2}}^{\mathbf{2}}}$ & $0.33 \%$ & 1 & $0.33 \%$ & 1 \\
\hline
\end{tabular}

The estimates of the uncertainties presented in Table 2 will be the basis for deriving the uncertainties, via error propagation, for the r's resulting from these 9975 package tests. $^{3}$ As indicated in this table, relative and absolute errors will be considered in this analysis for each measurement.

There is a need to understand the difference between using relative and absolute errors to represent or model these uncertainties. Let the true value for a measurement be represented by $\mathrm{M}_{\mathrm{T}}$. If the size of the errors afflicting $\mathrm{M}_{\mathrm{T}}$ is affected by the size of $M_{T}$ itself, then the use of relative errors would beappropriate. If the size of the errors is unaffected by the size of $\mathrm{M}_{\mathrm{T}}$, then the use of absolute errors is appropriate.

For example, the value of the sample volume, $\mathrm{V}$, varies from a low of $14.43 \mathrm{cc}$ to a high of $123.67 \mathrm{cc}$ over these tests. The bias, when considered as a relative $3 \%$ error, would range from $14.43 \times 0.03=0.433 \mathrm{cc}$ to $123.67 \times 0.03=3.71 \mathrm{cc}$. The bias, when considered as an absolute error, would be a constant $1 \mathrm{cc}$. The standard deviation of the random errors afflicting $V$, when considered as a relative error, would range from $14.43 \times 0.03=0.433 \mathrm{cc}$ to $123.67 \times 0.03=3.71 \mathrm{cc}$. The standard deviation would be a constant (an absolute) $1 \mathrm{cc}$ when these random errors are assumed to be unaffected by the size of $\mathrm{V}$.

It is not unusual for the absolute errors to dominate when $\mathrm{M}_{\mathrm{T}}$ is at the low end of the range of its possible values while relative errors dominate when $\mathrm{M}_{\mathrm{T}}$ is at the high end of its range. In the discussion that follows, error propagations are conducted that consider various combinations of these errors as relative or absolute, since the true models for these uncertainties are not known.

3 These estimates of bias and precision were developed during discussions of these issues and are felt to be representative of these measurement uncertainties. 
WSRC-RP-99-00595 :

Revision 0

Correlations among the biases and any among the random errors afflicting the measurements for any one test would be limited to the beginning and ending temperatures and the beginning and ending pressures. It is expected that such correlations would be positive in sign. Note, however, that the partial derivatives for the two pressures and those for the two temperatures are of different signs. This implies that any such correlations among these biases and/or among these random errors would tend to reduce the uncertainty of the resultant, $r$.

\section{SIGNIFICANT DIFFERENCES IN MOLES OF OXYGEN}

In the analyses that follow, the focus is on two primary situations. The first assumes that there are no correlations among these measurements and that the uncertainties of Table 2 are representative. In this situation, the error propagation is to be developed (i.e., the choice between each relative and absolute error model is made) to provide an upper bound on the uncertainties for the $r$ values (at a $95 \%$ confidence level). The second situation reflects highly correlated errors between the two temperature measurements, highly correlated errors between the two pressure measurements, and uncertainties for all measurements smaller than those appearing in Table 2 . The intent is to use the second situation to conduct a sensitivity analysis on the assumptions used in the first situation.

Table 3 provides the results for the first situation, the upper bounding case. It identifies each of the 9975 package tests, provides values for the 7 measurement terms from equation ( 1 ), evaluates the corresponding value for $r$, and propagates the uncertainties of the measurements into the resulting $r$, selecting the maximum of the relative and absolute error models for each measurement. No correlations = among the biases or random errors are considered in this table.

The next to the last column of this table provides the uncertainty of the measured difference, $r$, in $\mathrm{O}_{2}$, at a $95 \%$ confidence level. This is a $+1-$ uncertainty for the derived value of $r$. The last column indicates the results of assessing the difference between the calculated value of $r$ and zero in light of $r$ 's uncertainty. Three labels are used for the rows of this last column. If the value of $\mathbf{r}$ is sufficiently greater than zero, the label " $\mathrm{O}_{2}$ generated" is used for the row. If the value of $r$ is sufficiently less than zero, the label used is " $\mathrm{O}_{2}$ depleted." Otherwise, the label "No difference" is used for the row.

Exhibit A6 in the Appendix provides a plot of the results of Table 3 by test. It shows the upper and lower error bounds for each test plotted around zero. If the calculated value of $\mathrm{r}$ falls within this interval, there is no significance difference between the initial and final moles of $\mathrm{O}_{2}$. A plotted value about the upper limit, indicates that the final moles of $\mathrm{O}_{2}$ is significantly greater than the initial for that test, and a plotted value below the lower limit indicates that the final $\mathrm{O}_{2}$ moles are significantly less than the initial moles. Thus, this plot provides a graphical representation of the significance of the $\mathrm{O}_{2}$ difference relative to the $95 \%$ uncertainty limits. 
WSRC-RP-99-00595

Revision 0

Table 3: Results of Bounding Error Propagation by Test Number

\begin{tabular}{|c|c|c|c|c|c|c|c|c|c|c|c|}
\hline & & & & & & & & & & $95 \%$ & rvalue \\
\hline & & & & & & & & & & Uncertainty & relative to \\
\hline Test & 2 & $P I$ & $Y$ & $\mathrm{Tl}$ & m & $\mathbf{P 2}$ & $T 2$ & $\mathbf{R}$ & 5 & for $r$ & zero at $95 \%$ \\
\hline 1 & 0.20946 & 752.2 & 34.11 & 296.6 & 0.188 & 743.2 & 295.7 & 62324.73 & -0.000032 & 0.00003470 & No difference \\
\hline 2 & 0.20946 & 741.9 & 63.86 & 2947 & 0.179 & 711.8 & 297.2 & 62324.73 & -0.000101 & 0.00006254 & $\mathrm{O}_{2}$ Depleted \\
\hline 3 & 0.20946 & 740.9 & 30.50 & 299.3 & 0.211 & 741.3 & 295.9 & 62324.73 & 0.000005 & 0.00003222 & No difference \\
\hline 4 & 0.20946 & 748.3 & 30.90 & 298.5 & 0.201 & 751.5 & 295.4 & 62.324 .73 & -0.000007 & 0.00003182 & No difference \\
\hline 5 & 0.20946 & 755.5 & 29.81 & 297.3 & 0.228 & 891.3 & 295.5 & 62324.73 & 0.000074 & 0.00004012 & $\mathrm{O}_{2}$ Generated \\
\hline 6 & 0.20946 & 775.7 & 62.33 & 295.5 & 0.039 & 774.7 & 294.5 & 62324.73 & -0.000447 & 0.00007169 & $\mathrm{O}_{2}$ Depleted \\
\hline 7 & 0.20946 & 649.4 & 49.71 & 296.2 & 0.036 & 808.1 & 331.0 & 62324.73 & -0.000296 & 0.00005145 & $\mathrm{O}_{2}$ Depleted \\
\hline 8 & 0.20946 & 750.2 & 64.10 & 295.6 & 0.196 & 735.1 & 295.7 & 62324.73 & -0.000046 & 0.00006467 & No difference \\
\hline 9 & 0.20946 & 734.5 & 62.91 & 299.1 & 0.202 & 733.3 & 298.2 & 62324.73 & -0.000018 & 0.00006303 & No difference \\
\hline 10 & 0.20946 & 746.5 & 43.46 & 298.5 & 0.202 & 746.5 & 295.8 & 62324.73 & 0.000010 & 0.00004463 & No difference \\
\hline 11 & 0.20946 & 755.7 & 38.51 & 296.4 & 0.197 & 749.7 & 295.9 & 62324.73 & -0.000022 & 0.00003948 & No difference \\
\hline 12 & 0.20946 & 756.6 & 30.72 & 297.5 & 0.2 & 753.7 & 296.1 & 62324.73 & -0.000012 & 0.00003161 & No difference \\
\hline 13 & 0.20946 & 762.3 & 51.66 & 302.1 & 0.031 & 655.9 & 295.9 & 62324.73 & -0.000381 & 0.00005323 & $\mathrm{O}_{2}$ Depleted \\
\hline 14 & 0.20946 & 765.1 & 64.37 & 296.3 & 0.167 & 975.2 & 329.5 & 62324.73 & -0.000048 & 0.00007500 & No difference \\
\hline 15 & 0.20946 & 754.1 & 65.63 & 299.6 & 0.117 & 806.3 & 327.6 & 62324.73 & -0.000252 & 0.000066995 & $\mathrm{O}_{2}$ Depleted \\
\hline 16 & 0.20946 & 760.2 & 30.78 & 296.1 & 0.155 & 753.2 & 314.3 & 62324.73 & 0.000082 & 0.00003058 & $\mathrm{O}_{2}$ Depleted \\
\hline 17 & 0.20946 & 7622 & 42.04 & 298.0 & 0.206 & 779.1 & 297.2 & 62324.73 & 0.000003 & $0.00004546^{\circ}$ & No difference \\
\hline 18 & 0.20946 & 760.0 & 30.34 & 298.0 & 0.155 & 1179.8 & 296.4 & 62324.73 & 0.000040 & 0.00004593 & No difference \\
\hline 19 & 0.20946 & 751.7 & 52.40 & 298.4 & 0.182 & 744.5 & 297.4 & 62324.73 & -0.000061 & 0.00005307 & $\mathrm{O}_{2}$ Depleted \\
\hline 20 & 0.20946 & 753.4 & 53.82 & 297.6 & 0 & 1178.3 & 321.3 & 62324.73 & -0.000458 & 0.00008059 & $\mathrm{O}_{2}$ Depleted \\
\hline 21 & 0.20946 & 744.0 & 25.98 & 298.4 & 0.06 & 803.2 & 323.0 & 62324.73 & 0.000155 & 0.00002898 & $\mathrm{O}_{2}$ Depleted \\
\hline 22 & 0.20946 & 749.4 & 43.03 & 298.3 & 0.154 & 742.1 & 298.0 & 62324.73 & -0.000099 & 0.00004357 & $\mathrm{O}_{2}$ Depleted \\
\hline 23 & 0.20946 & 758.2 & 31.95 & 299.0 & 0.119 & 806.3 & 307.8 & 62324.73 & -0.000112 & 0.00003417 & $\mathrm{O}_{2}$ Depleted \\
\hline 24 & 0.20946 & 764.4 & 43.83 & 298.1 & 0.197 & 764.3 & 297.8 & 62324.73 & -0.000022 & 0.00004545 & No difference \\
\hline 25 & 0.20946 & 749.5 & 14.43 & 295.9 & 0.126 & 800.2 & 324.7 & 62324.73 & -0.000051 & 0.00001633 & $\mathrm{O}_{2}$ Depleted \\
\hline 26 & 0.20946 & 752.6 & 25.67 & 296.2 & 0.162 & 789.2 & 317.1 & 62324.73 & -0.000053 & 0.00002617 & $\mathrm{O}_{2}$ Depleted \\
\hline 28 & 0.20946 & 758.2 & 68.91 & 2967 & 0.242 & 829.8 & 297.9 & 62324.73 & 0.000153 & 0.00009085 & $\mathrm{O}_{2}$ Generated \\
\hline 29 & 0.20946 & 768.4 & 27.47 & 371.7 & 0.133 & 341.5 & 419.5 & 62324.73 & -0.000143 & 0.00001726 & $\mathrm{O}_{2}$ Depleted \\
\hline 30 & 0.20946 & 755.8 & 63.26 & 297.8 & 0.165 & 724.6 & 297.6 & 62324.73 & -0.000132 & 0.00006300 & $\mathrm{O}_{2}$ Deplated \\
\hline 31 & 0.20946 & 733.8 & 26.22 & 369.5 & 0.205 & 738.8 & 367.5 & 62324.73 & 0.000002 & 0.00002169 & No difference \\
\hline 32 & 0.20946 & 753.9 & 91.65 & 297.5 & 0.129 & 7722 & 296.9 & 62324.73 & -0.000287 & 0.00009684 & $\mathrm{O}_{2}$ Depleted \\
\hline 33 & 0.20946 & 760.0 & 38.54 & 298.8 & 0.202 & 751.8 & 296.8 & 62324.73 & 0.000013 & 0.00003982 & No difference \\
\hline 34 & 0.20946 & 768.9 & 38.98 & 298.9 & 0.202 & 760.5 & 296.9 & 62324.73 & 0.000013 & 0.00004072 & No difference \\
\hline 35 & 0.20946 & 745.8 & 53.04 & 296.4 & 0.189 & 755.3 & 297.4 & 62324.73 & -0.000040 & 0.00005432 & No difference \\
\hline 36 & 0.20946 & 748.5 & 61.32 & 297.9 & 0.013 & 3843.2 & 324.5 & 62324.73 & -0.000366 & 0.00026301 & $\mathrm{O}_{2}$ Depleted \\
\hline 37 & 0.20946 & 741.6 & 26.49 & 297.4 & 0.2 & 813.1 & 316.1 & 62324.73 & -0.000003 & 0.00002739 & No difference \\
\hline 38 & 0.20946 & 744.9 & 44.90 & 297.4 & 0.141 & 802.2 & 297.9 & 62324.73 & -0.000104 & 0.00004835 & $\mathrm{O}_{2}$ Depleted \\
\hline 39 & 0.20946 & 752.4 & 46.04 & 297.4 & 0.208 & 758.3 & 297.8 & 62324.73 & 0.000000 & 0.00004889 & No difference \\
\hline 40 & 0.20946 & 759.7 & 46.27 & 297.9 & 0.201 & 805.8 & 298.0 & 62324.73 & 0.000007 & 0.00005028 & No difference \\
\hline 41 & 0.20946 & 750.0 & 19.25 & 298.2 & 0.199 & 742.32 & .296 .4 & 62324.73 & $-0,000009$ & 0.00001952 & No difference \\
\hline 42 & 0.20946 & 751.6 & 72.90 & 301.3 & 0.197 & 739.1 & 296.9 & 62324.73 & $-0,000038$ & 0.00007337 & No difference \\
\hline 43 & 0.20946 & 7424 & 70.24 & 303.0 & 0.209 & 730.8 & 296.9 & 62324.73 & 0.000001 & 0.00007241 & No difference \\
\hline 44 & 0.20946 & 750.5 & 123.67 & 300.6 & 0.186 & 7227 & 297.4 & 62324.73 & -0.000141 & 0.00012212 & $\mathrm{O}_{2}$ Deplesed \\
\hline 45 & 0.20946 & 756.9 & 37.51 & 298.5 & 0.21 & 782.5 & 297.4 & 62324.73 & 0.000013 & 0.00004130 & No difference \\
\hline 46 & 0.20946 & 763.9 & 38.12 & 298.9 & 0.211 & 788.3 & 296.9 & 62324.73 & 0,000015 & 0.00004253 & No difference \\
\hline 47 & 0.20946 & 749.7 & 18.96 & 297.9 & 0.073 & 1197.3 & 370.0 & 62324.73 & -0.000088 & 0.00002573 & $\mathrm{O}_{2}$ Depleted \\
\hline 48 & 0.20946 & 7524 & 71.59 & 297.7 & 0.227 & 1095.2 & 336.7 & 62324.73 & 0.000240 & 0.00010292 & $\mathrm{O}_{2}$ Gerbrated \\
\hline 49 & 0.20946 & 744.4 & 69.90 & 297.8 & 0.297 & 10927 & 333.9 & 62324.73 & 0.000503 & 0.00013241 & $\mathrm{O}_{2}$ Generated \\
\hline 50 & 0.20946 & 748.8 & 122.76 & 298.2 & 0.189 & 736 & 298.4 & 62324.73 & 0.000118 & 0.00012278 & No difference \\
\hline 51 & 0.20946 & 755.7 & 18.74 & 298.1 & 0.199 & 753.4 & 298.1 & 62324.73 & -0.000008 & 0.00001917 & No difference \\
\hline 52 & 0.20946 & 762.5 & 45.15 & 298.8 & 0.2014 & 747.9 & 298.4 & 62324.73 & -0.000022 & 0.00004616 & No difference \\
\hline 53 & 0.20946 & 754.9 & 18.74 & 297.6 & 0.13 & 872.6 & 338.2 & 62324.73 & -0.000059 & 0.00002052 & $\mathrm{O}_{2}$ Depleted \\
\hline 54 & 0.20946 & 754.7 & 31.56 & 298.1 & 0.2 & 775.2 & 315.6 & 62324.73 & -0.000020 & 0.00003153 & No difference \\
\hline 55 & 0.20946 & 743.3 & 71.49 & 298.4 & 0.19 & 744.9 & 298.1 & 62324.73 & -0.000054 & 0.00007213 & No difference \\
\hline 56 & 0.20946 & 759.8 & 37.50 & 298.4 & 0.2 & 774.6 & 297.5 & 62324.73 & -0.000008 & 0.00003931 & No difference \\
\hline 57 & 0.20946 & 774.9 & 18.49 & 298.3 & 0.101 & 1048.9 & 300.6 & 62324.73 & -0.000057 & 0.00002561 & $\mathrm{O}_{2}$ Depleted \\
\hline 58 & 0.20946 & 750.0 & 31.27 & 298.8 & 0.00126 & 750.3 & 299.3 & 62324.73 & -0.00000594 & 0.00003234 & No difference \\
\hline 59 & 0.20946 & 7424 & 59.55 & 298.2 & 0.162 & 1019 & 322.6 & 62324.73 & -0.000009 & 0.00007296 & No difference \\
\hline
\end{tabular}

Table 4 repeats the conclusions from Table 3 and adds the results from three more approaches to the error propagation for equation (1). The columns of Table 4 headed "Correlations With Uncertainties" reflects the results of an error propagation using the information of Table 2 and assuming perfect positive correlations between the biases for the two pressure measurements, between the biases for the two temperature measurements, between the random errors for the two pressure measurements, and between the random errors for the two temperature measurements. The next pair of columns shows the results from the 
WSRC-RP-99-00595

Revision 0

approach of assuming these same correlations but reducing the uncertainties of Table 2 by a factor of 2 . The last pair shows the results from the error propagation assuming these same correlations and reducing the uncertainties of Table 2 by a factor of 5 . For these correlated situations, the minimum of the relative and absolute error models is selected to represent each and every uncertainty term of equations (3) and (4) involved in the error propagation.

Table 4: Comparisons Among The Error Propagation Approaches

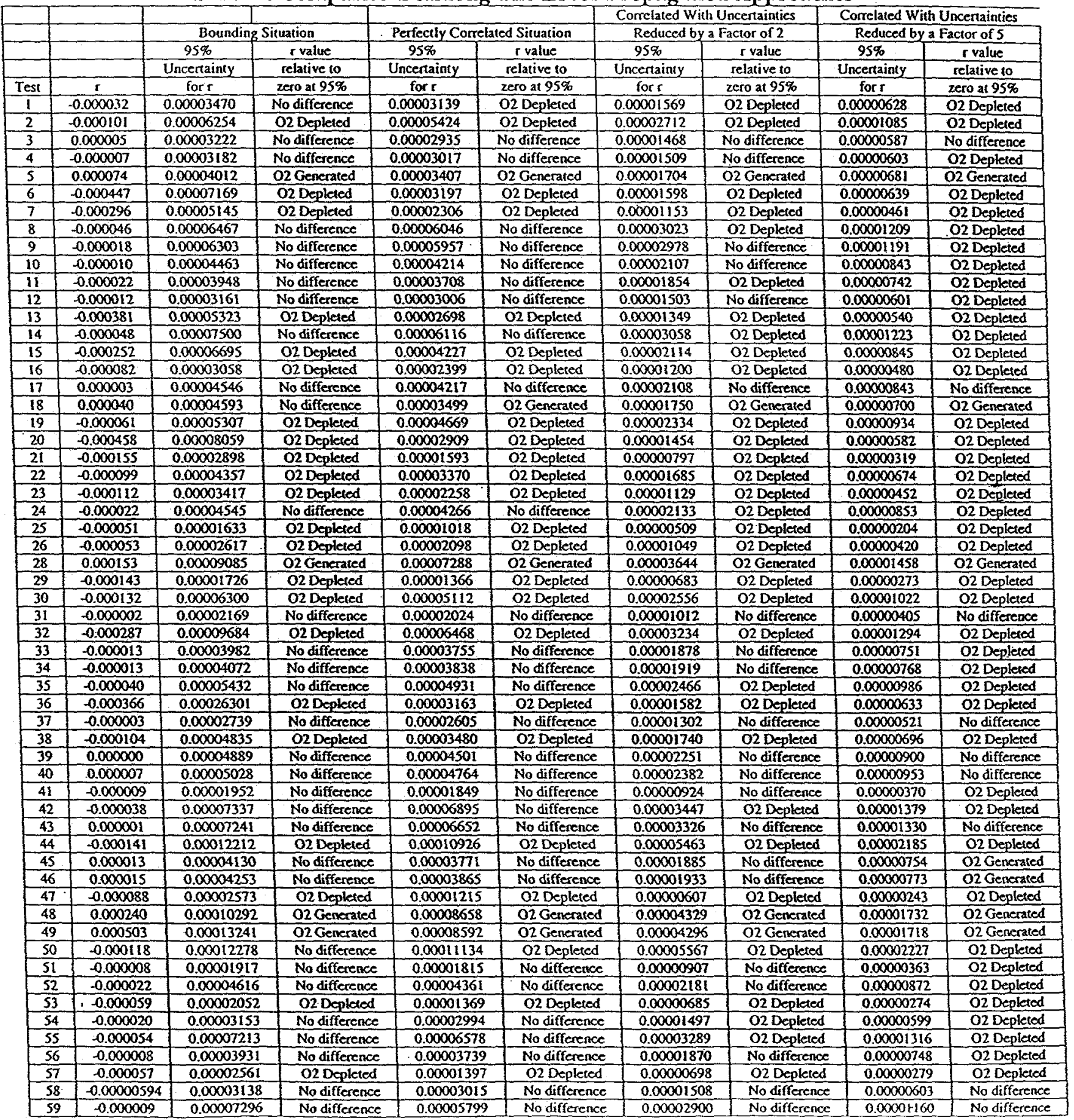


Table 5 summarizes the results from the various approaches to propagating the errors of Table 2 into equation (1). This table identifies those tests (by number) that reveal an $\mathrm{O}_{2}$ change significantly nonzero (at the $95 \%$ confidence level). The average of the uncertainties across all of the tests is also provided for each situation.

Table 5: Summary Information from Error Propagations

\begin{tabular}{|c|c|c|c|}
\hline $\begin{array}{c}\text { Description of Propagation } \\
\text { Approach }\end{array}$ & $\begin{array}{c}\text { Tests showing } \\
\text { an increased } \mathrm{O}_{2} \text { level }\end{array}$ & $\begin{array}{c}\text { Tests showing } \\
\text { a decreased } \mathrm{O}_{2} \text { level }\end{array}$ & $\begin{array}{c}\text { Average Uncertainty in } \mathrm{O}_{2} \\
\text { Change (moles) }\end{array}$ \\
\hline $\begin{array}{c}\text { Bounding Case } \\
\text { Using Maximum of Relative versus } \\
\text { Absolute Errors }\end{array}$ & $5,28,48,49$ & $\begin{array}{r}2,6,7,13,15,16, \\
19-23,25,26,29,30,32, \\
36,38,44,47,53,57\end{array}$ & 0.00005541 \\
\hline $\begin{array}{c}\text { Correlated Errors Using Minimum } \\
\text { of Relative versus Absolute Errors }\end{array}$ & $5,18,28,48,49$ & $\begin{array}{r}1,2,6,7,13,15,16,19- \\
23,25,26,29,30,32,36, \\
38,44,47,50,53,57\end{array}$ & 0.00004151 \\
\hline $\begin{array}{c}\text { Correlated Errors Using Minimum } \\
\text { of Relative versus Absolute Errors } \\
\text { with Initial Uncertainties Reduced } \\
\text { by a Factor of 2 }\end{array}$ & $5,18,28,48,49$ & $\begin{array}{r}1,2,6-8,11,13-16,19-26, \\
29,30,32,35,36,38,42, \\
44,47,50, \\
53-55,57\end{array}$ & 0.00002075 \\
\hline $\begin{array}{c}\text { Correlated Errors Using Minimum } \\
\text { of Relative versus Absolute Errors } \\
\text { with Initial Uncertainties Reduced } \\
\text { by a Factor of 5 }\end{array}$ & $5,18,28,45,46,48,49$ & $\begin{array}{r}1,2,4,6-16,19-26,29, \\
30,32-36,38,41,42,44, \\
47,50-57\end{array}$ & 0.00000830 \\
\hline
\end{tabular}

In comparing the test conditions indicated in Table $\mathrm{A} 2$ to the anticipated operational window for the 9975 package, several of the tests are deemed unrepresentative of the operational conditions or are considered to have led to questionable outcomes. The tests deemed unrepresentative include $29,35,40,46$, and 52 (due to under injection of the sample in the gas chromatography measurement), 5 and 18 (due to excessive moisture), and $28,35,42,43,48$, and 49 (due to the samples not having sand, slag, and crucible, SS\&C, components).

Exhibit A7 in the Appendix provides a plot the $\mathrm{O}_{2}$ changes for those remaining tests that are considered to be representative of the 9975-package operational conditions. Also, shown on this plot are the corresponding upper uncertainty limits for these oxygen differences. This plot shows that none of these tests have $\mathrm{O}_{2}$ changes indicating significant (at the $95 \%$ confidence level) increases in oxygen.

The average $\mathrm{O}_{2}$ change for these tests is -0.00009 moles, and the average uncertainties corresponding to the error propagation approaches of Table 5 range from a high of 0.000053 moles to a low of 0.0000094 moles. Expressed as relative uncertainties, these high and low values are $59 \%$ and $10 \%$, respectively.

Exhibit A8 in the Appendix provides a plot of the initial versus final moles of oxygen for these tests. A paired t-test for these data (assuming that these test results are representative of --- i.e., a random sample from --- the intended operational window for the 9975) is also provided in this exhibit. This statistical test reveals that the null hypothesis of a zero mean difference between the initial 
and final moles of oxygen (final - initial) for these experiments is strongly rejected (the probability of obtaining these results by chance alone is $l$ in 100,000 if there is no difference in the quantity of $\mathrm{O}_{2}$ ) in favor of the hypothesis that the mean oxygen difference is less than zero; i.e., in favor of the hypothesis that on average oxygen is depleted for these tests.

\section{CONCLUSIONS}

A review of the oxygen data from the gas generation tests supporting the 9975 SARP has been conducted including the development of an error propagation of the measurement uncertainties into the equation for the change in moles of $\mathrm{O}_{2}$. This analysis revealed tests with significant (at a $95 \%$ confidence level) differences between their beginning and ending moles of $\mathrm{O}_{2}$ based upon the measurement and analytical uncertainties assumed in this report.

\section{REFERENCES}

[1] Livingston, Ronald R., Gas Generation Test Support for Revision of 9975 SARP: Task Technical and Quality Assurance Plan," WSRC-RP-99-00164, February 18, 1999.

[2] SAS Institute, JMP® Statistics and Graphics Guide, Version 3 of JMP, SAS Institute Inc., Cary, NC, 1995.

[3] Coleman, Hugh W. and W. Glenn Steele, Jr., Experimentation and Uncertainty Analysis for Engineers, John Wiley \& Sons, Inc., New York, 1989. 
WSRC-RP-99-00595

Revision 0

This page intentionally left blank. 
WSRC-RP-99-00595

Revision 0

\section{APPENDIX:}

\section{TABLES AND EXHIBITS}


WSRC-RP-99-00595

Revision 0

This page intentionally left blank. 
Table A1: Test Measurements by Test Number ${ }^{4}$

\begin{tabular}{|c|c|c|c|c|c|c|c|c|c|c|c|c|c|c|c|c|c|}
\hline Test & $\begin{array}{c}\text { Voiume } \\
\text { (cc) }\end{array}$ & $\begin{array}{l}\text { Initial } \\
\text { Pressure } \\
\text { (torr) }\end{array}$ & $\begin{array}{c}\text { Initial } \\
\text { Temperature } \\
(" K)\end{array}$ & $\begin{array}{l}\text { Initial } \\
\text { Total } \\
\text { moles }\end{array}$ & $\begin{array}{c}\text { Estimate } \\
\text { Initial } \mathrm{N}_{2} \\
\text { moles }\end{array}$ & $\begin{array}{c}\text { Estimate } \\
\text { Initial } \mathrm{O}_{2} \\
\text { moles }\end{array}$ & $\begin{array}{l}\text { Final } \\
\text { Pressure } \\
\text { (torr) }\end{array}$ & $\begin{array}{c}\text { Final } \\
\text { Temperature } \\
\text { (C) }\end{array}$ & $\begin{array}{c}\text { Final } \\
\text { Temperature } \\
\left({ }^{3} \mathrm{~K}\right)\end{array}$ & $\begin{array}{l}\text { Final } \\
\text { Total } \\
\text { moles }\end{array}$ & $\mathrm{FH}_{2}$ & $\mathrm{mO}_{2}$ & $\% N_{2}$ & $\begin{array}{c}\text { Final } \\
\mathrm{H}_{2} \\
\text { moles }\end{array}$ & $\begin{array}{c}\text { Final } \\
\mathrm{O}_{2} \\
\text { moles }\end{array}$ & $\begin{array}{c}\text { Final } \\
\mathrm{N}_{2} \\
\text { moles }\end{array}$ & $\begin{array}{c}\Delta \mathrm{O}_{2} \\
\text { moles } \\
\text { (final-initia) }\end{array}$ \\
\hline 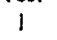 & 34.11 & 752.2 & 296.6 & $1.388 \mathrm{E}-03$ & $1.084 \mathrm{E}-03$ & $2.907 \mathrm{E}-04$ & 743.2 & 22.7 & 295.7 & $1.376 \mathrm{E}-03$ & 0.55 & 18.80 & 84.00 & $7.566 \mathrm{E} \cdot 06$ & $2.586 \mathrm{E}-04$ & $1.155 \mathrm{E}-03$ & $.3 .212 \mathrm{E} .05$ \\
\hline 2 & 63.86 & 741.9 & 294.7 & $2.579 \mathrm{E}-03$ & $2.014 E-03$ & $5.403 E-04$ & 711,8 & 24.2 & 297.2 & $2,454 \mathrm{E}-03$ & 0.00 & 17.90 & 84.50 & $0.000 \mathrm{E}+00$ & 4.393E.04 & $2.074 \mathrm{E}-03$ & .1 .0108 .04 \\
\hline 3 & 30.50 & 740.9 & 299.3 & $1.2118-03$ & $9.459 \mathrm{E}-04$ & $2.537 \mathrm{E}-04$ & 741.3 & 22.9 & 295.9 & $1.226 \mathrm{E}-0.3$ & 0.00 & 21.10 & 82.30 & $0.000 E+\infty$ & $2.587 E-04$ & $1.009 \mathrm{E} .03$ & $4.942 \mathrm{E}-06$ \\
\hline 4 & 30.90 & 748.3 & 298.5 & $1.243 \mathrm{E}-03$ & $9.705 \mathrm{E}-04$ & $2.603 \mathrm{E}-04$ & 751.5 & 22.4 & 295.4 & $1.261 \mathrm{E} \cdot 03$ & 0.00 & 20.10 & 82.50 & $0.000 E+\infty$ & $2.535 \mathrm{E}-04$ & $1.041 \mathrm{E}-03$ & $.6 .814 \mathrm{E} .06$ \\
\hline 5 & 29.81 & 755.5 & 297.3 & $1.215 \mathrm{E}-03$ & $9.491 \mathrm{E}-04$ & $2.546 \mathrm{E}-04$ & 891.3 & 22.5 & 295.5 & $1.443 \mathrm{E} .03$ & 10.80 & 22.80 & 61.70 & $1.558 \mathrm{E}-04$ & $3.289 \mathrm{E} \cdot 04$ & $8.901 \mathrm{E}-04$ & $7.434 \mathrm{E} \cdot 05$ \\
\hline 6 & 62.33 & 775.7 & 295.5 & $2.625 E-03$ & $2.0508-03$ & $5.499 E-04$ & 774.7 & 21.5 & 294.5 & $2.631 \mathrm{E}-03$ & 4.20 & 3.90 & 81.60 & $1.105 \mathrm{E}-04$ & $1.026 E-04$ & $2.147 \mathrm{E}-03$ & $-4.473 \mathrm{E} \cdot 04$ \\
\hline 7 & 49.71 & 649.4 & 296.2 & $1.749 \mathrm{E}-03$ & $1.365 \mathrm{E}-03$ & $3.663 \mathrm{E}-04$ & 808.1 & 105.5 & 331.0 & $1.947 \mathrm{E}-03$ & 3.70 & 3.60 & 87.00 & $7.206 \mathrm{E}-05$ & 7.011E-0S & $1.694 \mathrm{E}-03$ & $-2.962 \varepsilon-04$ \\
\hline 8 & 64.10 & 750.2 & 295.6 & $2.610 \mathrm{E}-0.3$ & $2.038 \mathrm{E}-03$ & $3.467 \mathrm{E}-04$ & 735.1 & 22.7 & 295.7 & $2.557 \mathrm{E}-03$ & 0.05 & 19.60 & 86.00 & $1.278 \mathrm{E}-06$ & S.011E-04 & $2.199 \mathrm{E}-03$ & $-4.560 \mathrm{E}-05$ \\
\hline 9 & 62.91 & 734.5 & 299.1 & $2.479 E-03$ & $1.936 \mathrm{E}-03$ & $5.192 E-04$ & 733.3 & 25.2 & 298.2 & $2.482 \mathrm{E}-03$ & 0.08 & 20.20 & 85.10 & $1.986 \mathrm{E}-06$ & $5.014 \mathrm{E}-04$ & $2.112 \mathrm{E} \cdot 03$ & $-1.780 \mathrm{E}-05$ \\
\hline 10 & 43.46 & 746.5 & 298.5 & $1.744 E-03$ & $1.362 \mathrm{E}-03$ & $3.653 E-04$ & 746.5 & 22.8 & 295.8 & $1.760 \mathrm{E}-03$ & 0.62 & 20.20 & 83.80 & $1.091 \mathrm{E}-05$ & $3.555 \mathrm{E}-04$ & $1.475 \mathrm{E} .03$ & $.9 .794 \mathrm{E}-06$ \\
\hline 11 & 38.51 & 755.7 & 296.4 & $1.575 E-03$ & $1.230 \mathrm{E}-03$ & $3.300 \mathrm{E}-04$ & 749.7 & 22.9 & 295.9 & $1.566 \mathrm{E} \cdot 03$ & 0.26 & 19.70 & 88.10 & $4.070 \mathrm{E} .06$ & $3.084 \mathrm{E} \cdot 04$ & $1.379 E .03$ & .2 .1578 .05 \\
\hline 12 & 30.72 & 756.6 & 297.5 & $1.254 \mathrm{E}-03$ & $9.788 \mathrm{E}-04$ & $2.626 \mathrm{E}-04$ & 753.7 & 23.1 & 296.1 & $1.255 \mathrm{E}-03$ & 0.54 & 20.00 & 84.80 & $6.775 \varepsilon-06$ & $2.509 \mathrm{E}-04$ & $1.064 E-03$ & .1 .1648 .05 \\
\hline 13 & 51.66 & 762.3 & 302.1 & $2.092 E-03$ & $1.633 \mathrm{E}-03$ & $4.381 E-04$ & 655.9 & 22.9 & 295.9 & $1.837 \mathrm{E}-03$ & 6.19 & 3.10 & 90.80 & $1.137 \mathrm{E}-04$ & $5.696 \mathrm{E} \cdot 05$ & $1.668 \mathrm{E}-03$ & $.3 .811 \mathrm{E} .04$ \\
\hline 14 & 64.37 & 765.1 & 296.3 & $2.667 \mathrm{E}-03$ & $2.082 \mathrm{E}-03$ & $5.586 \mathrm{E}-04$ & 975.2 & 97.8 & 329.5 & $3.057 \mathrm{E}-03$ & 0.89 & 16.70 & 80.00 & $2.721 \mathrm{E}-05$ & $5.105 \mathrm{E}-04$ & $2.446 \mathrm{E} .03$ & $.4 .809 \mathrm{E}-05$ \\
\hline is & 65.63 & 754.1 & 299.6 & $2.65 ! E-03$ & $2.070 E-03$ & $5.552 \mathrm{E}-04$ & 806.3 & 111.7 & 327.6 & $2.592 \mathrm{E}-03$ & 0.00 & 11.70 & 82.60 & $0.000 \mathrm{E}+00$ & $3.032 E-04$ & $2.141 \mathrm{E} 0.3$ & $.2 .520 \mathrm{E}-04$ \\
\hline 16 & 30.78 & 760.2 & 296.1 & $1.268 \mathrm{E}-03$ & $9.901 \mathrm{E}-04$ & $2.656 \mathrm{E}-04$ & 753.2 & 109.2 & 314.3 & $1.184 \mathrm{E}-03$ & 0.22 & 15.50 & 78.20 & $2.604 E .06$ & $1.835 \mathrm{E}-04$ & $9.256 \mathrm{E} .04$ & $.8 .211 \mathrm{E} .05$ \\
\hline 17 & 42.04 & 762.2 & 298.0 & $1.725 E-03$ & $1.347 \mathrm{E}-03$ & $3.614 E-04$ & 779.1 & 24.2 & 297.2 & $1.768 \mathrm{E}-03$ & 1.64 & 20.60 & .79 .60 & $2.900 \mathrm{E} \cdot 05$ & $3.643 \mathrm{E}-04$ & $1.408 \mathrm{E}-03$ & $2.889 \mathrm{E}-06$ \\
\hline 18 & 30.34 & 760.0 & 298.0 & $1.242 \mathrm{E} .03$ & $9.694 \mathrm{E}-04$ & $2.600 \mathrm{E}-04$ & 1179.8 & 23.4 & 296.4 & $1.938 \mathrm{E}-03$ & 24.15 & 15.50 & $\$ 3.10$ & $4.680 \mathrm{E}-04$ & $3.003 \mathrm{E}-04$ & $1.029 \mathrm{E}-03$ & $4.029 \mathrm{E}-05$ \\
\hline 19 & 52.40 & 751.7 & 298.4 & $2,118 \mathrm{E} \cdot 03$ & $1.654 \mathrm{E}-03$ & $4.436 \mathrm{E}-04$ & 744.5 & 244 & 297.4 & $2.105 \mathrm{E}-03$ & 0.00 & 18.20 & 83.80 & $0.000 \mathrm{E}+\infty$ & $3.831 E-04$ & $1.764 \mathrm{E}-03$ & $.6 .057 \mathrm{E}-05$ \\
\hline 20 & 53.82 & 753.4 & 297.6 & $2.186 \mathrm{E}-03$ & $1.707 \mathrm{E}-03$ & $4.579 \mathrm{E}-04$ & 1178.3 & 25.1 & 321.3 & $3.167 \mathrm{E}-03$ & 80.00 & 0.00 & 23.60 & $2.534 \mathrm{E}-0.3$ & $0.000 \mathrm{E}+\infty$ & $7.474 \mathrm{E}-04$ & $.4 .579 \mathrm{E}-04$ \\
\hline 21 & 25.98 & $744.0^{\circ}$ & 298.4 & $1.039 \mathrm{E}-03$ & $8.115 E-04$ & 2.177E-04 & 803.2 & 94.7 & 323.0 & $1.037 \mathrm{E}-03$ & 2.60 & 6.00 & 95.60 & 2.695E-05 & $6.220 \mathrm{E}-05$ & $9.910 \mathrm{E}-04$ & $.1 .555 \mathrm{E}-04$ \\
\hline 22 & 43.03 & 749.4 & 298.3 & $1.734 \mathrm{E}-03$ & $1.354 \mathrm{E} .03$ & $3.533 \mathrm{E}-04$ & 742.1 & 25 & 298.0 & 1.719 & 0.13 & 15.40 & 86.30 & 2.23 & & 1.48 & $.9 .853 \mathrm{E}-05$ \\
\hline 23 & 31.95 & 758.2 & 299.0 & $1.300 \mathrm{E}-03$ & $1.015 E-03$ & $2.723 \mathrm{E}-04$ & 806.3 & 96.9 & 307.8 & $1.343 \mathrm{E}-03$ & 1.60 & 11.90 & 88.60 & $2.149 \mathrm{E}-05$ & $1.598 \mathrm{E}-04$ & $1.190 \mathrm{E}-03$ & $-1.125 E-04$ \\
\hline 24 & 43.83 & 764.4 & & $1.803 \mathrm{E}-03$ & $1.408 \mathrm{E}-03$ & 3.777 & 764.3 & 24.8 & 297.8 & $1.805 E-03$ & 5.00 & 19.70 & 76.60 & $9.024 \mathrm{E}-05$ & $3.556 \mathrm{E}-04$ & $1.383 \mathrm{E} .03$ & $.2 .216 \mathrm{E} \cdot 05$ \\
\hline 25 & 14.43 & 749.5 & 295.9 & $5.865 \mathrm{E}-04$ & $4.579 E-04$ & $1.228 \mathrm{E}-04$ & 800.2 & 92.6 & 324.7 & $5.705 \mathrm{E} \cdot 04$ & 2.17 & 12.60 & 82.70 & $1.238 \mathrm{E}-05$ & $7.189 \mathrm{E}-05$ & $4.718 \mathrm{E}-04$ & $.5 .095 \mathrm{E}-05$ \\
\hline 26 & 25.67 & 752.6 & 5.2 & $1.047 \mathrm{E}-03$ & $8.172 \mathrm{E}-04$ & $2.192 \mathrm{E}-04$ & 789.2 & 94.4 & 317.1 & $1.025 \mathrm{E} .03$ & 1.19 & 16.20 & 79.40 & $1.220 \mathrm{E}-05$ & $1.661 \mathrm{E}-04$ & 8.140E.04 & $-5.312 \mathrm{E} .05$ \\
\hline 28 & 68.91 & & .7 & $2.825 \mathrm{E}-03$ & 2.20 & 5.91 & 829.8 & 24.9 & 297 & $3.080 \mathrm{E} \cdot 03$ & 1.82 & 24.20 & 68.20 & 5.60 & .04 & $2.100 \mathrm{E}-03$ & 1.535E-04 \\
\hline 29 & 27.47 & 768.4 & 371.7 & $9.112 \mathrm{E}-04$ & $7.115 \mathrm{E}-04$ & $1.909 \mathrm{E}-04$ & 341.5 & 99.3 & 419.5 & $3.588 \mathrm{E}-04$ & 0.46 & 13.30 & 85.80 & $1.650 \mathrm{E}-06$ & $4.772 \mathrm{E}-0 \mathrm{~S}$ & $3.078 E-04$ & $-1.43\} E .04$ \\
\hline 30 . & 63.26 & 755.8 & 297.8 & $2.576 \mathrm{E}-03$ & 2.011E-03 & $5.396 \mathrm{E}-04$ & 724.6 & 24.6 & 297.6 & $2.471 E \cdot 03$ & 1.27 & 16.50 & 75.80 & $3.139 \mathrm{E}-05$ & $4.078 \mathrm{E}-04$ & $1.873 \mathrm{E}-03$ & $.1318 \mathrm{E} .04$ \\
\hline 31 & 26.22 & 733.8 & 369.5 & $8.355 \mathrm{E}-04$ & 6.52 & 1.75 & 73 & 94 & & & 0.03 & 20.50 & 76.00 & $2.537 \mathrm{E} .07$ & 1.73 & $6.428 \mathrm{E} \cdot 04$ & $-1.621 \mathrm{E} .06$ \\
\hline 32 & 91.65 & .9 & 297.5 & $3.726 \mathrm{E}-03$ & $2.910 \mathrm{E}-03$ & $7.805 \mathrm{E}-04$ & 772.2 & 23.9 & 296.9 & $3.825 \mathrm{E}-03$ & 8.13 & 12.90 & 78.50 & $3.109 \mathrm{E} \cdot 04$ & $4.934 \mathrm{E}-04$ & $3.002 E-03$ & $-2.872 \mathrm{E} .04$ \\
\hline 33 & 38.54 & 760.0 & 298.8 & $1.573 \mathrm{E} .03$ & $1.228 \mathrm{E}-03$ & $3.294 \mathrm{E}-04$ & 751.8 & 23.8 & 296.8 & $1.566 \mathrm{E}-03$ & 1.60 & 20.20 & 76.40 & 2.50 & $3.164 \mathrm{E} \cdot 04$ & $1.197 \mathrm{E} \cdot 03$ & $-1.304 \mathrm{E} \cdot 05$ \\
\hline 34 & 38.98 & 9 & & $1.609 \mathrm{E} .03$ & $1.256 \mathrm{E}-03$ & $3.370 \mathrm{E}-04$ & 760.5 & 23.9 & & $1.602 \mathrm{E}-0.3$ & 0.20 & 20.20 & 76.90 & 3.20 & 3.236 & 1.232 & $-1.339 \mathrm{E}-05$ \\
\hline 35 & 53.04 & & 296.4 & $2.141 \mathrm{E} .03$ & $1.672 E-03$ & $4.485 \mathrm{E}-04$ & 755.3 & 24.4 & 297.4 & $2.161 \mathrm{E}-03$ & 0.00 & 18.90 & 55.20 & $0.000 E+\infty$ & $4.085 \mathrm{E}-04$ & 1. $193 \mathrm{E}-03$ & $.4 .003 \mathrm{E}-05$ \\
\hline 36 & 61.32 & 748.5 & & $2.472 E-03$ & 1.930E-03 & $5.178 \mathrm{E}-04$ & 3843.2 & 106.3 & 32 & 1.16 & 74.70 & 1,30 & 17.90 & $8.703 E-0.3$ & $1.515 \mathrm{E}-04$ & $2.086 \mathrm{E}-03$ & $.3 .663 \mathrm{E}-04$ \\
\hline 37 & 26.49 & 741.6 & 297.4 & $1.060 \mathrm{E} .03$ & $8.276 \mathrm{E}$ & $2.220 \mathrm{E}-04$ & 813.1 & 106.1 & 316.1 & $1.093 \mathrm{E}-03$ & 0.40 & 20.00 & 64.20 & $4.373 \mathrm{E}-06$ & $2.187 \mathrm{E}-04$ & $7.019 E .04$ & $.3,334 \mathrm{E}-06$ \\
\hline 38 & 44.90 & & & $1.804 \mathrm{E}-03$ & & & 802.2 & 24.9 & 297.9 & & 7.40 & 14.10 & 77.70 & & & & $.1,044 \mathrm{E}-04$ \\
\hline 39 & 46.04 & 752.4 & & $1.869 \mathrm{E}-03$ & $1,459 E-03$ & 3.9151 & 75 & & & & 6.50 & 20.80 & 72.10 & & & & $.2 .066 E .07$ \\
\hline 40 & 46. & & & $93 \mathrm{E}-03$ & $1.478 \mathrm{E}-0.3$ & $3.966 \mathrm{E}-04$ & 805.8 & 25.0 & & 2.007 & 3.00 & 20.10 & 54.40 & 6.0221 & 4.035 & $1.092 E \cdot 0.3$ & $6.940 \mathrm{E} \cdot 06$ \\
\hline 4) & 19 & 75 & 2 & $7.769 \mathrm{E} .04$ & 6.066 & $1.627 \mathrm{E}$ & 742.32 & 2. & 20 & 7.73 & 0.70 & 19.90 & 81.20 & $5.41 .5 \mathrm{E} \cdot 06$ & 1.53 & 6.28 & $.8 .780 \mathrm{E} .06$ \\
\hline 42 & 72.90 & & & $18 \mathrm{E}-0.3$ & & & & & & & 0.10 & 19.70 & 80.00 & $2.912 \mathrm{E} \cdot 06$ & & $\mathrm{E} \cdot 0.3$ & $\begin{array}{r}.3 .754 \mathrm{E}-05 \\
\end{array}$ \\
\hline 43 & 70.24 & 742.4 & 303.0 & $2.761 E .03$ & $2.156 \mathrm{E}-03$ & $5.784 \mathrm{E}-04$ & 730.8 & 23.9 & 296.9 & $2.774 \mathrm{E}-03$ & 0.00 & 20.90 & 79.50 & & $5.798 E-04$ & $2.205 \mathrm{E} .03$ & $1.384 E-06$ \\
\hline 4 & 123.67 & 750.5 & 300.6 & $4.954 \mathrm{E}-03$ & $3.868 \mathrm{E}-03$ & $1.038 \mathrm{E}-03$ & 722.7 & 24. & 297.4 & $4.822 \mathrm{E}-03$ & 0.20 & 18.60 & 82.40 & $9.644 \mathrm{E}-06$ & $8.969 \mathrm{E}-04$ & $3.973 \mathrm{E}-03$ & $\begin{array}{r}-1.408 \mathrm{E}-04 \\
\end{array}$ \\
\hline 45 & 37.51 & 9 & 298.5 & $1.526 \mathrm{E}-03$ & $1.192 \mathrm{E}-03$ & $3.196 \mathrm{E}-04$ & 782.5 & 24.4 & 297.4 & $1.583 E .03$ & 2.30 & 21.00 & 76.80 & $3.642 \mathrm{E} .05$ & $3.325 \mathrm{E} .04$ & $1.216 \mathrm{E}-03$ & $1.289 \mathrm{E} .05$ \\
\hline
\end{tabular}

Test 27 was unsuccessful due to equipment failure. 
Table A1: Test Measurements by Test Number (continued)

\begin{tabular}{|c|c|c|c|c|c|c|c|c|c|c|c|c|c|c|c|c|c|}
\hline Test & $\begin{array}{l}\text { Yolume } \\
\text { (cc) }\end{array}$ & $\begin{array}{l}\text { Initial } \\
\text { Pressure } \\
\text { (torr) }\end{array}$ & $\begin{array}{c}\text { Initial } \\
\text { Temperature } \\
\left({ }^{\prime} K\right)\end{array}$ & $\begin{array}{l}\text { Initial } \\
\text { Total } \\
\text { moles }\end{array}$ & $\begin{array}{c}\text { Estimate } \\
\text { Initial } N_{1} \\
\text { moles }\end{array}$ & $\begin{array}{c}\text { Estimace } \\
\text { Initinl } \mathrm{O}_{2} \\
\text { moles }\end{array}$ & $\begin{array}{c}\text { Final } \\
\text { Pressure } \\
\text { (torr) }\end{array}$ & $\begin{array}{c}\text { Final } \\
\text { Temperature } \\
\text { ("C) }\end{array}$ & $\begin{array}{c}\text { Final } \\
\text { Tempernture } \\
\text { ("K) }\end{array}$ & $\begin{array}{l}\text { Final } \\
\text { Total } \\
\text { moles }\end{array}$ & $\% \mathrm{H}_{2}$ & $\% \mathrm{O}_{2}$ & $\% \mathrm{~N}_{2}$ & $\begin{array}{c}\text { Final } \\
\mathrm{H}_{2} \\
\text { moles }\end{array}$ & $\begin{array}{c}\text { Final } \\
\mathrm{O}_{2} \\
\text { moles }\end{array}$ & $\begin{array}{c}\text { Final } \\
\mathrm{N}_{2} \\
\text { moles. }\end{array}$ & 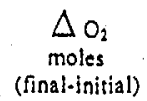 \\
\hline 46 & 38.12 & 763.9 & 298.9 & $1.563 \mathrm{E}-03$ & $1.221 \mathrm{E}-03$ & $3.274 \mathrm{E}-04$ & 788.3 & 23.9 & 296.9 & $1.624 \mathrm{E}-03$ & 1.20 & 21.10 & 62.10 & $1.949 \mathrm{E}-05$ & $3.427 E-04$ & $1.009 \mathrm{E}-03$ & $1.524 \mathrm{E}-05$ \\
\hline $47^{\circ}$ & 18.96 & 749.7 & 297.9 & $7.654 \mathrm{E}-04$ & $5.977 \mathrm{E}-04$ & $1.603 \mathrm{E} \cdot 04$ & 1197.3 & 97 & 370.0 & $9.842 \mathrm{E}-04$ & 3.40 & 7.30 & 81.80 & $3.346 \mathrm{E}-0 \mathrm{~S}$ & $7.185 \mathrm{E}-0 \mathrm{~S}$ & 8.051 E.04 & $-8.847 \mathrm{E}-05$ \\
\hline 48 & 71.59 & 752,4 & 297.7 & $2.903 \mathrm{E}-03$ & $2.267 \mathrm{E}-03$ & $6.081 \mathrm{E}-04$ & 1095.2 & 63.7 & 336.7 & $3.736 \mathrm{E}-03$ & 0.00 & 22.70 & 74.00 & $0.000 \mathrm{E}+\infty$ & $8.480 \mathrm{E} \cdot 04$ & $2.765 \mathrm{E}-03$ & $2.399 \mathrm{E}-04$ \\
\hline 49 & 69.90 & 744.4 & 297.8 & $2.804 \mathrm{E}-03$ & $2.189 \mathrm{E}-03$ & $5.872 \mathrm{E}-04$ & 1092.7 & 60.9 & 3.33 .9 & $3.670 \mathrm{E}-0.3$ & 1.50 & 29.70 & 66.40 & $5.506 \mathrm{E} \cdot 05$ & $1.090 \mathrm{E}-03$ & $2.437 \mathrm{E}-0.3$ & $5.029 \mathrm{E} .04$ \\
\hline so & 122.76 & 748.8 & 298.2 & $4.946 \mathrm{E}-03$ & $3.862 \mathrm{E}-03$ & $1.036 \mathrm{E}-03$ & 736 & 25.4 & 298.4 & $4.858 \mathrm{E}-03$ & 0.40 & 18.90 & 79.20 & $1.943 \mathrm{E}-05$ & $9.182 \mathrm{E}-04$ & $3.848 \mathrm{E}-0.3$ & $-1.178 \mathrm{E} \cdot 04$ \\
\hline 51 & 18.74 & 755.7 & 298.1 & $7.623 \mathrm{E}-04$ & $5.952 \mathrm{E}-04$ & $1.597 \mathrm{E}-04$ & 753.4 & 25.1 & 298.1 & $7.599 \mathrm{E}-04$ & 1.50 & 19.90 & 73.40 & $1.140 \mathrm{E} \cdot 05$ & $1.512 E \cdot 04$ & $5.578 \mathrm{E} .04$ & $.8 .435 \mathrm{E} \cdot 06$ \\
\hline 52 & 45.15 & 762.5 & 298.8 & $1,848 \mathrm{E}-0.3$ & $1.443 \mathrm{E}-0.3$ & $3.872 \mathrm{E}-04$ & 747.9 & 25.4 & 298.4 & $1.815 \mathrm{E} \cdot 03$ & 0.55 & 20.14 & 78.36 & $9.985 \mathrm{E}-06$ & $3.656 \mathrm{E}-04$ & $1.423 \mathrm{E} \cdot 03$ & $-2.154 \mathrm{E}-0.5$ \\
\hline 53 & 18.74 & 754.9 & 297.6 & $7.627 \mathrm{E}-04$ & $5.956 \mathrm{E}-04$ & $1.598 \mathrm{E}-04$ & 872.6 & 63.2 & 338.2 & $7.758 \mathrm{E}-04$ & 1.32 & 13.00 & 85.00 & $1.024 \mathrm{E}-0.5$ & $1.009 \mathrm{E}-04$ & $6.594 \mathrm{E} \cdot 04$ & $.5 .891 \mathrm{E} .05$ \\
\hline 54 & 31.56 & 754.7 & 298.1 & $1.282 \mathrm{E}-03$ & $1.001 \mathrm{E} \cdot 03$ & $2.686 \mathrm{E}-04$ & 775.2 & 42.6 & 315.6 & $1.244 \mathrm{E}-0.3$ & 0.00 & 20.00 & 74,00 & $0.000 \mathrm{E}+\infty$ & $2.488 \mathrm{E} \cdot 04$ & $9.205 \mathrm{E}-04$ & $.1 .977 \mathrm{E} \cdot 05$ \\
\hline ss & 71.49 & 743.3 & 298.4 & $2.857 \mathrm{E}-03$ & $2.231 \mathrm{E}-03$ & $5.985 \mathrm{E}-04$ & 744.9 & 25.1 & 298.1 & $2.866 \mathrm{E}-0.3$ & 0.36 & 19.00 & 84,00 & $1.032 \mathrm{E}-05$ & $5.446 \mathrm{E}-04$ & $2.408 E .03$ & $.5 .389 \mathrm{E} \cdot 0 \mathrm{~S}$ \\
\hline 56 & 37.50 & 759.8 & 298.4 & $1.532 \mathrm{E}-03$ & $1.196 \mathrm{E}-03$ & $3.209 \mathrm{E}-04$ & 774.6 & 24.5 & 297.5 & $1.567 \mathrm{E}-03$ & 0.25 & 20.00 & 84.00 & $3.917 \mathrm{E}-06$ & $3.133 \mathrm{E} \cdot 04$ & $1.316 \mathrm{E}-03$ & $.7 .580 \mathrm{E}-06$ \\
\hline 57 & 18.49 & 774.9 & 298.3 & $7.707 \mathrm{E}-04$ & $6.018 \mathrm{E}-04$ & $1.614 \mathrm{E}-04$ & 1048.9 & 27.6 & 300.6 & $1.035 \mathrm{E}-0.3$ & 1.80 & $10: 10$ & 81.50 & $1.863 \mathrm{E} \cdot 0.5$ & $1.046 \mathrm{E} .04$ & $8.437 \mathrm{E}-04$ & $-5.687 \mathrm{E} .05$ \\
\hline 58 & 31.27 & 750.0 & 298.8 & $1.259 \mathrm{E}-03$ & $9.83 \mathrm{E}-04$ & 2.64E-04 & 750.3 & 26.3 & 299.3 & $1.258 \mathrm{E} \cdot 0.3$ & 0.00 & 20.50 & 78.10 & $0.000 \mathrm{E}+\infty 0$ & $2.58 \mathrm{E}-04$ & $9.82 \mathrm{E} \cdot 04$ & $-5.945 \mathrm{E}-06$ \\
\hline 59 & 59.55 & 742.4 & 298.2 & $2.379 \mathrm{E}-0.3$ & $1.857 \mathrm{E} \cdot 03$ & $4.983 \mathrm{E}-04$ & 1019 & 49.6 & 322.6 & $3.018 \mathrm{E}-03$ & 0.70 & 16.20 & 81.60 & $2.113 \mathrm{E} \cdot 0 \mathrm{~S}$ & $4.890 \mathrm{E}-04$ & $2.463 \mathrm{E}-03$ & $-9.281 \mathrm{E} \cdot 06$ \\
\hline
\end{tabular}


Table A2: Description of 9975 Test by Test Number ${ }^{5}$

\begin{tabular}{|c|c|c|c|c|c|c|c|c|c|c|c|c|c|c|c|c|}
\hline $\begin{array}{c}\text { Run } \\
\# \\
\end{array}$ & $\begin{array}{c}\text { Description } \\
\text { 2/20/99 Start - - Set } 1 \\
\end{array}$ & $\begin{array}{l}\text { Time } \\
\text { (days) } \\
\end{array}$ & $\begin{array}{c}\text { Container } \\
\text { Volume }\end{array}$ & $\begin{array}{l}\text { Grams } \\
\mathrm{PuO}_{2}\end{array}$ & $\begin{array}{c}\text { Buik } \\
\text { Weight(g) } \\
\end{array}$ & $\begin{array}{l}\text { Mensured } \\
\text { Yolume }\end{array}$ & $\begin{array}{l}\text { Temp } \\
\text { ("C) }\end{array}$ & $\begin{array}{c}\text { Run } \\
\#\end{array}$ & $\begin{array}{c}\text { Sample \# } \\
\text { 2/2009 Start.-. Set } 1\end{array}$ & $\begin{array}{c}\mathrm{H}_{2} \\
(\mathrm{vol} \%) \\
\end{array}$ & $\begin{array}{c}\mathrm{O}_{2} \\
(\mathrm{vol} \%)\end{array}$ & $\begin{array}{c}\mathrm{N}_{2} \\
(\text { vol\% } \%)\end{array}$ & $\begin{array}{c}\mathrm{CO}_{2} \\
(\mathrm{VO} 1 \%) \\
\end{array}$ & $\begin{array}{c}\mathrm{N}_{2} \mathrm{O} \\
(\mathrm{VO}) \%) \\
\end{array}$ & $\begin{array}{c}c 0 \\
(\mathrm{vol} \%)\end{array}$ & $\begin{array}{l}\text { sum } \\
\text { (vol\%) }\end{array}$ \\
\hline $\begin{array}{l}1 \\
2 \\
3 \\
4 \\
5 \\
6\end{array}$ & 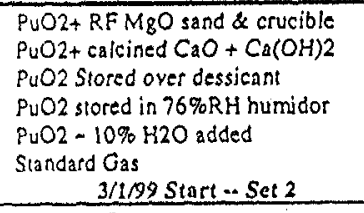 & $\begin{array}{l}8.83 \\
8.92 \\
9.65 \\
9.71 \\
6.66 \\
3.73\end{array}$ & $\begin{array}{l}25 \mathrm{cc} \\
50 \mathrm{cc} \\
5 \mathrm{cc} \\
5 \mathrm{cc} \\
5 \mathrm{cc} \\
50 c c\end{array}$ & $\begin{array}{l}9.59 \\
8.85 \\
7.65 \\
8.54 \\
7.57 \\
0.00\end{array}$ & $\begin{array}{l}37.83 \\
35.80 \\
7.65 \\
8.54 \\
7.57 \\
0.00\end{array}$ & $\begin{array}{l}34.11 \\
63.86 \\
30.50 \\
30.90 \\
29.81 \\
62.33\end{array}$ & $\begin{array}{l}\text { nmbient } \\
\text { ambient } \\
\text { ambient } \\
\text { ambient } \\
\text { ambient } \\
\text { ambient }\end{array}$ & $\begin{array}{l}1 \\
2 \\
3 \\
4 \\
5 \\
6\end{array}$ & $\begin{array}{c}3-123637 \\
3-123636 \\
3-123635 \\
3 \cdot 123634 \\
3 \cdot 123633 \\
3-123638 \\
31199 \text { Start -. Set 2 } \\
\end{array}$ & $\begin{array}{c}0.55 \\
0.00 \\
0.00 \\
0.00 \\
10.80 \\
4.20\end{array}$ & $\begin{array}{l}18.8 \\
17.9 \\
21.1 \\
20.1 \\
22.8 \\
3.9\end{array}$ & $\begin{array}{r}84 \\
84.5 \\
82.3 \\
82.5 \\
61.7 \\
81.6\end{array}$ & $\begin{array}{l}0 \\
0 \\
0.05 \\
0.16 \\
0.1 \\
1.8\end{array}$ & $\begin{array}{l}0 \\
0 \\
0 \\
0 \\
0 \\
0.5\end{array}$ & $\begin{array}{c}0 \\
0 \\
0 \\
0 \\
0 \\
1.2\end{array}$ & $\begin{array}{l}103.35 \\
102.40 \\
103.45 \\
102.78 \\
95.40 \\
93.20 \\
0.00 \\
\end{array}$ \\
\hline $\begin{array}{l}7 \\
8 \\
9 \\
10 \\
11 \\
12\end{array}$ &  & $\begin{array}{l}6.31 \\
6.14 \\
6.83 \\
5.75 \\
6.12 \\
6.82\end{array}$ & $\begin{array}{l}50 c c \\
50 c c \\
50 c c \\
25 c c \\
25 c c \\
5 c c\end{array}$ & $\begin{array}{l}0.00 \\
7.73 \\
9.83 \\
7.90 \\
9.32 \\
9.52\end{array}$ & $\begin{array}{l}0.00 \\
31.30 \\
39.85 \\
15.80 \\
36.76 \\
9.52\end{array}$ & $\begin{array}{l}49.71 \\
64.10 \\
62.91 \\
43.46 \\
38.51 \\
30.72\end{array}$ & $\begin{array}{c}90 \\
\text { ambient } \\
\text { ambient } \\
\text { ambient } \\
\text { ambient } \\
\text { nmbient }\end{array}$ & $\begin{array}{c}7 \\
8 \\
9 \\
10 \\
11 \\
12\end{array}$ & 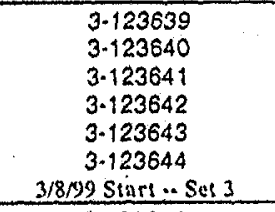 & $\begin{array}{l}3.70 \\
0.05 \\
0.08 \\
0.62 \\
0.26 \\
0.54\end{array}$ & $\begin{array}{c}3.6 \\
19.6 \\
20.2 \\
20.2 \\
19.7 \\
20\end{array}$ & $\begin{array}{c}87 \\
86 \\
85.1 \\
83.8 \\
88.9 \\
84.8\end{array}$ & $\begin{array}{l}N R \\
0.1 \\
0.09 \\
0.06 \\
0.05 \\
0.12\end{array}$ & $\begin{array}{c}\text { NR } \\
0 \\
0.02 \\
0 \\
0.04 \\
0.12\end{array}$ & $\begin{array}{c}4.08 \\
0 \\
0 \\
0 \\
4.28 \\
0\end{array}$ & $\begin{array}{l}98.36 \\
105.75 \\
105.49 \\
104.68 \\
112.43 \\
105.58\end{array}$ \\
\hline $\begin{array}{l}13 \\
14 \\
15 \\
16 \\
17 \\
18\end{array}$ & $\begin{array}{l}44 \mathrm{~g} \text { of RF SS\&C sample } 46 \\
\text { H9 heated } \\
\text { A8 heated } \\
\text { puO2 stored at } 100 \% \text { RH + Heat } \\
\text { Pu Cake (no added moisture) } \\
\text { \#5 mixed with } 2 \mathrm{~g} \text { Ca metal } \\
\text { 3/17999 Start- Sct } 4 \\
\end{array}$ & $\begin{array}{l}7.88 \\
7.88 \\
8.16 \\
7.77 \\
7.61 \\
7.56\end{array}$ & $\begin{array}{l}50 c c \\
50 c c \\
50 c c \\
5 e c \\
25 c c \\
5 c c\end{array}$ & $\begin{array}{c}15.50 \\
9.83 \\
7.73 \\
7.26 \\
32.01 \\
4.88\end{array}$ & $\begin{array}{c}43.84 \\
39.85 \\
31.30 \\
7.26 \\
35.66 \\
6.93\end{array}$ & $\begin{array}{l}51.66 \\
64.37 \\
65.63 \\
30.78 \\
42.04 \\
30.34\end{array}$ & $\begin{array}{c}\text { ambient } \\
90 \\
90 \\
90 \\
\text { ambient } \\
\text { ambien }\end{array}$ & $\begin{array}{l}13 \\
14 \\
15 \\
16 \\
17 \\
18\end{array}$ & $\begin{array}{c}3.123645 \\
3.123646 \\
3.123647 \\
3.123648 \\
3.123649 \\
3.123650 \\
3 / 17999 \text { Starin Set } 4 \\
\end{array}$ & $\begin{array}{c}6.19 \\
0.89 \\
0.00 \\
0.22 \\
1.64 \\
24.15\end{array}$ & $\begin{array}{c}3.1 \\
16.7 \\
11.7 \\
15.5 \\
20.6 \\
15.5\end{array}$ & $\begin{array}{l}90.8 \\
80 \\
82.6 \\
78.2 \\
79.6 \\
53.1\end{array}$ & $\begin{array}{c}0.03 \\
5.2 \\
0 \\
0.48 \\
0.06 \\
0.03\end{array}$ & $\begin{array}{c}1.6 \\
0.25 \\
0 \\
0.04 \\
0.05 \\
0\end{array}$ & $\begin{array}{l}0 \\
0 \\
0 \\
0 \\
0 \\
0\end{array}$ & $\begin{array}{c}101.72 \\
103.04 \\
94.30 \\
94.44 \\
101.95 \\
92.78 \\
0.00 \\
\end{array}$ \\
\hline $\begin{array}{l}19 \\
20 \\
21 \\
22 \\
23 \\
24\end{array}$ & $\begin{array}{l}\text { CaF2 at } R T \text { repeat } \# 14 \text { and } \# 9 \\
\# 13 \text { heated } \\
\# 10 \text { heared } \\
\text { PuO2+MgO } 1: 1 \text { ratio } \\
\# 11 \text { heated } \\
\text { PuO2 }+\mathrm{Mg}(\mathrm{OH}) 2 \\
3 / 2602 \text { Start- Set } 5\end{array}$ & $\begin{array}{l}6.8 \\
6.8 \\
6.81 \\
6.81 \\
6.78 \\
6.79\end{array}$ & $\begin{array}{l}50 c c \\
50 c c \\
10 c c \\
25 c c \\
10 c c \\
25 c c\end{array}$ & $\begin{array}{l}9.83 \\
15.50 \\
7.50 \\
9.73 \\
4.66 \\
7.26\end{array}$ & $\begin{array}{l}39.85 \\
43.84 \\
15.00 \\
19.45 \\
20.00 \\
17.26\end{array}$ & $\begin{array}{l}52.40 \\
53.82 \\
25.98 \\
43.03 \\
31.95 \\
43.83\end{array}$ & $\begin{array}{l}\text { ambient } \\
90 \\
90 \\
\text { anbient } \\
90 \\
\text { ambient }\end{array}$ & $\begin{array}{l}19 \\
20 \\
21 \\
22 \\
23 \\
24\end{array}$ & $\begin{array}{r}3 \cdot 123651 \\
3 \cdot 123652 \\
3 \cdot 123653 \\
3 \cdot 123654 \\
3 \cdot 123655 \\
3 \cdot 123656 \\
3 / 26199 \text { Star1 }- \text { SRI } 5 \\
\end{array}$ & $\begin{array}{l}0.00 \\
80.00 \\
2.60 \\
0.13 \\
1.60 \\
5.00\end{array}$ & $\begin{array}{c}18.2 \\
0 \\
6 \\
15.4 \\
11.9 \\
19.7\end{array}$ & $\begin{array}{l}83.8 \\
23.6 \\
95.6 \\
86.3 \\
88.6 \\
76.6\end{array}$ & $\begin{array}{l}0.37 \\
0 \\
0.16 \\
0.09 \\
0.22 \\
0.03\end{array}$ & $\begin{array}{c}0.08 \\
0 \\
0.2 \\
0.11 \\
0.17 \\
0.09\end{array}$ & $\begin{array}{l}0 \\
0 \\
0 \\
0 \\
0 \\
0\end{array}$ & $\begin{array}{c}102.45 \\
103.60 \\
104.56 \\
102.03 \\
102.49 \\
101.42 \\
0.00 \\
\end{array}$ \\
\hline $\begin{array}{l}25 \\
26\end{array}$ & $\begin{array}{l}\mathrm{PuO2}+\mathrm{MgO} \text { with } 10 \text { water } \\
\mathrm{PuO2}+\mathrm{MgO} \text { with med water } \\
4 / 699 \text { Start.- Set } 6\end{array}$ & $\begin{array}{c}10.11 \\
9.74\end{array}$ & $\begin{array}{l}10 \mathrm{cc} \\
10 \mathrm{cc}\end{array}$ & $\begin{array}{l}6.60 \\
6.24\end{array}$ & $\begin{array}{l}25.00 \\
23.43\end{array}$ & $\begin{array}{l}14.43 \\
25.67\end{array}$ & $\begin{array}{l}90 \\
90\end{array}$ & $\begin{array}{l}25 \\
26\end{array}$ & $\begin{array}{c}3.123658 \\
3.123659 \\
4 / 6 / 99 \text { Start. }- \text { Set } 6 \\
\end{array}$ & $\begin{array}{l}2.17 \\
1.19\end{array}$ & $\begin{array}{l}12.6 \\
16.2\end{array}$ & $\begin{array}{l}82.7 \\
79.4\end{array}$ & $\begin{array}{l}<.1 \\
<.1\end{array}$ & $\begin{array}{l}<.1 \\
<.1\end{array}$ & $\begin{array}{l}<.1 \\
<.1\end{array}$ & $\begin{array}{l}97.47 \\
96.79\end{array}$ \\
\hline $\begin{array}{l}30 \\
31 \\
32 \\
33 \\
34\end{array}$ & $\begin{array}{l}\text { RFETS } \mathrm{H2} \\
\text { PUO2+MgO w/ hi walestheat } \\
\text { RFETS H7 } \\
\text { A } 18 \text { repeaced } \\
\text { RFETS } 48 \\
\quad 4 / 1699 \text { Stan } . . \text { Set } 7 \\
\end{array}$ & $\begin{array}{l}7.69 \\
8.83 \\
7.71 \\
7.71 \\
7.69\end{array}$ & $\begin{array}{l}50 c c \\
10 c c \\
100 c c \\
10 c c \\
10 c c\end{array}$ & $\begin{array}{l}8.18 \\
\text { \#REF! } \\
6.77 \\
4.65 \\
8.49\end{array}$ & $\begin{array}{l}43.10 \\
23.09 \\
14.60 \\
6.60 \\
10.80\end{array}$ & $\begin{array}{l}63.26 \\
26.22 \\
91.65 \\
38.54 \\
38.98\end{array}$ & $\begin{array}{l}\text { ambient } \\
90 c \\
\text { ambient } \\
\text { ambient } \\
\text { ambient }\end{array}$ & $\begin{array}{l}30 \\
31 \\
32 \\
33 \\
34\end{array}$ & $\begin{array}{c}3.125514 \\
3.125515 \\
3.125516 \\
3.125517 \\
3.125518 \\
4 / 16199 \text { Start .. Set? } \\
\end{array}$ & $\begin{array}{l}1.27 \\
0.03 \\
8.13 \\
1.6 \\
0.2\end{array}$ & $\begin{array}{l}16.5 \\
20.5 \\
12.9 \\
20.2 \\
20.2\end{array}$ & $\begin{array}{c}75.8 \\
76 \\
78.5 \\
78.4 \\
76.9\end{array}$ & $\begin{array}{l}<.1 \\
<.1 \\
<.1 \\
<.1 \\
<.1\end{array}$ & $\begin{array}{l}<.1 \\
<.1 \\
<.1 \\
<.1 \\
<.1\end{array}$ & $\begin{array}{l}<.1 \\
<.1 \\
<.1 \\
<.1 \\
<.1\end{array}$ & $\begin{array}{l}93.57 \\
96.53 \\
99.53 \\
98.20 \\
97.30\end{array}$ \\
\hline $\begin{array}{l}36 \\
37 \\
38\end{array}$ & $\begin{array}{l}\text { RFETS Sample H2 } \\
\text { \#31 repeared } \\
\text { PuO2 }+5 \% \mathrm{H}_{2} \mathrm{O} \\
4 / 23 / 99 \text { Start } \ldots \text { Set } 8 \\
\end{array}$ & $\begin{array}{l}5.61 \\
5.66 \\
5.69\end{array}$ & $\begin{array}{l}50 c c \\
10 c c \\
25 c c\end{array}$ & $\begin{array}{l}8.18 \\
6.15 \\
9.66\end{array}$ & $\begin{array}{l}43.10 \\
23.09 \\
10.29\end{array}$ & $\begin{array}{l}61,32 \\
26,49 \\
44.90\end{array}$ & $\begin{array}{c}90 \\
90 \\
\text { ambient }\end{array}$ & $\begin{array}{l}36 \\
37 \\
38\end{array}$ & $\begin{array}{r}3.125520 \\
3.125521 \\
3 \cdot 125522 \\
4 / 23 / 99 \text { Start +. Set } 8 \\
\end{array}$ & $\begin{array}{l}74.70 \\
0.40 \\
7.40\end{array}$ & $\begin{array}{c}1.3 \\
20 \\
14.1\end{array}$ & $\begin{array}{l}17.9 \\
64.2 \\
77.7\end{array}$ & $\begin{array}{l}0.02 \\
0.03 \\
0.08\end{array}$ & $\begin{array}{l}3.1 \\
0.02 \\
0.04\end{array}$ & $\begin{array}{l}<.1 \\
<.1 \\
<.1\end{array}$ & $\begin{array}{l}93.92 \\
84.65 \\
99.32\end{array}$ \\
\hline $\begin{array}{l}41 \\
44 \\
45 \\
46\end{array}$ & $\begin{array}{l}\text { PuO2+100\% RH - 2weeks } \\
\text { PuCake no treatment like } \# 17 \\
\text { PuO2 + } 2.5 \% \text { water } \\
\text { PuO2 } 2.5 \% \text { water }\end{array}$ & $\begin{array}{l}5.6 \\
5.77 \\
5.77 \\
5.84\end{array}$ & $\begin{array}{l}10 c c \\
100 c c \\
10 c c \\
10 c c\end{array}$ & $\begin{array}{l}10.08 \\
27.65 \\
12.17 \\
9.83\end{array}$ & $\begin{array}{l}10.08 \\
30.80 \\
12.50 \\
10.32\end{array}$ & $\begin{array}{l}19.25 \\
123.57 \\
37.51 \\
38.12\end{array}$ & $\begin{array}{l}\text { ambient } \\
\text { ambient } \\
\text { ambient } \\
\text { ambient }\end{array}$ & $\begin{array}{l}41 \\
44 \\
45 \\
46\end{array}$ & $\begin{array}{l}3 \cdot 125525 \\
3-125528 \\
3 \cdot 125529 \\
3 \cdot 125530\end{array}$ & $\begin{array}{l}0.7 \\
0.2 \\
2.3 \\
1.2\end{array}$ & $\begin{array}{c}19.9 \\
18.6 \\
21 \\
21.1\end{array}$ & $\begin{array}{l}81.2 \\
82.4 \\
76.8 \\
62.1\end{array}$ & $\begin{array}{l}N R \\
0.32 \\
<0.1 \\
<0.1\end{array}$ & $\begin{array}{l}\text { NR } \\
<0.1 \\
<0.1 \\
<0.1\end{array}$ & $\begin{array}{l}<0.1 \\
<0.1 \\
<0.1 \\
<0.1\end{array}$ & $\begin{array}{l}101.80 \\
101.52 \\
100.10 \\
.84 .40\end{array}$ \\
\hline
\end{tabular}

Samples $28,29,35,40,42,43,48$ and 49 contained materials that do not conform to the content description of SS\&C residues. 
Table A2: Descriptions of Tests by Test Number (continued)

\begin{tabular}{|c|c|c|c|c|c|c|c|c|c|c|c|c|c|c|c|c|}
\hline Run & $\begin{array}{c}\text { Description } \\
2120199 \text { Start } \ldots \text { Set } 1\end{array}$ & $\begin{array}{c}\text { Time } \\
\text { (days) }\end{array}$ & $\begin{array}{l}\text { Contalner } \\
\text { Volume }\end{array}$ & $\begin{array}{l}\text { Grams } \\
\mathrm{PuO}_{3}\end{array}$ & $\begin{array}{c}\text { Bulk } \\
\text { Welght(g) }\end{array}$ & $\begin{array}{l}\text { Measured } \\
\text { Yolume } \\
\end{array}$ & $\begin{array}{l}\text { Temp } \\
\left({ }^{\circ} \mathrm{C}\right)\end{array}$ & $\begin{array}{c}\text { Run } \\
\#\end{array}$ & $\begin{array}{c}\text { Sample } \\
\text { 2/20/99 Start - - Set } 1\end{array}$ & $\begin{array}{c}M_{2} \\
\langle\text { vol\% }\end{array}$ & $\begin{array}{c}\mathrm{O}_{2} \\
(\mathrm{vol} \%)\end{array}$ & $\begin{array}{c}\mathrm{N}_{2} \\
(\mathrm{vol} \%)\end{array}$ & $\begin{array}{l}\mathrm{CO}_{2} \\
(\mathrm{vol} \%)\end{array}$ & $\begin{array}{l}\mathrm{N}_{2} \mathrm{O} \\
(\mathrm{VO} O \%)\end{array}$ & $\begin{array}{c}\text { Co } \\
(\text { vol\% })\end{array}$ & $\begin{array}{c}\text { sum } \\
\text { (vol\%) }\end{array}$ \\
\hline $\begin{array}{l}47 \\
50 \\
51 \\
52\end{array}$ & $\begin{array}{l}\text { PuO2+2.5\%H2O+Heat } \\
\text { PuCake- replicatel } \\
\text { HAl repeated } \\
\text { PuCake - replicate } 12 \\
5 / 2809 \text { Start - Set } 10\end{array}$ & $\begin{array}{l}6.77 \\
6.76 \\
6.76 \\
6.77\end{array}$ & $\begin{array}{l}10 c c \\
100 c c \\
10 c c \\
25 c c\end{array}$ & $\begin{array}{l}12.17 \\
27.34 \\
10.08 \\
14.98\end{array}$ & $\begin{array}{l}12.50 \\
30.46 \\
10.08 \\
16.69\end{array}$ & $\begin{array}{c}18.96 \\
122.76 \\
37.11 \\
45.15\end{array}$ & $\begin{array}{l}90 \\
\text { ambient } \\
\text { ambient } \\
\text { ambient }\end{array}$ & $\begin{array}{l}47 \\
50 \\
51 \\
52\end{array}$ & $\begin{array}{c}3.125531 \\
3.125534 \\
3.125535 \\
3.125536 \\
\text { 5/1809 Stant - Set 10 } \\
\end{array}$ & $\begin{array}{l}3.4 \\
0.4 \\
1.5 \\
0.55\end{array}$ & $\begin{array}{c}7.3 \\
18.9 \\
19.9 \\
20.14\end{array}$ & $\begin{array}{l}81.8 \\
79.2 \\
73.4 \\
78.36\end{array}$ & $\begin{array}{l}<0.1 \\
<0.1 \\
<0.1 \\
<0.1\end{array}$ & $\begin{array}{l}<0.1 \\
<0.1 \\
<0.1 \\
0.05\end{array}$ & $\begin{array}{l}<0.1 \\
<0.1 \\
<0.1 \\
<0.1\end{array}$ & $\begin{array}{l}92.50 \\
98.50 \\
94.80 \\
99.10\end{array}$ \\
\hline $\begin{array}{l}53 \\
54 \\
53 \\
36\end{array}$ & 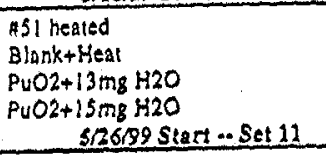 & $\begin{array}{l}7.95 \\
7.95 \\
7.95 \\
7.95\end{array}$ & $\begin{array}{l}10 c c \\
10 c c \\
50 c c \\
10 c c\end{array}$ & $\begin{array}{l}10.08 \\
0.00 \\
12.57 \\
10.42\end{array}$ & $\begin{array}{l}10.08 \\
0.00 \\
12.70 \\
10.57\end{array}$ & $\begin{array}{l}18.74 \\
31.56 \\
71.49 \\
37.50\end{array}$ & $\begin{array}{c}90 \\
90 \\
\text { ambient } \\
\text { ambient }\end{array}$ & $\begin{array}{l}53 \\
54 \\
55 \\
56\end{array}$ & $\begin{array}{c}3-127169 \\
3.127170 \\
3.127171 \\
3.127172 \\
\text { s/26199 Start +. Sel 11 } \\
\end{array}$ & $\begin{array}{c}1.32 \\
0 \\
0.36 \\
0.25\end{array}$ & $\begin{array}{l}13 \\
20 \\
19 \\
20\end{array}$ & $\begin{array}{l}85 \\
74 \\
84 \\
84\end{array}$ & $\begin{array}{l}<0.1 \\
<0.1 \\
<0.1 \\
<0.9\end{array}$ & $\begin{array}{l}<0.1 \\
<0.1 \\
<0.1 \\
<0.1\end{array}$ & $\begin{array}{l}<0.1 \\
<0.1 \\
<0.1 \\
<0.1\end{array}$ & $\begin{array}{c}99.32 \\
94.00 \\
103.36 \\
104.25\end{array}$ \\
\hline $\begin{array}{l}57 \\
58 \\
50\end{array}$ & PuO2+15mg H2O & 7.75 & $\begin{array}{l}10 \mathrm{cc} \\
10 \mathrm{cc}\end{array}$ & $\begin{array}{l}10.42 \\
0.00 \\
1.52\end{array}$ & $\begin{array}{l}10.57 \\
0.00 \\
12.70\end{array}$ & $\begin{array}{l}18.49 \\
31.27 \\
59.55\end{array}$ & $\begin{array}{c}90 \\
\text { ambient } \\
90\end{array}$ & $\begin{array}{l}57 \\
58 \\
59\end{array}$ & $\begin{array}{l}3+127173 \\
3 \cdot 127174 \\
3+127175\end{array}$ & $\begin{array}{c}1.8 \\
0 \\
0.7\end{array}$ & $\begin{array}{l}10.1 \\
20.5 \\
16.2\end{array}$ & $\begin{array}{l}81.5 \\
78.1 \\
81.6\end{array}$ & $\begin{array}{l}<0.1 \\
<0.1 \\
2.8\end{array}$ & $\begin{array}{l}<0.1 \\
<0.1 \\
0.31\end{array}$ & $\begin{array}{l}<0.1 \\
<0.1 \\
<0.1\end{array}$ & $\begin{array}{c}93.40 \\
98.60 \\
101.61\end{array}$ \\
\hline
\end{tabular}




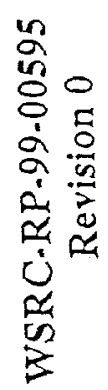

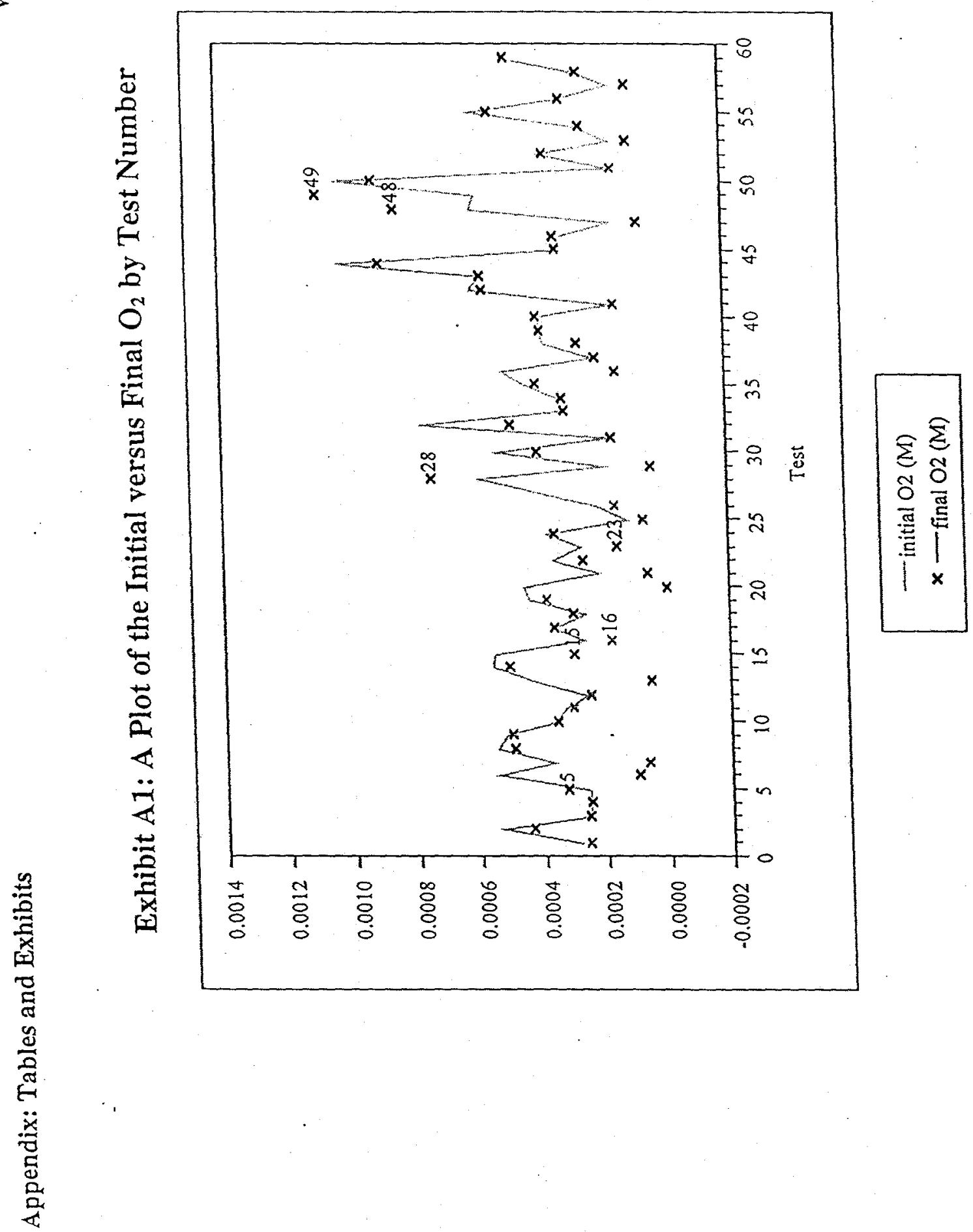

苗

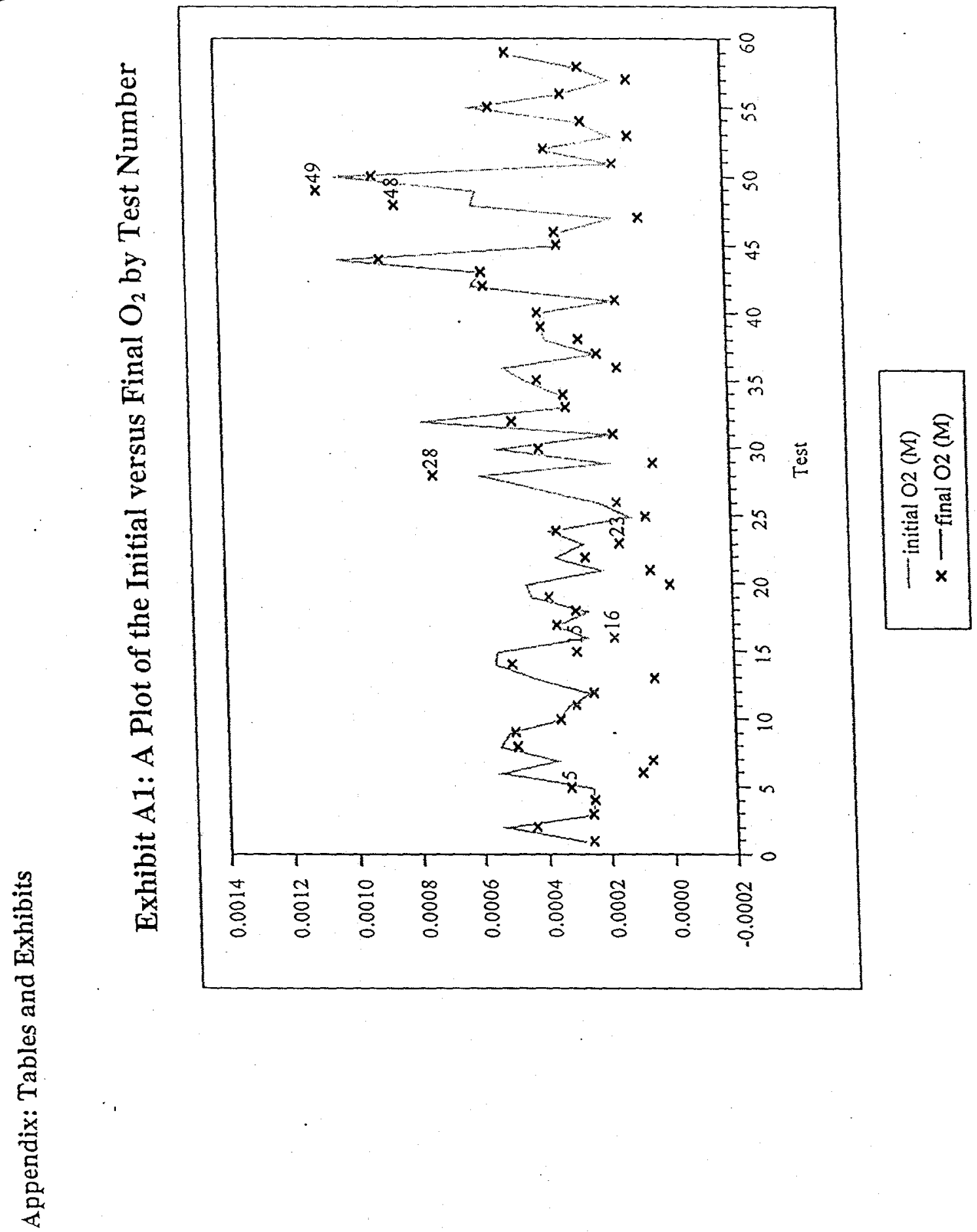




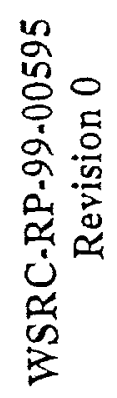



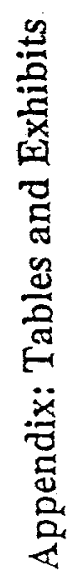


Exhibit A3: A Plot of the Change in $\mathrm{O}_{2}\left(\right.$ Delta $\left.\mathrm{O}_{2}\right)$ by Type Group

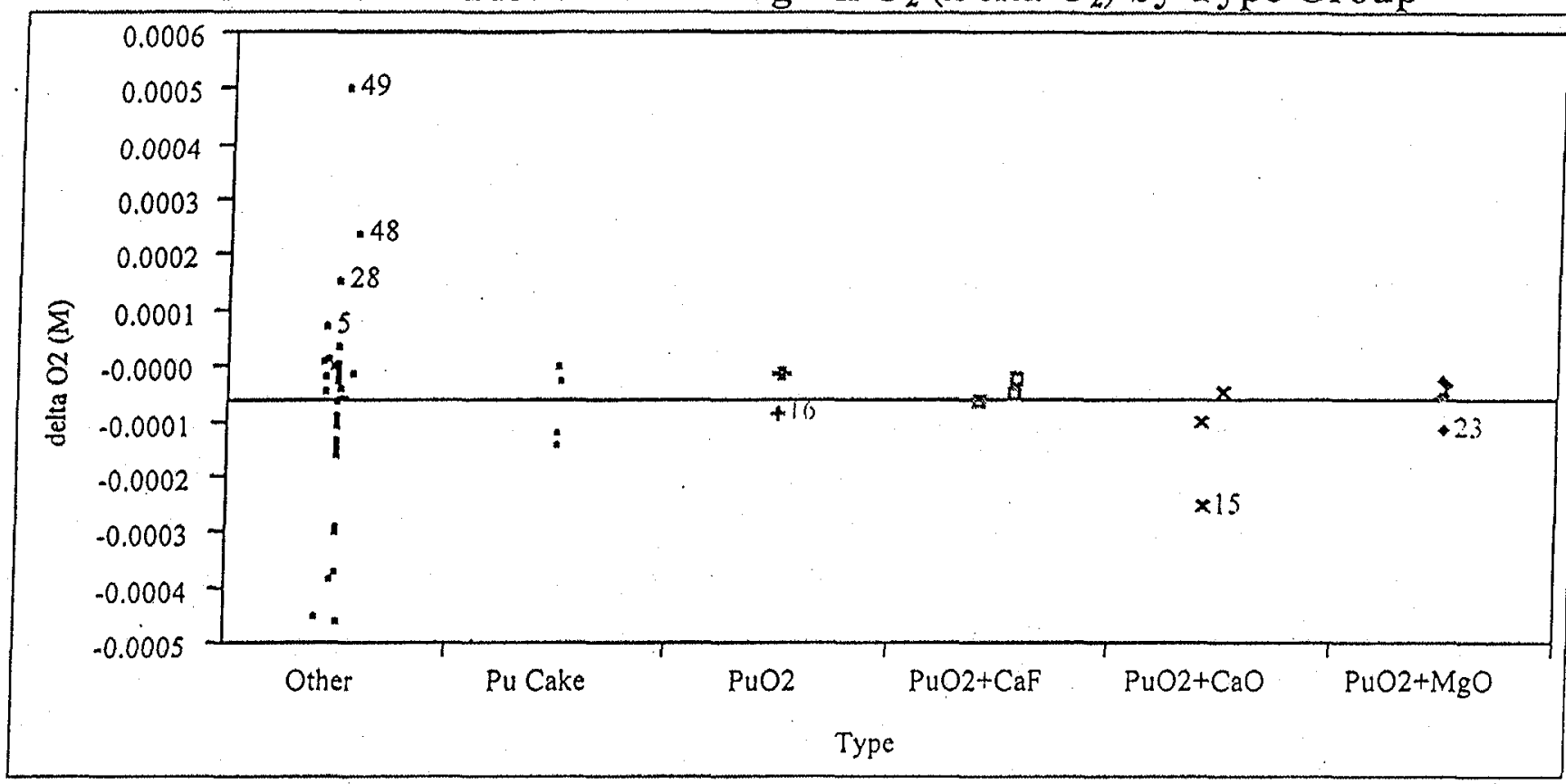

Means and Std Deviations

\begin{tabular}{lrrrrrr} 
& & & & \multicolumn{2}{c}{ Excluding Heated Tests } \\
Level & Number & Mean & Std Dev & Number & Mean & Std Der \\
Other & 39 & -0.00006 & 0.000176 & & & \\
Pu Cake & 4 & -0.00007 & 0.000071 & 3 & -0.00001 & 0.000002 \\
PuO2 & 4 & -0.00003 & 0.000036 & 2 & -0.00007 & 0.000039 \\
PuO2 $+\mathrm{CaO}$ & 3 & -0.00013 & 0.000107 & & \\
PuO2 $+\mathrm{CaF}$ & 3 & -0.00004 & 0.000022 & 4 & -0.00004 & 0.000015 \\
PuO2+MgO & 5 & -0.00005 & 0.000035 & 4
\end{tabular}


Exhibit A4: A Plot of the Change in $\mathrm{O}_{2}\left(\right.$ Delta $\left.\mathrm{O}_{2}\right)$ by Headspace Volume (cc)

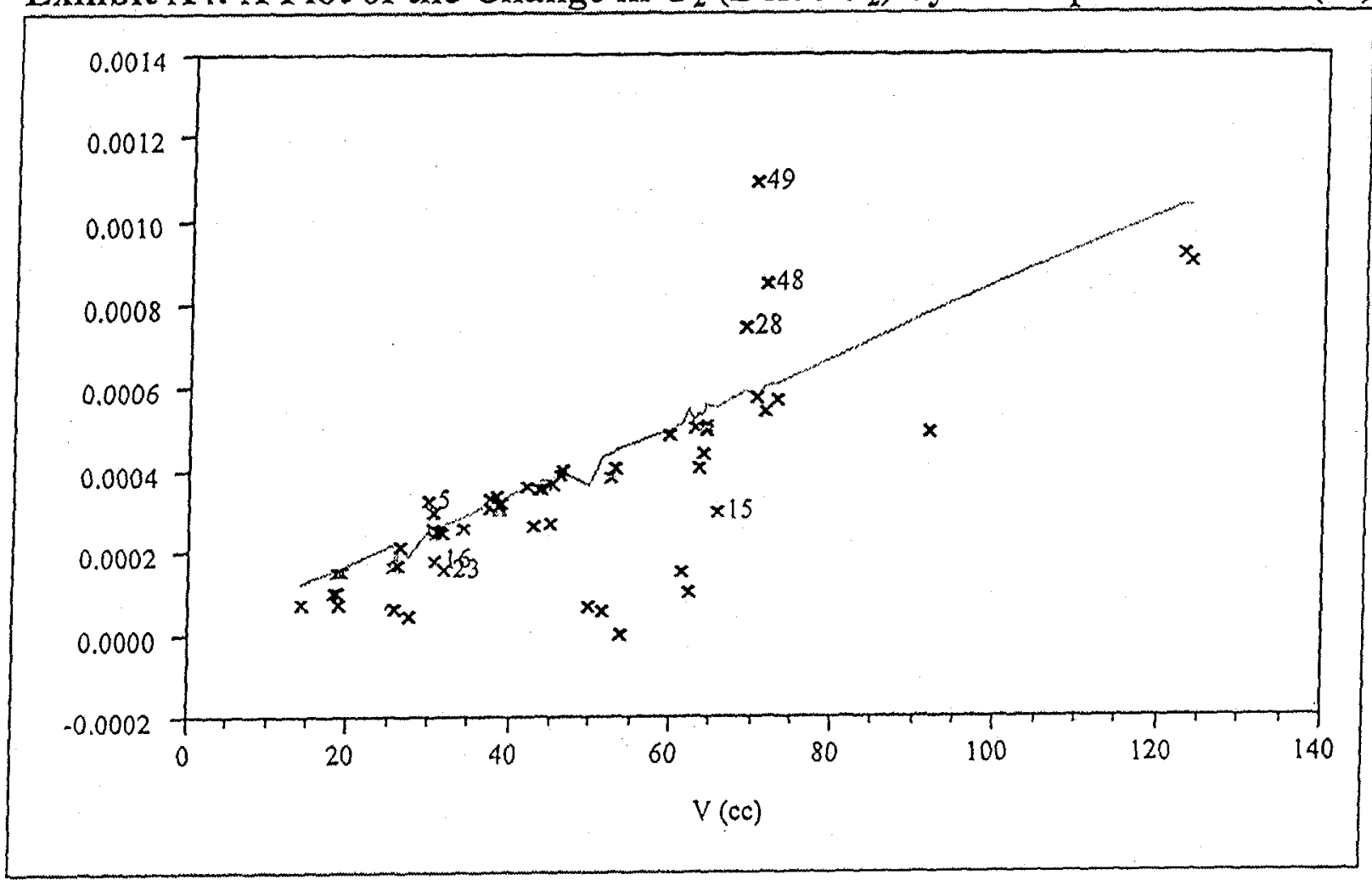

Symbols are shaded to designate the categories of Table 1 (i.e., they are shaded as in Exhibit A3). 
Exhibit A5: A Plot of the Change in $\mathrm{O}_{2}\left(\right.$ Delta $\left.\mathrm{O}_{2}\right)$ by Total Sample Volume Percent

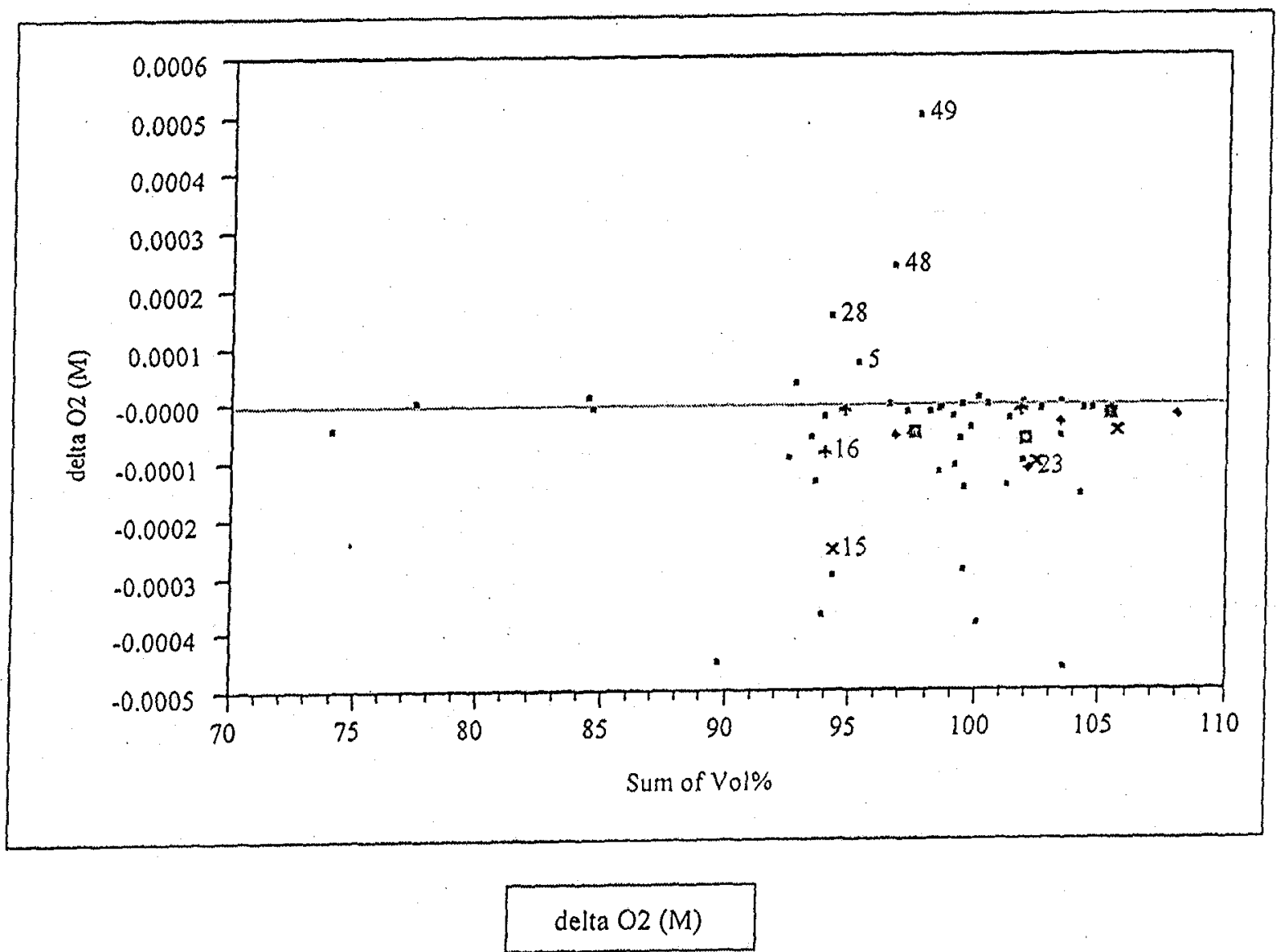

Symbols are shaded to designate the categories of Table 1 (i.e., they are shaded as in Exhibit A3). 
Exhibit A6: A Plot of the Change in $\mathrm{O}_{2}\left(\right.$ Delta $\left.\mathrm{O}_{2}\right)$ by Test Number with Bounding Uncertainties

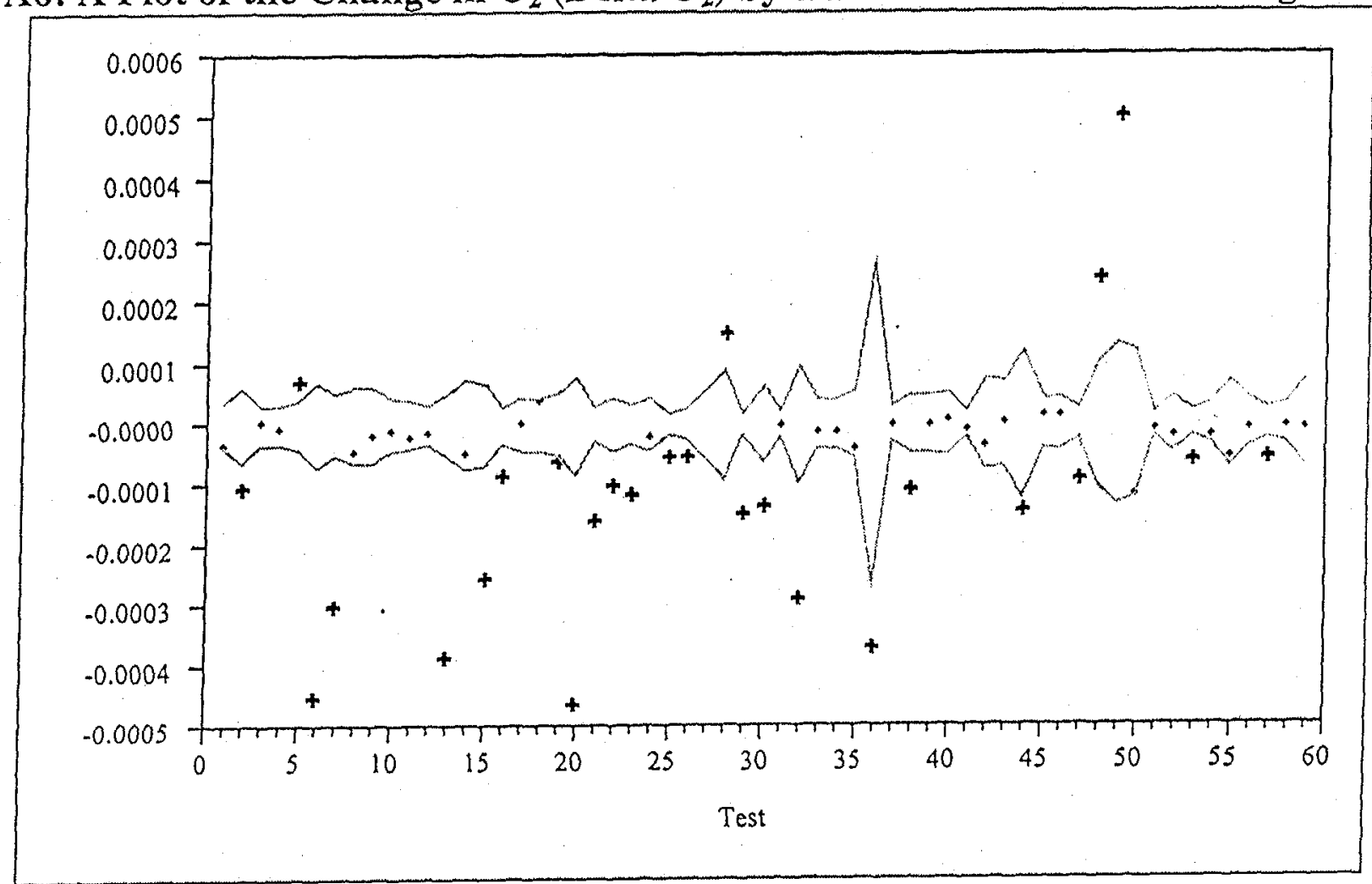

$+-r$

Lower Uncertainty Limit

Upper Uncertainty Limit

Bold symbols are used to designate statistically significant (at the $95 \%$ confidence level) test results. 
Exhibit A7: A Plot of the Change in $\mathrm{O}_{2}$ (Delta $\mathrm{O}_{2}$ ) by Test Number with Bounding Uncertainties for Representative Tests

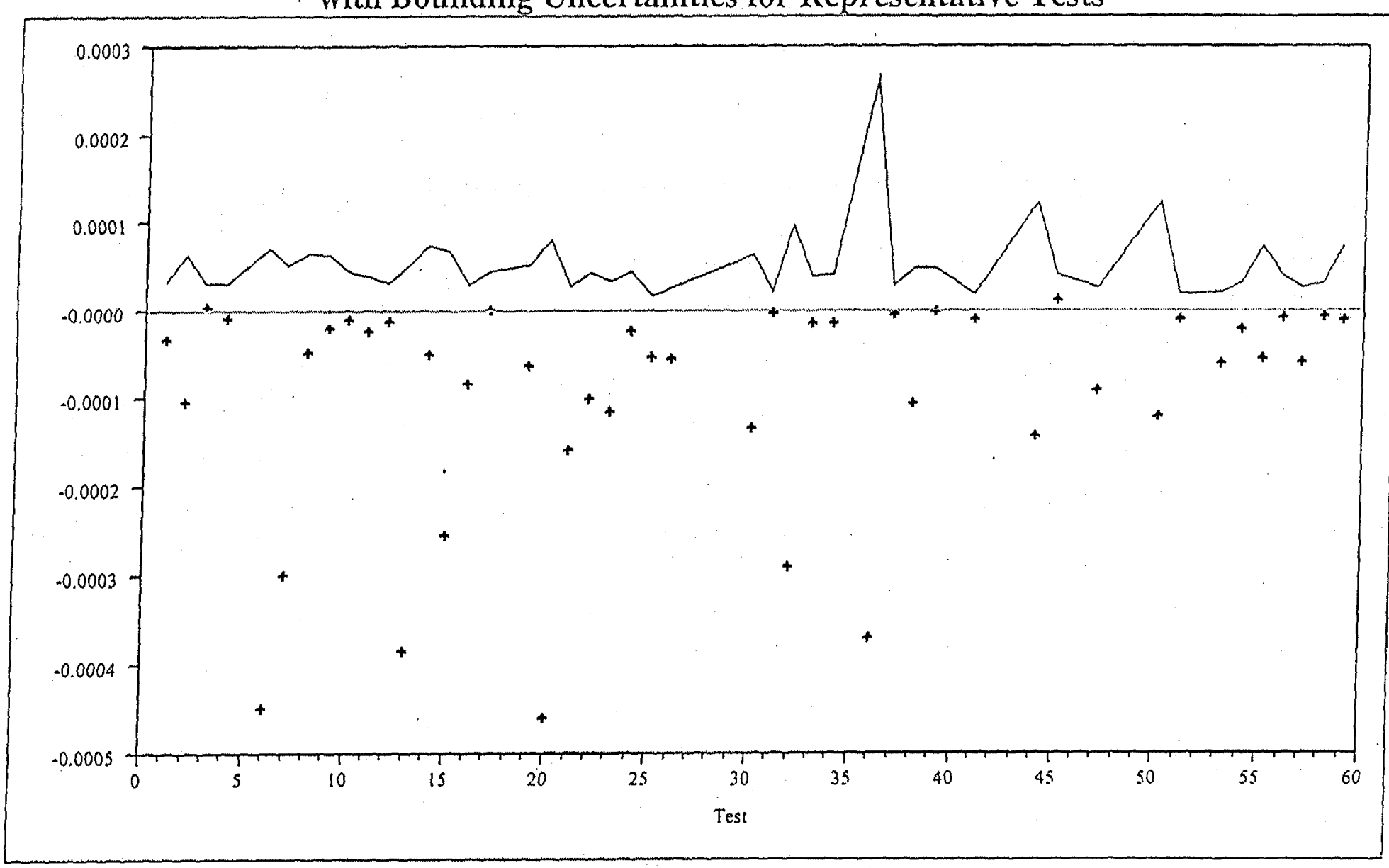

+ - deita $\mathrm{O} 2(\mathrm{M})$

-Upper Uncertainty Limit 
Exhibit A8: A Plot of the Initial Versus Final Moles of Oxygen for Representative Tests

initial $\mathrm{O} 2(\mathrm{M})$ By final $\mathrm{O} 2(\mathrm{M})$

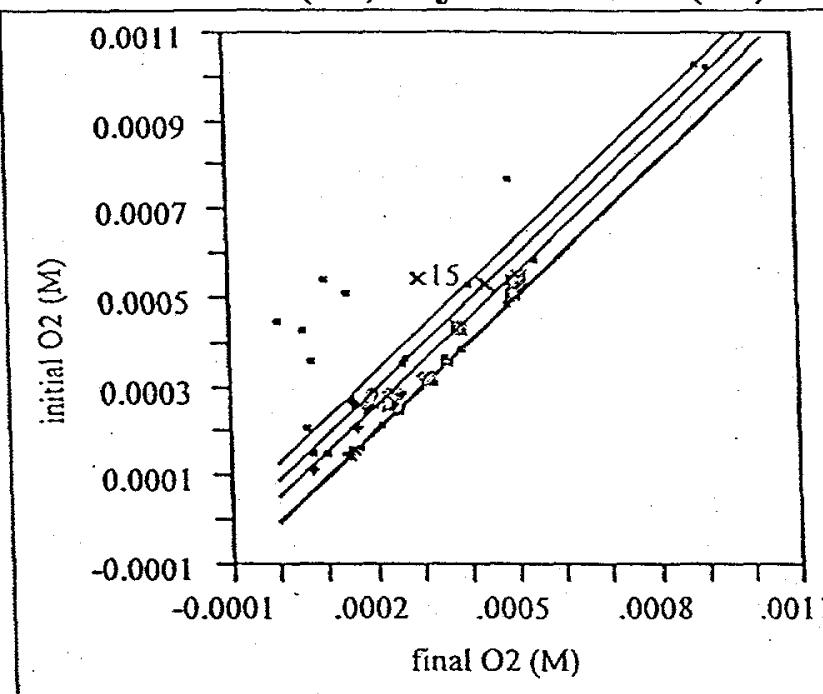

$\equiv$ Paired t-Test

Paired t-Test

final O2 (M) - initial O2 (M)
Mean Difference

Std Error

t-Ratio

DF

$\begin{aligned}-0.00009 & \text { Prob }>|t| \\ 0.000018 & \text { Prob }>t \\ -5.0429 & \text { Prob }<t \\ 45 & \end{aligned}$

0.0000080

0.9999960

0.0000040

Symbols are shaded to designate the categories of Table 1 (i.e., they are shaded as in Exhibit A3). 
Chuck Armitage, 703-F

Mark Schinitz, 703-F

Clint Wolfe, 773-A

Don Green, 773-A

Bill Shingler, 703-F

Dan Wood, 704-F

Allen Blancett, 773-A

Tami Cappeletti, 773-A

Bob Maher, 703-A

Sue King, 773-54A

Ed Claxton, 704-F

Tim Hasty, 235-F

Dave Poss, 707-C

Martha Ebra, 773-42A

Joel Williams, 707-F

Jim Schornhorst, 992-3W

John Marra, 704-T

Major Thompson, 773-A

Jeff Schaade, 703-F

Lee Hyder, 773-A, C-109

Ned Bibler, 773-A

Tom Walters, 773-A

Alice Murray, 773-A

Steve Hensel, 773-42A

Chip McClard, 703-F

Frank Graham, 773-A

Paul Korinko, 773-A

Tommy Edwards, 773-42A

Danny Prince, 773-41A

Doug Wilhelm, 773-A

Joel Jones, 730-A

John Young, 773-A

Paul Blanton, 773-54A

Neal Askew, 773-A

Ed Moore, 773-41A

Richard Balzer, 773-43A

Charles Keilers,719-14A

Susan Wood, 773-A

Todd Wright, 773-A

Paul Deason, 773-A

ATS File

CTS File 